\title{
Using blended instruction to teach academic vocabulary collocations: A case study
}

\author{
M. Teresa das Neves Seesink \\ West Virginia University
}

Follow this and additional works at: https://researchrepository.wvu.edu/etd

\section{Recommended Citation}

das Neves Seesink, M. Teresa, "Using blended instruction to teach academic vocabulary collocations: A case study" (2007). Graduate Theses, Dissertations, and Problem Reports. 3475.

https://researchrepository.wvu.edu/etd/3475

This Dissertation is protected by copyright and/or related rights. It has been brought to you by the The Research Repository @ WVU with permission from the rights-holder(s). You are free to use this Dissertation in any way that is permitted by the copyright and related rights legislation that applies to your use. For other uses you must obtain permission from the rights-holder(s) directly, unless additional rights are indicated by a Creative Commons license in the record and/ or on the work itself. This Dissertation has been accepted for inclusion in WVU Graduate Theses, Dissertations, and Problem Reports collection by an authorized administrator of The Research Repository @ WVU.

For more information, please contact researchrepository@mail.wvu.edu. 
Using Blended Instruction to Teach Academic Vocabulary Collocations: A Case Study

M. Teresa das Neves Seesink

Dissertation submitted to the College of Human Resources and Education at West Virginia University

in partial fulfillment of the requirements for the degree of

\author{
Doctor of Education \\ in \\ Technology Education
}

\author{
Neal Shambaugh, Ph.D., Chair \\ Susan M. Braidi, Ph.D. \\ David L. McCrory, Ph.D. \\ Jacqueline L. Webb-Dempsey, Ph.D. \\ Ernest R. Goeres, Ph.D.
}

Department of Technology Learning and Culture

Morgantown, West Virginia

2007

Keywords: academic vocabulary collocation, collocation teaching, learners' perceptions, blended instruction, case study

Copyright $(\underset{0}{2007}$ M. Teresa das Neves Seesink 


\title{
Abstract \\ Using Blended Instruction to Teach Academic Vocabulary Collocations: A Case Study
}

\author{
M. Teresa das Neves Seesink
}

Learning second language vocabulary has always been a challenge for second language (L2) learners. Transferring new vocabulary to an active stage has been an even greater challenge.

In the 1990s, Lewis (2002a) proposed the Lexical Approach as a means to help L2 learners with vocabulary acquisition. This approach encouraged the teaching of vocabulary in chunks, or in other words, putting emphasis on collocations. Focus on vocabulary collocations was suggested by several researchers (Brown, 1974; Hinkel, 2004; Lewis, 2001). They supported the teaching of collocations via in-class exercises. Cobb (1999) and Kaur and Hegelheimer (2005) showed that the use of a concordancer-an online resource which provides information on collocation-was beneficial to learners' development of active vocabulary. However, studies focusing on explicit teaching of academic vocabulary collocation via blended instruction, which consists of a combination of in-class and online instruction, were not found.

This case study examined how teaching academic vocabulary collocations affected the writing development of six students in an Intensive English Program (IEP). Collocation was presented and taught both in-class and via Moodle, the course management software used as the online environment. The study also looked at how these learners perceived blended instruction. These learners came from various language backgrounds. Data were collected via a questionnaire, in-class observations, and learners' journals, writing samples, mid-course reflections, online logs, and interviews. The class instructor also provided data in the form of instructor's journals and an interview.

The results demonstrated that prior to teaching collocations, the teacher needed to clarify the concept and its importance to learners. Moreover, the results showed that learners benefited from explicit teaching of vocabulary collocations. Regarding blended instruction, the learners perceived the online component as a review/practice tool rather than an integral part of the course. The study also revealed a certain lack of commitment with the online exercises, especially when these exercises were not directly affecting the learners' grades. 


\section{Dedication}

Para meus pais, José e Celcínia Pelo amor e apoio incondicionais durante todos os meus anos de estudos.

For my undergraduate English professor, Solange Bonn

For my husband, Frank 


\section{Acknowledgements}

Completing this project was only possible because of the help, guidance, patience, and support from numerous people. First of all, my eternal gratitude to my parents whose unconditional love and support helped me throughout the years of my graduate studies. Also, I am grateful to Frank for constantly encouraging and supporting me by finding Moodle -the course management software with which I worked- helping me edit the 200 plus pages of this document, and always being understanding of my long studying hours. My brother as well was an inspiration as he strived to finish his own studies.

Thanks to all my professors in Brazil, especially Solange Bonn and Carrozzo, who helped me to build the foundation of what I know today.

In addition, I would like to express my gratitude to my committee for their care and attention. Thanks to my advisor, Dr. Neal Shambaugh, for his guidance, assistance, valuable tips, and for persevering with me all through these long years of the doctorate program. Special thanks to Dr. Susan Braidi for being a mentor, a teacher, and above all a friend. Her guidance in both my master's and doctorate projects was invaluable. I am grateful as well to Dr. David McCrory, Dr. Jaci Webb-Dempsey, and Dr. Ernest Goeres for their pointed questions, suggestions, and comments.

Helen Huntley played a very important role because she was the first one to believe in my project and to encourage me in so many ways to pursue it. Moreover, thanks to the teacher with whom I worked - her help throughout the study was priceless - and the students who kindly gave their time to my project.

I must acknowledge Dr. John Wells in whose classes I learned so much. In addition, I am grateful to Carol Spirof and Ann Crabtree for always being attentive and ready to help 
me, as well as all the other people who assisted me with the administrative part of the process.

Finally, I would like to show my gratitude to all my family members and friends who understood the long periods of my absence. I could not have accomplished this without their collaboration.

Muito obrigada a todos! 


\section{Table of Contents}

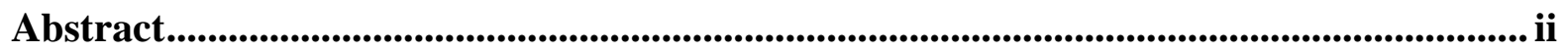

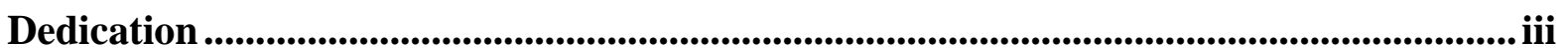

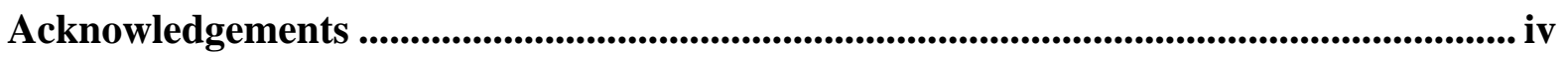

Table of Contents ............................................................................................................. vi

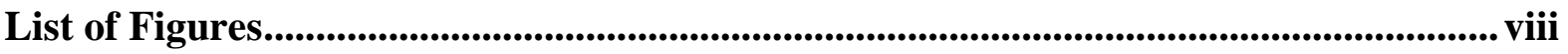

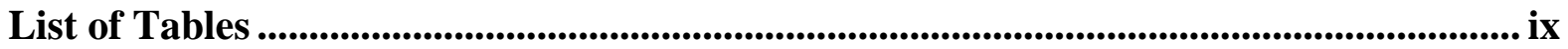

Chapter 1 Introduction.............................................................................................................. 1

Research Questions....................................................................................... 5

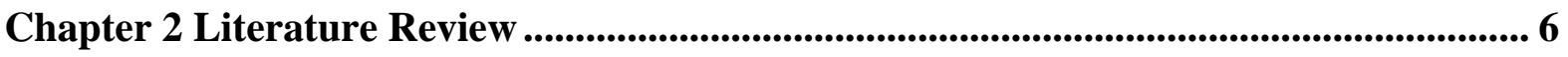

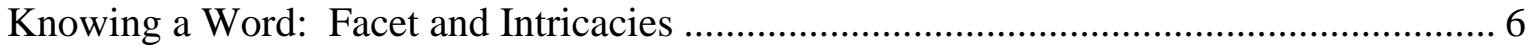

Collocation: Word Combination or Chunking........................................................ 7

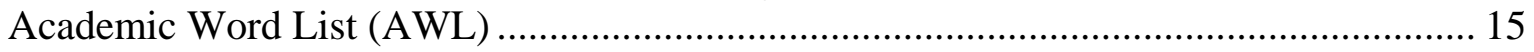

Academic Vocabulary, Collocation, and Writing....................................................... 18

L2 Vocabulary, Explicit Teaching, and Intentional Learning ..................................... 21

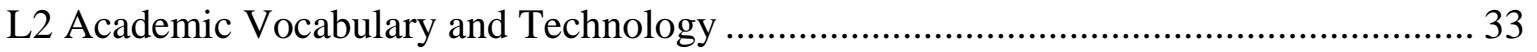

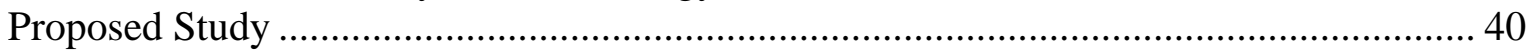

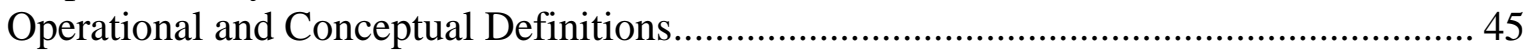

Chapter 3 Methodology ............................................................................................ 47

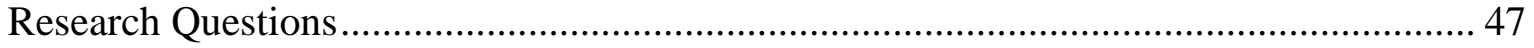

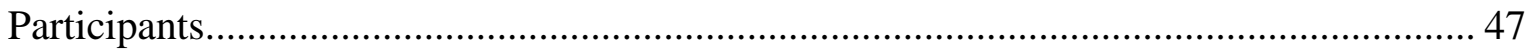

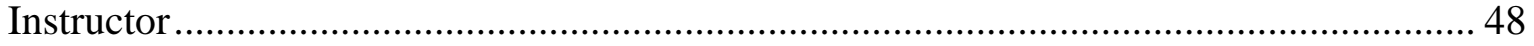

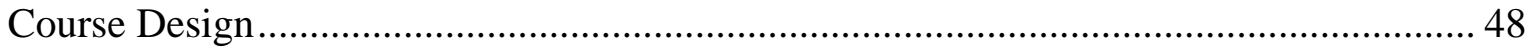

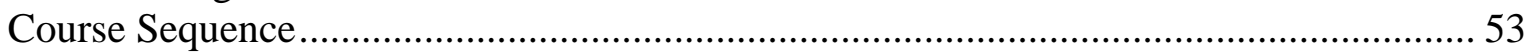

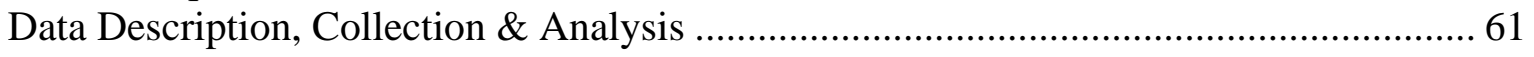

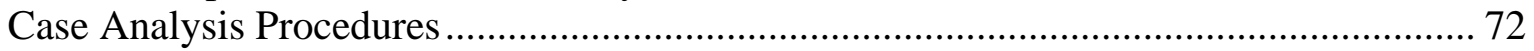

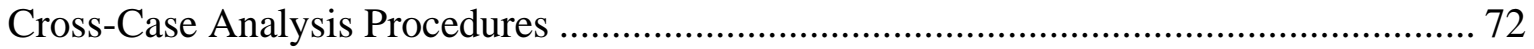

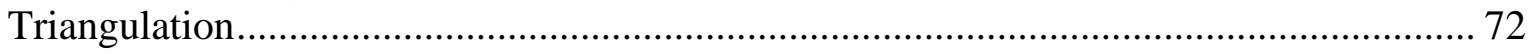

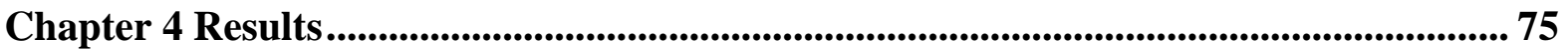

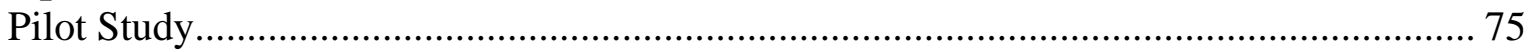

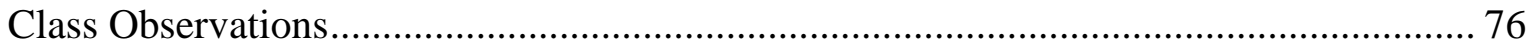

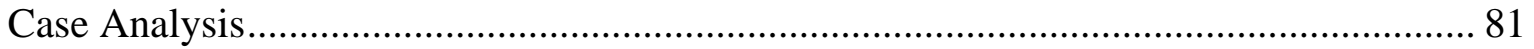

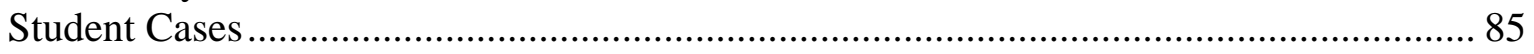

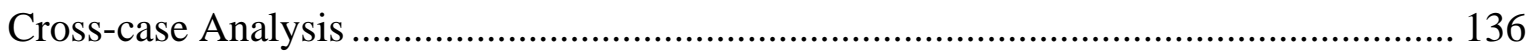

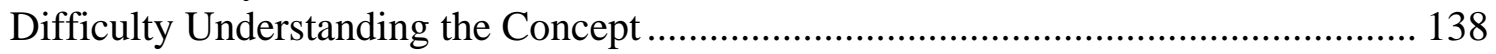

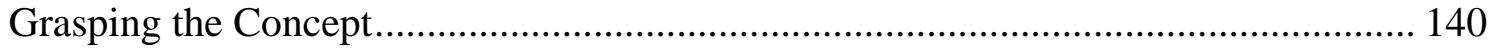

Improvement of Collocation Use as the Semester Progressed ................................. 142

Difficulty with Certain Combinations Remained ................................................... 150

More advanced students integrated longer chunks in their writing ........................... 151

Students’ Perceptions of Blended Instruction.............................................................. 152 


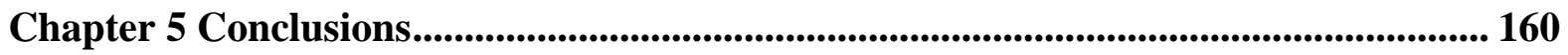

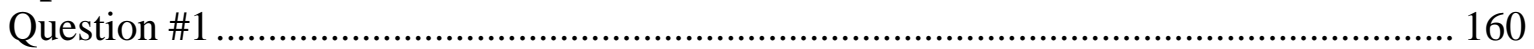

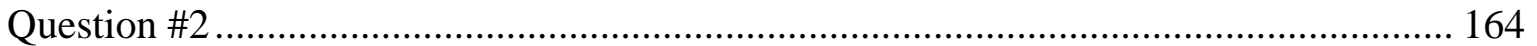

Course Improvements for Teaching Collocations via Blended Instruction...................... 167

Limitations of the Study .................................................................................... 170

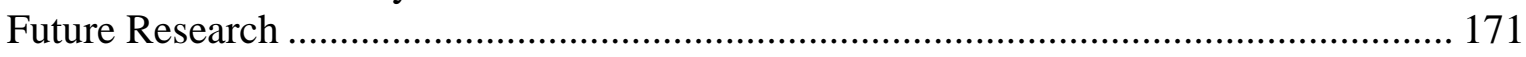

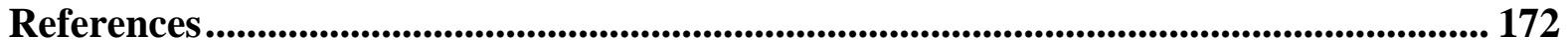

Appendix A Academic Vocabulary Syllabus.......................................................... 180

Appendix B Classroom Speaking Activities .................................................................. 183

Appendix C Coxhead (2000) AWL Sublists ....................................................................... 184

Appendix D Concordances of research from the Online Concordancer using the University Word List corpus............................................................................................... 187

Appendix E Background and technology understanding questionnaire ........................ 188

Appendix F Moodle Sample Exercise - Odd one out ...................................................... 189

Appendix G Journal Entry ............................................................................... 190

Appendix H Mid-Course Reflection/Feedback ................................................................... 191

Appendix I Writing Sample - Assignments instructions ............................................... 192

Appendix J Interview - Sample Questions..................................................................... 193

Appendix K Vocabulary Journal, Chap 9 ..................................................................... 194

Appendix L Final Exam - Collocation Section. ................................................................. 195

Appendix M Moodle Sample Exercise - Moodle Short Answer exercise..................... 196

Appendix N Moodle Sample Exercise - Hot Potatoes rational cloze exercise................ 197

Appendix O Abbas' Writing Samples................................................................................... 198

Appendix P Tariq's Writing Samples .................................................................................. 199

Appendix Q Atsushi’s Writing Samples ...................................................................... 200

Appendix R Naomi's Writing Samples...................................................................................... 202

Appendix S Yunjin's Writing Samples.................................................................. 204

Appendix T Ziyi's Writing Samples............................................................................... 206 


\section{List of Figures}

Figure 1. A sample of Cobb’s (1999) software interface ................................................ 36

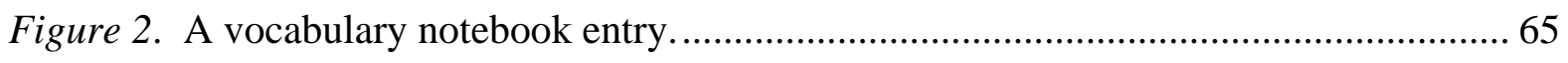

Figure 3. Web Vocabprofiler results from Naomi's first writing sample............................ 82

Figure 4. An entry in Longman Dictionary of Contemporary English Online .................. 129 


\section{List of Tables}

Table 1 Summary of Blended Course .............................................................................. 53

Table 2 Summary of Research Questions, Data Sources, and Description of Results ........... 61

Table 3 Data Description, Collection, and Analysis ......................................................... 70

Table 4 Detailed Analysis of Abbas’ Writing Samples ........................................................ 86

Table 5 Summary of Abbas' Performance in Writing ......................................................... 90

Table 6 Abbas’ Perception of Blended Instruction ........................................................... 91

Table 7 Detailed Analysis of Tariq's Writing Samples....................................................... 97

Table 8 Overall Results of Tariq's Performance in Writing............................................. 100

Table 9 Tariq's Perception of Blended Instruction ............................................................ 101

Table 10 Detailed Analysis of Atsushi's Writing Samples ................................................. 105

Table 11 Overall Results of Atsushi's Performance in Writing ......................................... 108

Table 12 Atsushi's Perception of Blended Instruction .................................................... 110

Table 13 Detailed Analysis of Naomi’s Writing Samples .................................................. 112

Table 14 Overall Results of Naomi's Performance in Writing ........................................... 115

Table 15 Naomi's Perception of Blended Instruction...................................................... 116

Table 16 Detailed Analysis of Yunjin’ Writing Samples................................................... 120

Table 17 Overall Results of Yunjin's Performance in Writing .......................................... 123

Table 18 Yunjin's Perception of Blended Instruction..................................................... 127

Table 19 Detailed Analysis of Ziyi's Writing Samples ..................................................... 130

Table 20 Overall Results of Ziyi's Performance in Writing ............................................. 133

Table 21 Ziyi’s Perception of Blended Instruction ............................................................ 135

Table 22 Summary of Students’ Backgrounds ................................................................ 137

Table 23 Summary of Students' Performance in Collocation .......................................... 138

Table 24 Summary of Students’ Comments on Blended Instruction .................................... 152 


\section{Chapter 1}

\section{Introduction}

"Without grammar little can be conveyed; without vocabulary nothing can be conveyed.” David Wilkins' comment cited in Lewis (2001, p. 8) sums up the relevance of vocabulary learning in a language. His point of view is shared by various second language (L2) researchers. Zimmerman (1997a), for instance, comments that "vocabulary is central to language and of critical importance to the typical language learner” (p. 5). Laufer (1998) mentions that "learners associate progress in language learning with an increase in the number of words they know” (p. 256). Kitajima (2001) observes that vocabulary constitutes “an essential component of vocabulary acquisition" and adds that "without words ... a speaker cannot express intended meanings” (p. 470). Gass \& Selinker (2001) point out that “... there are numerous reasons for believing that lexis is important in second language acquisition. In fact, the lexicon may be the most important language component for learners” (p. 372). These comments illustrate the importance of vocabulary in language acquisition either in an L2 or a foreign language (FL).

Being a non-native speaker myself, I have experienced the challenges that vocabulary poses. Despite having studied English for about fifteen years and having lived in an English speaking country for six months, I still did not obtain satisfactory results on a vocabulary test. This event showed me that achieving an advanced vocabulary level takes a great deal of time and effort. In addition, this vocabulary-related episode sparked my interest in the topic and a wish to find ways to facilitate the learning of vocabulary for my students.

Vocabulary learning has many facets, and one of its challenging aspects consists of collocations or word combinations. For instance, we can talk about developing, encouraging, 
and stimulating creativity; however, we do not say persuading creativity. Other examples of acceptable word combinations are safety procedure or emergency procedure. On the other hand, we do not say income procedure. This word combination is not acceptable in English.

Observing students as an instructor, I noticed that when studying vocabulary they tend to focus on the translation and the meaning of words, and very often they stop there. However, when these students try to use these new words, they face the task of combining them and at times fail to do so accurately.

In the 1990s Michael Lewis (2001) proposed the Lexical Approach as a way to teach vocabulary with an emphasis on collocation. This approach entails teaching words already in their chunks as opposed to individual items. By doing so, the learners are exposed to one or several appropriate combinations. Since then the Lexical Approach has been explored and utilized by various instructors to teach vocabulary. Some instructors swear by it; whereas others are still experimenting with it (Lewis, 2001). This is one of the various approaches to vocabulary teaching discussed in the last few decades.

Vocabulary acquisition strategies have been studied extensively in the last 25 to 30 years. Researchers have looked at indirect and direct teaching of vocabulary. Some researchers have looked at strategies to help vocabulary learning, including mnemonic devices, vocabulary notebooks, dictionary use, grids, and diagrams.

The depth of processing theory has also been discussed in the literature of L2 vocabulary acquisition. Developed by Craik and Lockhart (1972), this theory suggested that retention could be increased by a deeper processing of the information. Craik and Lockhart (1972) defined depth of processing as “.... series or hierarchy of processing stages where greater ‘depth’ implies a greater degree of semantic or cognitive analysis” (p. 675). The 
authors supported the notion that deeper analysis or processing led to “...more elaborate, longer lasting, and stronger traces” (p. 657). These traces would be like etchings left on the memory. According to Craik and Lockhart, stronger traces led information to long-term memory and consequently led to deeper levels of retention and recall.

Research on vocabulary acquisition is far from being exhausted. As Wesche and Paribakht (1996) said, "the process by which a learner acquires new vocabulary in a second language is poorly understood” (p. 13). Sökmen (1997) agreed that more research on vocabulary was necessary. She commented that it was relevant to do "research on the effectiveness of methods of vocabulary instruction.” Sökmen highlighted the importance of research in areas such as "semantic elaboration, ways to productively learn collocations and lexical phrases, and computer assisted vocabulary activities” (p. 257). In addition, Kitajima (2001) commented that "classroom research on vocabulary learning is still limited" (p. 470). It appears that more vocabulary research may help to shed some light on this complex issue. More recently researchers have explored the potential of computer technology as a tool to support second language acquisition. Warschauer and Healey (1998) commented that the more we research, the better understanding we will have “...of the role that technology can and should play” (p. 61). They also pointed out that computer technology techniques still need to be perfected so that learners can fully benefit from the activities and programs. Adair-Hauck, Willingham-McLain, and Youngs (1999) corroborate Warschauer and Healey’s suggestion when they say, “...the examination of integration of technology into second language teaching and learning is fertile ground for future research” (p. 295). In other words, research on the use of technology for second language teaching is still pertinent. 
Even though the researchers here were referring to second language teaching/learning in general, such research would also be relevant in the case of L2 vocabulary teaching/learning . In this study, I combined the Lexical Approach with blended instruction to teach academic vocabulary. The goal of the study was to directly teach or focus on an aspect of vocabulary which students often forget (collocations), to guide them to locate these combinations in reading and listening passages, and to provide practice in combining words so that the students would eventually develop the ability to transfer this knowledge to their writing.

The blended instruction consisted of a combination of face-to-face and online environments to teach academic vocabulary collocations. The target lexis included words from the class textbook, which contained words from the new Academic Word List (AWL) compiled by Coxhead (2000). The study looked into how focusing on teaching collocation contributed to learners' collocation usage in writing and how learners perceived the use of the two environments to study academic vocabulary collocation.

In the subsequent sections, I introduce what it means to know a word (Nation, 2001) and also present studies which have investigated strategies to approach the topic using conventional tools - paper and pencil. Moreover, I talk about how computer technology has been used to teach academic vocabulary and/or collocations. I also describe the design of the blended instruction, data sources, data collection, and data analysis procedures. 


\section{Research Questions}

The present study focused on the contribution of studying collocations to learners' writing development. It also looked into learners' perceptions of blended instruction when studying academic vocabulary collocations.

Question \#1. How does focusing on academic vocabulary collocations contribute to ESL learners' performance in academic writing?

Question \#2. What are learners’ perceptions of blended instruction? 


\section{Chapter 2}

\section{Literature Review}

Both vocabulary teaching and learning have been a concern in Second Language Acquisition (SLA) research for some time now. Throughout the years, researchers have explored a number of approaches and techniques to enhance acquisition. Various strategies have been found to help improve vocabulary learning. With the introduction of computer technology and the Internet, a new trend of vocabulary research has begun. Researchers have started investigating the potential of this new environment in L2 teaching and learning.

In this chapter, I include a brief explanation of what it means to know a word, which puts into perspective the complexity of learning vocabulary. I also explain what collocation is and why it is important when transferring vocabulary from a receptive to a productive stage. Moreover, I give details about what the academic word list is and why it is important. Subsequently, I present the connection between collocation and writing. Finally, I present the research which has informed me about vocabulary teaching and learning in the classroom as well as in the online environment.

\section{Knowing a Word: Facet and Intricacies}

Learning vocabulary involves understanding a number of details and nuances about words. Richards (1976) stressed the importance of becoming familiar with a word's sociolinguistic attributes, its semantic behavior, its derivational aspects (prefixes and suffixes), and its possible combinations (p. 83). Nation (2001) complemented Richards' (1976) assumptions by dividing them into sets of questions concerning the word form (i.e., spoken, written, and word parts), meaning (i.e., form and meaning, concept and referents, and associations), and use (i.e., grammatical functions, collocations, and constraints on use) 
(p. 27). In addition, Nation made a distinction between receptive and productive vocabulary knowledge. The former refers to words that learners understand in speech and reading, whereas the latter are words learners actively utilize in conversation and writing. By observing what is involved in knowing a word, one can understand why teaching and learning vocabulary constitutes an arduous task.

In this study, I looked at one aspect of vocabulary acquisition; specifically, collocations, even though the teacher I worked with covered essentially all of the aspects mentioned above. Collocation is one vocabulary aspect that can help learners to use words more accurately. Also, Hill (in Lewis, 2001) commented that "within the mental lexicon, collocation is the most powerful force in the creation and comprehension of all naturallyoccurring text” (p. 49). Moreover, collocation knowledge helps learners to create more native-like sentences (Nation, 2001). In the following section, I define collocation and discuss its relevance for vocabulary learning and language learning in general.

\section{Collocation: Word Combination or Chunking}

Kennedy (1990) reported that there was a controversy on whether collocations existed or not. He said that researchers like Krashen and Scarcella (1978) did not believe that collocation was dominant in the language. Conversely, Kennedy commented that researchers such as Nattinger, Pawley, and Sinclair maintained that collocations were "overwhelmingly pervasive” in English (p. 217). These claims are supported more recently by Nation (2001) who mentioned that “corpus [linguistics] studies [have found] that certain groups of words recur” (p. 333).

Kennedy (1990) presented a variety of terminology used to refer to collocations. He mentioned that "researchers have often used different terms, many of which are synonymous, 
for collocation” (p. 217). Some of the terms included "prefabricated routines," “prefabricated patterns,” “formulaic speech,” “lexicalized sentence stems,” and "fixed phrases” to name a few (p. 217). The term collocation, though, has been used more often recently to refer to this aspect of vocabulary.

Oxford Collocations (2002) defines the term as "the way words combine in a language to produce natural-sounding speech and writing” (p. vii). Nation (2001) refers to collocation as a term "used to refer to a group of words that belong together, either because they commonly occur together like take a chance, or because the meaning of the group is not obvious from the parts... by the way or take someone in" (p. 317).

Collocation is not a new concept. Already in the 1970s Brown (1974) talked about students' difficulty in using proper collocations. Brown called attention to the difficulty of collocating verbs. She also highlighted the importance of providing collocation exercises to the students and presented a number of collocation activities for the classroom.

Nattinger (1980) underscored "the importance of prefabricated speech routines in language behavior" (p. 337). He added that "it [was] generally agreed that the sequence of words in phrases with less variation [was] more predictable, an extremely important fact in communication which accounts for much of the way we produce language” (pp. 338 - 9). He presented examples of prefabricated sentences which could be more readily stored and recalled if taught as a unit. Nattinger divided these phrases under various categories such as “deictic locutions” (as far as I know, for that matter), "sentence builders" (not only... but also), "verbatim texts" (better late than never), "situational utterances" (how can I ever repay you?), to name a few (p. 340). All these phrases consisted of chunks commonly used by native speakers in speech and/or writing. 
Looking at Nattinger's (1980) examples, one can notice that there are a number of prefabricated phrases/sentences in English, which, if taught as a chunk, could assist learners in vocabulary use and possibly enhance their fluency and accuracy in the L2. Nattinger (1980) suggested that ESL instructors could take advantage of these existing patterns and present them to learners as such. Then "our teaching... would center on these patterns and the ways they can be pieced together, along with the ways they vary and the situation in which they occur” (p. 341). His focus seemed to have been teaching communicative functions. However, this idea can be expanded to teaching various types of vocabulary chunks.

Lewis (2001) points out that some writers refer to two types of collocations: grammatical and lexical collocations. Grammatical/syntactic collocations relate to combining a main word with a grammatical word, such as an adjective + a preposition (happy about, suspicious of, absent from), a verb + a preposition (talk about, participate in, know of/about), or a noun + a preposition (research on, approach to). Lexical/semantic collocations are combinations in which two (or more) words add to each other's meaning. Richards (1976) provides an example of adjective + noun combinations. When referring to fruits, we use adjectives such as ripe, green, sweet, or bitter, while when talking about meat, we say tender and tough (p. 79). A few other examples using academic vocabulary are a specific source, identified variables, and an established business. There are also verb + noun combinations such as obtain benefits, analyze data, establish a policy, and conduct research, for instance. Examples of noun + verb combinations include data indicate, research shows, and the study demonstrates. 
The examples above underline the importance of collocations. Hill (in Lewis, 2001) provides one of the reasons for focusing on collocation. He says that "two, three, four, five word collocations make up a huge percentage of all naturally occurring text, spoken and written” (p. 53). Lewis (2002b) adds that although "collocation is not determined by logic or frequency, but is arbitrary, decided only by linguistic convention” (p. 29), collocations are predictable. In addition, Nation (2001) points out that "most of the language we use consists of familiar combinations” (p. 323). Nation also comments that collocational knowledge of a word constitutes “one important aspect of vocabulary knowledge” (p. 328). The researchers here agree that teaching collocation is valuable to L2 learners. I would add that this is true especially when these learners tend to struggle to put sentences together.

A second reason for focusing on collocation is that the human brain seems to work well with chunks. Newell (1990), cited in Nick Ellis (1997), states that “a chunk is a unit of memory organisation, formed by bringing together a set of already formed chunks in memory and welding them together into a larger unit... Chunking appears to be a ubiquitous feature of human memory. Conceivably, it could form the basis for an equally ubiquitous law of practice” (pp. 124 - 5). Hill (in Lewis, 2001) endorses Newell's point and adds that chunks appear to be more easily stored in and retrieved from memory. He compares learning chunking words with memorizing phone numbers and addresses. Hill also believes that learning collocations facilitates learners’ thinking, leading to more fluidity when communicating in spoken and written language (pp. 54 - 5). Moreover, he says that lack of collocation knowledge leads students to produce language in a convoluted manner (pp. 49 50). 
A third reason to focus on collocation is to help students with fluency. Nick Ellis (1997) points out that "an important index of native-like competence is that the learner uses idioms fluently. So language learning involves learning sequences of words (frequent collocations, phrases and idioms) as well as sequences within words” (p. 130). Nation (2001) points out that "by having chunks of language in long-term memory, language reception and language productions are made more effective” (p. 321).

As learners become familiar with chunks, they will also be exposed to the stress and intonation used to produce these chunks. Therefore, "if learners learn the stress pattern of a phrase as a whole their stress and intonation will be better.” It is crucial that "correctly understood and stored, [chunks] should be available for immediate use” (Hill in Lewis, 2001, p. 56). Moreover, according to Oxford Collocations (2002), learners who utilize correct collocations "will make [their] speech and writing sound much more natural, more nativespeaker-like, even when basic intelligibility does not seem to be an issue” (p. vii). Finally, Nation (2001) states that "lexicalised sentence stems and memorised sentences are the building blocks of fluent speech” (p. 324).

In spite of the relevance of collocation, some researchers believe that there has not yet been enough research done on the topic. Shei and Pain (2002) point out that "though the role that collocation plays in language acquisition is an important topic, very few systematic studies can be found that address this issue.” Nesselhauf (2003) agrees with them when she comments that despite it being a known difficulty and essential part of language acquisition for students, “collocations have not been investigated in much detail so far” (p. 223). The research found dealt with the analysis of students' writing and how these students collocated the words. These studies have identified problems in students' use of collocation. 
Some of the research on collocation has investigated the way students combine words in their writing. Nesselhauf (2003) looked at how advanced English learners handled collocation production. She analyzed 32 essays written by university students whose first language was German. Nesselhauf focused on the verb-object (noun) collocations. Prior to analyzing the data, she clarified that she would look at three types of combinations: free combinations [F] (as in buy a house), restricted collocations [RC] (as in gain knowledge), and idioms [I] (as in sleep on it). Lastly, she would verify the acceptability of the combinations the students produced. The chunking classification and acceptability were based on dictionary information—Oxford Advanced Learner's Dictionary (2000) and Collins Cobuild English Dictionary (1995) —as well as a native speaker's perception. By the end of the analysis a new criterion had been included: RC? (restricted collocation), the question mark indicating that the analysis had been inconclusive.

In the analysis, Nesselhauf (2003) located 1072 verb-object-noun combinations, which were divided into 213 RC or RC?, 846 free combinations, and 13 idioms. She found that about $1 / 4$ of the combinations had some form of error and that the majority of the mistakes were related to choosing the wrong verb. Her analysis led her to conclude that on average $50 \%$ of the mistakes were related to L1 influence. Thus, L1 seemed to play an important role in students' collocation mistakes. Nesselhauf's results showed that "even advanced students have considerable difficulty in the production of collocations” (p. 237).

Howarth (1998) compared the writings of native speakers to those of non-native speakers. He worked with full-time postgraduate students at British universities. These students came from a variety of backgrounds, such as Botswana, Germany, Greece, Hong Kong, Japan, Taiwan, and Thailand. Howarth focused on the verb + noun combination in the 
writings of both groups. His analysis showed that "a much greater incidence of non-standard phraseology [was] ... found in non-native writing, reflecting the learner's general lack of awareness of the phenomenon” (p. 186). Howarth called attention to learners' difficulty in handling collocations. He commented that "although they [were] not all major errors in themselves, and while the degree to which intelligibility [was] affected [varied], they [could] have an appreciable impact on the effectiveness of a piece of writing, and their cumulative effect [could] be a serious loss of precision” (p. 162).

Howarth (1998) concluded that "the evidence of NNS collocation deviation... [showed] that many learners [failed] to understand the existence of the central area of the phraseology spectrum between free combinations and idioms.” Learners had difficulty using restricted collocations (see above example from Nesseuhalf, 2003), and their sentences contained "errors of both a lexical and grammatical nature” (p. 186).

Granger (1998), on the other hand, looked at French speakers’ use of adverbs in English. She compared the use of adverbs between native speakers and non-native speakers (NNS), and concluded that there was L1 influence in the adverb use in the L2. Granger also found that non-native speakers “[underused] native-like collocations and [used] atypical word-combinations” (p. 152). Granger was of the opinion that if we "[exposed] L2 learners to prefabs," the learners would improve the use of grammar also. Moreover, she pointed out that her study showed that “learners' phraseological skills [were] severely limited: they [used] too few native-like prefabs and too many foreign-sounding ones” (p. 158).

These studies demonstrate that indeed learners, and even advanced learners, have difficulty collocating various types of words. Their writings show examples of collocation transfer from L1, poor use of phraseology, and the creation of atypical combinations. 
Learners' lack of awareness of collocations may have led them to make such mistakes. Oxford Collocations (2002) points out that when learners select appropriate collocations they not only "express [themselves] much more clearly" but also convey meaning more accurately. Considering that in writing learners' only have words with which to communicate, the clearer their language the better.

Because of this limitation of learners', Nesselhauf (2003) suggests that collocations be explicitly taught, and when possible that teachers call learners' attention to the collocational differences between L1 and L2. Wray (2002) also supports collocation explicit teaching when she says that “... collocations can only be learned if they are encountered, and it may be that our expectations of learners are too high, relative to their experience of language input” (p. 183). In other words, teachers may need to bring the collocations to the learners' attention, especially because learners may not notice these combinations unless teachers point them out.

Lewis (2001) reinforces the idea of teaching collocations when he says, "given the present stage of our knowledge of acquisition, it is likely to be helpful to make learners explicitly aware of the lexical nature of language ... this means helping learners develop an understanding of the kinds of chunks found in the texts they meet” (p. 161). Lewis concludes that "the more aware learners are of the chunks of which any text is made, the more likely that the input they notice will contribute to intake” (p. 163). Nation (2001) also agrees that time spent on collocation is justifiable "because of the return in fluency and nativelike selection” (p. 317). In other words, it is important to direct students to examples of collocations in 'real' texts because it illustrates to students that collocations are truly part of 
the language, and that by making use of such combinations the students will add fluidity and a native-like trait to their written work.

In this study, I focused on collocations in writing. Considering learners' difficulty with writing in an academic setting, I deemed it important to focus on an aspect of vocabulary which would help students when completing academic assignments. Collocation “skills,” as Lewis (2001) said, “equip[ped] learners to expand their individual mental lexicons in a way which [was] relevant, personal and a skill which [could] be taken away as a tool for life” (p. 196). By helping learners understand and encouraging them to use collocations, I aimed at providing a tool which they would be able to use beyond the classroom and throughout their academic life.

Depending on the type of vocabulary considered, time spent on collocations would be indeed justified. Specialized types of vocabulary, such as academic vocabulary, would be one such type of vocabulary because it would need to be learned not only for receptive purposes but also for productive purposes. Collocational knowledge of academic vocabulary would be essential for ESL learners who intended to pursue a degree in an English-speaking university. In the subsequent section, I give details about the academic vocabulary list (AWL) and also explain why it is relevant to teach the AWL.

\section{Academic Word List (AWL)}

L2 learners are faced with learning various kinds of vocabulary, e.g., high-frequency words, low-frequency words, and technical words. High-frequency words are defined as words which appear in all types of texts and entail $80 \%$ of a text (Nation, 2001). A few examples of high-frequency words are clock, days, message, decision, and have. On the other hand, low-frequency words consist of "a very large group of words that occur very 
infrequently and cover only a small portion of any text” (Nation, 2001, p. 19). Nation (1990) points out that approximately 2/3 of these words are of Latin, French, or Greek origin (p. 19). Technical vocabulary is the type of low-frequency vocabulary which is used in a specific subject area.

Academic vocabulary consists of a type of low-frequency vocabulary typically used in an academic environment for such purposes as participating in classes and writing research and studies. To facilitate access to these specific words, Coxhead (2000) compiled a list of the more frequent words found in academic texts, and created the AWL, which consists of 570 word families selected from a “3,500,000 token corpus of academic English” (p. 254). By word families it is meant that a word (for instance, clarify) as well as its inflections (clarified, clarifies, and clarifying) and derivations (clarification) are included. The reason for including the inflections and derivatives as part of the word family lies in the fact that learning them together does not increase learning burden, provided that learners are familiar with the base word and know how to handle "basic word-building processes" (Coxhead, 2000, p. 218). The words included on the AWL list were selected from arts, science, law, and commerce texts. The criteria for selecting words included range and frequency. Range relates to the number of subject areas in which a word is found; while frequency relates to the number of times a word appears in the texts.

Coxhead and Nation (2001) present four reasons for focusing on academic vocabulary: (1) these words are "common to a wide range of academic texts,” (2) these words are relevant to learners when reading academic texts because these words "account for a substantial number of words in academic texts...,” (3) learners’ are more familiar with technical than academic vocabulary, and (4) ESL instructors are able to assist learners with 
this type of specialized vocabulary (pp. 254 - 6). Furthermore, these words are important to learners “no matter what their specialist area of academic study” is (Nation, 2001, p.191).

Considering that these words fall into the low frequency category and that they appear in a very specific setting, academic vocabulary tends to pose difficulty to learners (Coxhead, 2000, p. 218, referring to a comment in Bauer \& Nation, 1993). Therefore, it is worthwhile for teachers to take class time to help learners who intend to pursue a degree in an English-speaking university to increase their knowledge of these words. Coxhead (2000) reiterates the need for class time when she says, "the AWL might be used to set vocabulary goals for EAP [English for Academic Purpose] courses, construct relevant teaching materials, and help learners focus on useful vocabulary items” (p. 227). For learners learning English for academic purposes, the AWL is essential. In this particular instance, Nation (2001) equates the AWL to a high-frequency type of vocabulary for these students. He adds that “... any time spent learning [this list] is time well spent” (p. 196).

When teaching these words, Coxhead and Nation (2001) point out that instructors should include tasks which deal with all four skills: listening, reading, speaking, and writing, since in an academic environment learners are exposed to and have to cope with these words in these areas. The authors also suggest that the words be explicitly taught. Finally, they point out the importance of students developing the ability to fluently use these words. One way to assist learners in improving their productive use of academic vocabulary is to make them aware of the collocations of these words. In the following section, I talk about the importance of academic vocabulary collocation in writing. 


\section{Academic Vocabulary, Collocation, and Writing}

According to Laufer and Nation (1995), “a well-written composition, among other things, makes effective use of vocabulary” (p. 307). Writing effectively in an L1 can be a challenge. Writing effectively in an L2 poses an extra challenge. Among other things, L2 writers need to have a reasonable vocabulary pool that they can actively utilize. Indeed, Laufer (1994) states that "writing progress can be measured through lexical progress since lexical quality and writing quality are interconnected" (p. 21). She agrees that there are other factors that contribute to good writing; however, "rich vocabulary is likely to have a positive effect on the reader” (p. 22).

When writing for an academic audience, in addition to the regular vocabulary, students need to have access to a more refined lexis which is typically used in the academic circle. Santos (1988) commented in a study that university professors believed that poor vocabulary knowledge constituted one of the rather grave problems in students' writings. In the study, Santos looked at 178 professors' responses to the writings of a Korean student and a Chinese student. The professors were from varied fields (humanities, social sciences, and physical sciences). There were both native and non-native English speakers in the group. The results showed that "the error type considered most serious was the lexical error" (p. 81). The reason for this was that lexical mistakes were the type of mistake that could affect comprehension of the text. Santos pointed out that "when the wrong word is used, the meaning is very likely to be obscured” (p. 84). In the study, Santos suggested including a vocabulary component in ESL writing classes to help students build their lexical knowledge. Nation (2001) commented that "clearly, vocabulary plays a significant role in the assessment 
of the quality of written work” (p. 178). The inability to use vocabulary affected students' writing quality and professors considered it a serious problem.

Kaur and Hegelheimer (2005) stated that "formal writing in an academic setting require[d] L2 learners to have a strong linguistic foundation, including a vast range of lexical skills” (p. 288). They called attention to the fact that L2 learners did not have as much exposure to the target language as native speakers do, so they had a more limited command of the language as well as of vocabulary. Hinkel (2004) affirmed that "if NNS [non-native speakers] college and university students [were] to succeed in competition for grades and attain their educational objectives, the level of accuracy in their writing need[ed] to at least attempt to approximate that of NS [native speakers] of similar academic standing” (p. 34). Hinkel also commented that "written academic discourse [was] highly conventionalized and its features [were] recurrent” (p. 37). Lewis (2001) presented examples of such academic conventions (or collocations): "the above examples all seem to suggest," "in the present study," "it should be noted that," "on the basis of," and "the extent to which" (pp. 139, 141). The predictable aspect of the academic discourse reinforces the idea that introducing collocations to students will help them develop their writing for an academic setting.

Considering the conventional language used in academic writing, one possible way to help learners achieve accuracy in writing would be to teach them how to adequately collocate academic vocabulary. Such knowledge may enhance learners' ability to cope with academic writing. Citing research by N. Ellis (1997), Lewis (1997), and Nattinger and DeCarrio (1992), Hinkel (2004) points out that research indicates that "the effectiveness of learning grammar in contextual lexicalized chunks and sentence stems, ... are fundamental in both L1 and L2 learning and use” (p. 38). 
As seen earlier, Granger (1998), Howarth (1998), and Nesselhauf (2003) conducted studies in which they analyzed the writings of advanced ESL learners. When analyzing students’ writings, these three researchers identified deficiencies in learners’ writing production. Only Howarth was dealing specifically with academic vocabulary collocations; however, they all analyzed students’ use of collocations in advanced learners’ writings. Their results led to the conclusion that learners' lack of knowledge of collocation affected the learners' writings. Moreover, the results reinforced the point that learners have difficulty collocating words. Howarth’s (1998) and Nesselhauf's (2003) studies, in particular, indicated that students had difficulty with the verb + noun combination.

Once again, referring to the works of N. Ellis (1997), Lewis (1997), and Nattinger and DeCarrio (1992), Hinkel (2004) concludes that "stock grammatical and lexical chunks can become an efficient means to expand L2 writers' arsenals particularly when learners are also taught how to substitute discrete elements appropriately and in practical ways” (p. 38). She also adds that teaching chunks may be a way to make the most of class time. Alluding to the works of DeKeyser and Juffs (in press) and Wood (2001), Hinkel (2004) comments that teaching chunks may be a means to facilitate students’ development of L2 accuracy and fluency "that leads to production and subsequent automatization" (p. 39). She believes that directing students' attention to the use of the grammar and vocabulary would help reduce NNS mistakes when writing in the L2. Furthermore, Nation (2001) notes that "research on receptive and productive language processing indicates that learners may need to experience the language chunks in the medium in which they need to use them” (p. 324). In other words, to develop their writing ability, students need to use the new collocations in writing. 
No study was found that focused on how the actual teaching of collocations affected learners' writing production. A few studies, to be presented in a later section, dealt with the use of concordance software and its effects on students' writing. These studies “taught” collocation in the sense that they exposed students to collocations via a concordance program. Nevertheless, some researchers indicated that the students were not always aware of collocation and its importance. Moreover, researchers seemed to believe that some explicit form of vocabulary teaching might be beneficial to learners’ productive use of vocabulary. In the following section, I present what research and researchers have found in relation to explicit teaching and intentional learning.

\section{L2 Vocabulary, Explicit Teaching, and Intentional Learning}

Below I discuss explicit and implicit vocabulary teaching and their relevance to vocabulary acquisition. I present a definition of these terms and discuss their relevance to L2 vocabulary acquisition. Finally, I introduce general studies which demonstrate the relevance of explicit vocabulary instruction.

Explicit instructions studies. In the last three decades, vocabulary acquisition has been extensively researched. When examining this research, it can be observed that researchers have gone in a number of different directions. Read (2000) points out that “although the amount of research on second language vocabulary acquisition has increased in recent years, the field has tended to lack coherence” (p. 38).

One aspect on which some researchers have disagreed is whether vocabulary is better learned explicitly (directly) or implicitly (indirectly). When explaining what the terms mean, Nation and Newton (1997) point out that direct vocabulary teaching entails allotting time to do "explicit vocabulary exercises, which may include word-building exercises, matching 
words with various types of definitions, studying vocabulary in context, semantic mapping and split information activities focusing on vocabulary.” In contrast, they explain that indirect vocabulary teaching involves learning vocabulary via “communicative activities like listening to stories, information gap activities, and group work,” as well as extensive reading (p. 241).

Considering the number of words in a language, a combination of both approaches might be the ideal way to go. On the one hand, Ellis (1994) points out that it is unrealistic to expect that learners would be taught all the necessary words in an L2; part of learners’ vocabulary would be acquired incidentally (p. 2). On the other hand, teachers may be able to save students' time if they can help students learn fundamental types of vocabulary.

Stoller \& Grabe (1993) agree that vocabulary development most likely occurs using a combination of incidental learning and instruction (p. 31). When talking about students using context clues to learn vocabulary, they point out that "without sustained explicit training, however, students are not likely to make efficient use of redundancies, collocations, and cohesive devices used in writing” (p. 32). Finally, Schmitt (2000) states that "L2 learners benefit from a complementary combination of explicit teaching and incidental learning” (p. 137). He believes that explicit teaching can introduce a word to learners, yet these learners would need several exposures to the word before fully understanding it, also because “vocabulary acquisition is incremental in nature” (Schmitt, 2000, p. 117).

Certain words are so important for learners’ language development that it would be worthwhile to employ both approaches to teach them. For example, when dealing with vocabulary such as high-frequency words, Nation (1990) points out that "these words deserve considerable time and attention from teachers and learners” (p. 15). In fact, Nation 
(2001) suggests that the words can be taught via “direct teaching, direct learning, incidental learning, and planned meetings with the words” (p. 16). Another type of vocabulary worth teachers' time and attention is academic vocabulary because these words are frequently found in all types of academic texts (Nation, 1990).

As mentioned earlier, Nation (2001) equates academic vocabulary to high-frequency vocabulary, and as such "it should be taught and studied in a variety of complementary ways” (p. 19). On explicitly teaching academic vocabulary, more specifically the AWL, Coxhead (2000) says that "the direct learning and direct teaching of the words in the AWL also have value.” Citing Rod Ellis (1990) and Long (1988), she adds that “courses that involve direct attention to language features have been found to result in better learning than courses that rely solely on incidental learning” (p. 228). Finally, Coxhead (2000) suggests that "direct teaching through vocabulary exercises, teacher explanation, and awareness raising, and deliberate learning using word cards need to be balanced with opportunities to meet the vocabulary” in both passive (listening and reading) and active (speaking and writing) situations (p. 228). The following studies illustrate the relevance of and need for a more explicit approach to vocabulary teaching.

Laufer (1994). Laufer (1994) conducted a longitudinal study to investigate "changes in the lexical quality in the writing of learners” whose major was English as a foreign language (p. 23). To evaluate the pieces of writing, she utilized a Lexical Frequency Profile (LFP), “which classifie[d] the vocabulary of an essay into frequency levels” (p. 21). She looked at the percentage of the University Word List (UWL) items as well as non-frequent words that learners used. The UWL was created by Xue \& Nation (1984) and was a 
precursor of the AWL. In addition, she looked at the lexical variability in the text. She compared these "scores" in various pieces of writing to assess the learners' progress.

The participants were 48 university students whose first language was either Hebrew or Arabic. Laufer (1994) commented that at the university the students participated in a variety of courses (12 - 16 hours) none of which taught vocabulary explicitly. As part of the material, Laufer collected compositions written by the students at three different points during the school year (one from the entrance exam, one at the end of the first semester, and one at the end of the second semester). Students wrote the compositions in class as part of their class evaluation.

At the end of both semesters, the number of UWL items in the composition increased significantly. The same was not true for the non-frequent words. The results showed that the lexical profile of the students changed as semesters progressed. She commented that "the general tendency [was] for basic vocabulary to decrease and be replaced by a more advanced vocabulary” (p. 29). Laufer (1994) also reported that "there was no significant change in lexical variation" in comparison to the 70\% lexical variation encountered in NS's writing in a study conducted by Linnarud in 1983 (p. 30).

When comparing the students' results with that of native speakers, Laufer realized that the non-native speakers' productive vocabulary was developing at a rather slow pace if the objective was for the non-native speakers to reach near-native proficiency. Her study indicated that "explicit vocabulary teaching [was] needed to compensate for the insufficient quantity of input” (p. 31). Laufer (1994) deemed that "if explicit vocabulary teaching became an integral part of a written proficiency course, the lexical profiles of the students 
might be more impressive at the end of such a course” (p. 31). In other words, explicit vocabulary teaching has a place in L2 teaching.

Zimmerman (1997). Zimmerman (1997b), on the other hand, conducted a pilot study in which she investigated the effectiveness of reading plus vocabulary instruction. She worked with 35 intermediate-to-advanced level ESL students preparing to study at a university in the U.S. In the study, the control group had different teachers, whereas the treatment group had the same teacher. Both groups had $24-25$ hours of instruction per week, including reading, composition, speaking, and academic skills. The treatment group experienced "3 hours per week of interactive vocabulary instruction.” Interactive instruction included a variety of activities such as various encounters with the target words, words in different contexts, "rich and varied information about each word," and connections between students' background knowledge and instruction (p. 125). The students participated actively in the learning process. In other words, the students worked on meaning, comprehension in context, and communicative activities. The treatment group’s teacher received specific instructions from the researcher on how to conduct the class. In the control group, on the other hand, the teachers worked essentially with readings and only talked about vocabulary when students asked questions, and they did not get special instructions from the researcher. Besides their class work, both groups were assigned 5 hours of self-selected reading per week. They were supposed to report how many hours of self-selected reading they had done at the end of every week. Students did not receive extra credit for doing that. The students completed a pre-and post-test on their knowledge of academic words taken from the University Word list (UWL), the precursor of the AWL. At the beginning and at the end of 
the experiment, students answered a questionnaire on background information and their “perceptions about how words [were] best added to one’s vocabulary” (p. 128).

The results reported that the treatment group obtained a better mean score in the posttest. Zimmerman’s (1997b) questionnaire analysis led her to believe that "by focusing students' attention on a limited set of words and drawing their attention to a limited set of lexical features, vocabulary instruction could make the word-learning task appear more manageable and could lead to increased motivation to learn vocabulary” (p. 135). This analysis also indicated that students preferred to study vocabulary through reading and class activities which presented the words in some form of context. Zimmerman stated that the results of her pilot study showed that students needed to study words beyond the definitions. Lastly, she concluded that "students need[ed] a knowledge of academic vocabulary to gain access to texts and comprehend teaching. Lexical issues should indeed constitute a high priority for both teachers and researchers; vocabulary cannot be left to look after itself” (p. 138).

Laufer and Shmueli (1997). Another study which showed the importance of explicit vocabulary instruction came from Laufer and Shmueli (1997). They worked with high school students whose L1 was Hebrew. In four treatment groups, they tested four different ways to approach vocabulary learning: using a vocabulary list, working with words in a sentence (this group also had access to a translation or definition of the target vocabulary), working with words in a short text, and working with an elaborated text. The elaborated text was adapted to facilitate understanding with the addition of embedded synonyms or a sentence explanation. 
All treatment groups worked on a practice session with the new vocabulary and subsequently completed a "consolidation exercise” which consisted of “a cloze exercise [a type of fill-in-the-blank exercise] focusing on the 20 target words” (p. 96). A control group, on the other hand, was given a list of 20 words, asked to check the meanings on their own, and informed they would have a quiz on the words.

Students were tested right after the treatment (short-term retention) as well as five weeks later (long-term retention), and only the control group was aware of the post-tests. That was probably why Laufer and Shmueli (1997) defined their study as a quasi-incidental. Their results showed that the control group, who had not received any special vocabulary instruction, performed the least in both short and long term retention. The most effective method for short-term retention was the one which provided a definition and an example. In the case of long-term retention, both treatment groups that worked with the list and the sentence method produced similar results. Students who translated the words into the L1 had better results.

Despite awareness of post-tests, the control group did not perform as well as the others on either post-test (short or long-term retention). However, the treatment groups, who did study the words and also completed consolidation exercises, performed better. Laufer and Shmueli (1997) concluded that "incidental vocabulary acquisition [would] not occur if unfamiliar words [were] not attended to: not noticed or not processed deeply” (p. 106).

Paribakht and Wesche (1997). Yet another study which supported explicit vocabulary teaching was conducted by Paribakht and Wesche (1997). These researchers looked at the effectiveness of using what they called "reading plus" activities to enhance learners' L2 vocabulary acquisition. In their study, the researchers compared the results of a 
“reading plus group” and “reading only group.” The researchers worked with 38 intermediate-level students from varied language backgrounds. They pointed out that "the same subjects were exposed to both treatments, i.e., acted as their own controls” (p. 182). To separate the treatment and the control groups the researchers utilized different themes. Paribakht and Wesche commented that "since the same subjects were exposed to both treatments, it was necessary to use different themes for each” (p. 185). Altogether they used four themes (two themes each). For the Reading Plus (RP) treatment, the students worked with texts on media and the environment. For the Reading Only (RO) treatment, the students worked with the themes fitness and biological revolution. The treatments occurred consecutively.

The RP treatment consisted of reading texts that the researchers selected and later completing reading comprehension exercises at home. Besides the comprehension exercises, these students completed a variety of vocabulary exercises in class. These exercises included reading a word list and then locating these words in a text, matching a target word with its definition, locating in a text a word to match a definition, substituting words with the target words, categorizing connectives, and unscrambling words to create a sentence. Both the comprehension and the vocabulary exercises were corrected in class.

The RO treatment group read a main text and subsequently answered comprehension questions about the reading at home, which were later checked in class. Besides the main text, the group read two extra texts on the same themes as the main texts. The additional texts contained the target words found in the main text, thus presenting students repeated exposures of the target words. 
Paribakht and Wesche’s (1997) results showed that “both instructional treatments... resulted in significant gain in learners' vocabulary knowledge, but that the RP treatment led to greater gains” (pp. 195 - 6). Furthermore, the group who worked with RO remained at the word recognition level, whereas the RP tended to go further (p. 196). According to the researchers, their study "suggest[ed] that although instruction [made] a difference, more focused instruction [was] desirable when the learning period [was] limited and specific vocabulary outcomes [were] sought” (p. 197). The qualitative results showed that "in general, students found the vocabulary exercises helpful and useful, and were satisfied with the kinds and numbers of exercises used” (p. 195).

Laufer’s (1994) study showed that the NNS students tended to develop their vocabulary slowly when they did not receive vocabulary instruction, which led her to believe that students’ vocabulary development process could be accelerated if they received explicit vocabulary instruction. The other studies above employed in their treatment groups a more explicit teaching approach. Their results indicated that focusing attention on vocabulary and going beyond extensive reading was beneficial to learners’ vocabulary development. Hence, these studies indicated that a deeper processing of the words via definition, examples, context, and various types of consolidation exercises helped learners with vocabulary development and retention.

Information processing studies. Schmidt (2001) commented that "SLA literature indicate[d] that the construct of attention appear[ed] necessary for understanding nearly every aspect of second and foreign language learning” (p. 6). Referring to researchers such as Gass (1988), Schmidt and Frota (1986), Swain (1995) and others, Schmidt (2001) stated that "attention [was] what allows speakers to become aware of a mismatch or gap between 
what they [could] produce and what they need[ed] to produce, as well as between what they produce[d] and what proficient target language speakers produce[d]” (p. 6). In other words, attention enabled learners to become aware of where they were and where they needed to be if their goal was to become proficient in the L2. On explicit instruction, Schmidt (2001) said that one of its key roles was that "changing expectations, it help[ed] focus attention on forms and meanings in the input, a prerequisite for subsequent processing” (p. 10).

In addition to attending to the input, learners would need to process the information at a deeper level. Nick Ellis (1995) mentioned Craik and Lockhart’s (1972) depth of processing theory in which a deeper process of the information studied would lead to long-term retention (p. 111). Craik and Lockhart (1972) defined depth of processing as “...a series or hierarchy of processing stages where greater 'depth' implie[d] a greater degree of semantic or cognitive analysis" (p. 675). The authors supported that deeper analysis led to "more elaborate, longer lasting, and stronger traces” (p. 657). These traces would correspond to etchings that were left on the memory. According to Craik and Lockhart, stronger traces led information to long-term memory and consequently led to better levels of retention and recall. They viewed the depth of processing hypothesis as having three levels of storage in memory: sensory stores, short-term memory and long-term memory. In addition, “...various factors, such as amount of attention devoted to a stimulus, its compatibility with the analyzing structures, and the processing time available, [would] determine the depth to which it [was] processed” (Craik \& Lockhart, 1972, p. 676).

Schmitt (1997) concurred with the depth of processing hypothesis. He believed that processing words at deeper levels would bring about more effective learning. Citing Cohen and Aphek (1981), Schmitt pointed out that shallower tasks could be more adequate for 
beginners, whereas intermediate and advanced learners would benefit more from deeper tasks.

According to Laufer and Hulstijn (2001), in recent years the depth of processing theory has been questioned, “challenged, refined and modified, and eventually even abolished.” The reasons for this were that the depth of processing theory did not explain what "a 'level' of processing” was or how to determine that "one level [was] 'deeper' than another” (p. 5). Instead, Laufer and Hulstijn proposed a “construct of task-induced involvement load" that involved noticing, elaboration, and motivation. One could argue that their construct also utilized some degree of deeper processing. It appeared that they took the 'depth of processing' a step further because their "construct of involvement decompose[d] the concept of processing into two cognitive components (search and evaluation) and add[ed] a motivation component (need)” (p. 20). The second item was not included in the original depth of processing theory.

In spite of the criticism of the depth of processing, Laufer and Hulstijn (2001) agreed that elaboration was important to vocabulary acquisition. Their task-induced involvement load contained three components which involved deeper processing. Among other things, they suggested that the more actively involved learners were in the decoding process, the more likely they would retain the word. Laufer and Hulstijn also pointed out that if teachers and researchers created activities which required learners to engage more actively in the learning process, vocabulary retention would be more effective (p. 15 - 17). In their case, Laufer and Hulstijn (2001) proposed a ‘theory’ of students' involvement in deeper processing, and they also explained what different levels of involvement and processing meant. They suggested tasks which required learners to look up words, to use those words to 
understand a text and answer questions, and to use the words in a sentence or composition which would entail varying levels of involvement and of processing. In other words, one could say that involving students in such activities in class and/or online could lead students to a deeper processing of the vocabulary and to possibly better retention.

Such an assortment of activities could be used to teach individual words and also word chunks. Nick Ellis (1995) pointed out that Nation (1982), Carter (1987), and Richards (1976) supported explicit vocabulary instruction via more elaborate techniques, among them the teaching of collocation.

In studying academic vocabulary, the students in the present study experienced a "reading plus" situation in class since they not only read passages containing the target words, but they also worked on a number of different activities using the same words. The students were also being taught vocabulary collocations explicitly in class, and they were rehearsing the vocabulary by doing various online exercises.

The study presented here sought specific vocabulary outcomes for students to better cope with academic life, in particular writing. Furthermore, the students I worked with had a certain urgency to improve their language knowledge so they could enter the university. A more explicit teaching approach appeared to be more appropriate.

One component which would provide more opportunities for students to encounter academic vocabulary collocations outside class was the online environment. What follows is a brief background of the computers and second language acquisition (SLA) connection. I present a few ways in which academic vocabulary and/or collocation have been explored in this environment. 


\section{L2 Academic Vocabulary and Technology}

With accessibility to computers and the Internet, researchers and teachers had at their hands new tools to help students learn/study a second language. As a result, they started exploring ways to incorporate this technology in L2 teaching and learning. In the past twenty years or so, researchers have been investigating the usefulness of computer technology in L2 vocabulary acquisition, and research has shown that computers can be beneficial. What will follow is a brief background of the computer and second language acquisition (SLA) link. Subsequently, I consider research concerning vocabulary and computer technology.

Computer-assisted instruction started earlier than we would presume. According to Chapelle (2001), computer-assisted instruction was first introduced in the 1950s. She commented that Computer-Assisted Language Learning (CALL) started to be considered as a tool during the 1960s. In the 1960s and 1970s, small scale personal projects created the first experiences with Computer Applications in Second Language Acquisition (CASLA) (Chapelle, 2001). During that time, the use of computer technology was quite basic. Svenconis and Kerst (1994) explained that "until the mid 1980s, most of the software produced for computer assisted language learning (CALL) or computer assisted language instruction (CALI) was of drill and practice type” (p. 34). From the drill and practice type exercises, we have moved on to more sophisticated use.

Currently there are tools such as online dictionaries which contain a wealth of information about words, including synonyms, collocations, and sentences which provide examples of how a word is used. Some dictionaries also offer audio pronunciation of words and sentences. In addition to that, there are online tools such as concordancing. According to Stevens (1995), concordancing as a language learning resource started being used in the 
1980s “when computational power began to get scaled into small, affordable personal computers that have since appeared on teachers' desks” (p. 2). Flowerdew (1996) described the concordancer as a piece of software that can be utilized to find "objective data on both grammatical and lexical usage” (p. 92).

According to Flowerdew (1996), one of the first applications of concordancing was "in the field of lexicography and dictionary making". He mentioned that "this work has resulted in the Collins Cobuild dictionary” (p. 87). Lewis (2001) added that the Cobuild project consisted of the first “data-driven dictionary, where every example was taken from the corpus as a fully attended example of 'real English’” (p. 191) This dictionary is based on the Bank of English corpus (a collection of texts) "which now contains 400 million words of English” (Sinclair, 2001, p. ix). According to Lewis (2001), the renewed interest in collocations came from this work of "John Sinclair and his team at Cobuild" (p. 191). Schmitt (2000) added that "most of [the] discussion on collocation [was] based on evidence from corpora that was analyzed with computer programs called concordancers” (p. 78).

Stevens (1995) said that “concordance software and a natural language corpus [could] help in organizing natural language data, language learners can discern patterns more readily and thus become competent in the target language faster" (p. 8). He pointed out that one of the reasons to use a concordancer was that it allowed learners to get actively involved in the learning process. It also enabled learners to discover the language themselves. Schmitt (2000) explained that a concordancer identified "all the instances of a target word/string in a corpus being used" and the program also provided the lines where the target word/string was found (p. 78). In other words, learners could conduct queries themselves and find out how a word was used. (see Appendix D for a sample). 
Some researchers have been exploring concordance programs. For example, Cobb (1999) observed that developing ESL students’ vocabulary so that they could undertake academic studies was “one of the biggest challenges in English for Academic Purposes” (p. 345). He commented that his students needed to learn too many words in too little time. Hence, considering the amount of time available and the number of words necessary to learn, he thought that word lists and "acquisition through reading [would be] too slow for the time available" (p. 345). Cobb believed that "computer technology suggest[ed] new possibilities" (p. 345) to maximize this learning, and he viewed the concordance program as a possible tool to help students with vocabulary breadth as well as depth.

In his study, Cobb (1999) worked with EFL students whose first language was Arabic. The students needed English to be able to handle academic work. According to the researcher, the students had "a receptive vocabulary size of about 1,000 words" (p. 346), as determined by Nation’s (1990) vocabulary test. Cobb created a database utilizing the vocabulary from the texts students were to read during the school year. This database contained a list of words to be studied, concordancing information, and the texts to be read during the school year. The concordance program was simplified so students could more easily use it. Upon clicking on a word, students would have access to a list of concordances for that word in the reading material of that year (See Figure 1 below for a sample of his program). If the students clicked on a concordance line, they would have access to the "source text" and the target word would be highlighted.

In Cobb’s (1999) study, the students created their own individual word dictionaries or "personal word stacks," in which they could include a definition in English or a translation in Arabic, and also sentence(s) which showed how the word was utilized. In the concordancer, 
the students would identify "an example sentence that made [the word] meaning clear" (p.

349). Once the entry was created, students could print the word stacks and use them as

vocabulary cards. For 12 weeks, the students had to study 200 words per week. The

treatment groups created their own dictionaries with the concordance program and database,

whereas the control groups were given a list of the words and could use a dictionary. In

addition to the concordance program, the students had access to a stack program. All groups

also took periodic quizzes as well as pre- and post-tests.

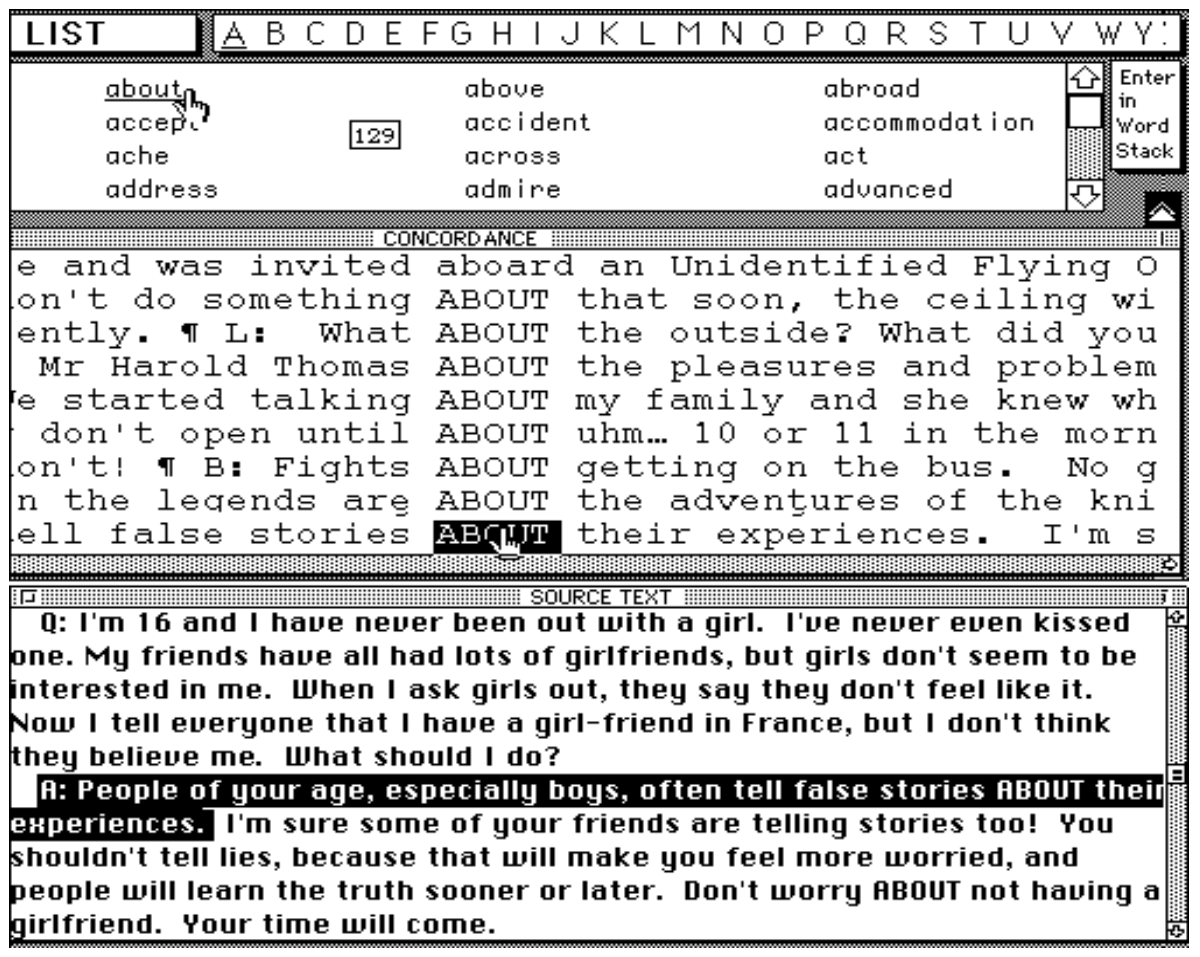

Figure 1. A sample of Cobb’s (1999) software interface

The results showed that both groups (control and treatment) performed well in terms

of retention of word definitions. However, the treatment groups performed better when using the words in a new context—a cloze exercise—which required some collocation knowledge.

Finally, the delayed test showed that "the control groups did not retain their definitional 
knowledge, while the concordance groups [treatment] if anything increased theirs with time" (p. 354).

Another study which used a concordance program was conducted by Horst, Cobb, and Nicolae (2005). In their experimental ESL course, Horst, Cobb, and Nicolae aimed at assessing a set of online activities, the quality of students' input in the Word Bank, computer use and learning results, and students' use of various tools. These activities included “examining concordance examples, consulting an on-line dictionary, reading hypertext, using the quiz feature of the on-line Word Bank, and entering texts into the cloze-passage maker” (p. 96). They aimed at having students processing academic vocabulary (from the AWL) at a deeper level as well as being more actively involved in the process of learning in the sense that part of the input into the computer program was entered by the students themselves, such as the Word Bank. Horst, Cobb, and Nicolae highlighted the relevance of rehearsal because they believed, as Hulstijn (2001) stressed, that rehearsal was essential in explicit vocabulary learning.

This study was carried out over two years. As the study progressed, the researchers revised and improved both the course design and the software program. At different stages of the study the researchers taught a varying number of students, and the students came from varied L1 backgrounds and were mostly at an intermediate level. Also, as the study progressed, the researchers added new online activities. In the last semester of the study, students worked with the five activities mentioned previously. Part of the study consisted of selecting readings for the students. These readings were selected keeping in mind Nation (2001) who indicated that newspaper articles would enable students to encounter more AWL items. After reading and summarizing the articles, students chose five unfamiliar words per 
text to include in an online Word Bank. The students themselves added the words, their definitions, a sentence (from the reading) containing each target word, and the name of the student who had added each word. All students participating in the study had access to the Word Bank. If students came across an unfamiliar word while reading, they had the concordancer, an online dictionary, and hypertext readings to consult. This part of the process was entitled “discovery strategies.” In the "practice strategies,” the students created personalized quizzes from the Word Bank sentences and cloze exercises using the online tools (Horst, Cobb, \& Nicolae, 2005, p. 96 - 97). Students could use the quizzes and cloze exercises to practice and review the new vocabulary.

The results showed students' improvement and knowledge retention of one third of the words included in the word bank "at the fairly high criterion of being able to produce accurate definitions” (Horst, Cobb, \& Nicolae, 2005, p. 105). The results also demonstrated that the students preferred to use the online dictionary and the Word Bank as opposed to the concordance software and the hypertext. Horst, Cobb, and Nicolae (2005) concluded that the Word Bank proved to be a good alternative for learners to create their own database and share it with others. Also, the material and strategies the researchers utilized proved to be effective for learners with varied language backgrounds. Moreover, the students managed to process and learn several of the words for both passive and active use. Finally, Horst, Cobb, and Nicolae commented that “deeper learning [was] encouraged by having learners contribute their own words, contexts, and definitions to the course materials, and providing them with opportunities to meet words in novel contexts through the concordance and the cloze-building features” (p. 106). 
In another study, Kaur and Hegelheimer (2005) investigated a possible approach to help learners to improve not only their use of AWL items but also to improve their collocational use of these words. Kaur and Hegelheimer conducted an exploratory study which "focused on the influence of the concordance on learners' productive word knowledge” (p. 291). The researchers worked with 18 ESL students in a writing class "at a major Midwestern research university” (p. 292).

For their study, Kaur and Hegelheimer (2005) utilized a concordance program, an online dictionary, 30 words from Coxhead's AWL, a pre-test, and a post-questionnaire. The students also had writing tasks which consisted of a cloze exercise, a sentence-building exercise, and a writing activity. The researchers worked with concordance software which provided students with possible collocations for the target words. While the treatment group used the concordance program and the online dictionary, the control group used the online dictionary only. Prior to using the tools, both groups received instruction on how to use the concordance program. The writing piece from both groups was written outside of class.

The researchers believed "concordancing [to be] advantageous because of the rich, systematic, and open-ended supply of data that encourage[d] learners to explore and discover the language patterns” (p. 289). They were also of the opinion that the software would help learners "become autonomous” as well as speed up the academic vocabulary acquisition process (p. 290).

According to Kaur and Hegelheimer (2005), the results showed that the treatment group "outperformed the control group in each of the tasks and also in the overall performance” (p. 295). Moreover, the students in the treatment group included more AWL items in their text and used the words more accurately. It was also noted that the students did 
not make as much use of the concordance software as the researchers expected. The students seemed to prefer the online dictionary. Kaur and Hegelheimer (2005) concluded that if students had access to both a dictionary and a concordance program "when they practice[d] vocabulary [students were] more likely to transfer the word knowledge correctly to their writing task” (p. 298).

The studies presented in this section showed that the online environment introduced beneficial resources for vocabulary teaching and learning. In these studies the concordance software was used as a tool to show students how words were used (collocation information and context). In addition to this, the researchers made use of various other online tools, such as a Word Bank created by students, hypertexts, and online dictionaries. The studies demonstrated that not only were the online tools beneficial to learners to improve their vocabulary, but they also helped learners with active use of words. The studies also seemed to indicate, however, that students did not appear to be as comfortable with the concordancer as they were with online dictionaries and a Word Bank. As Kaur and Hegelheimer (2005) said, learners seemed to prefer to stay in their comfort zone.

\section{Proposed Study}

The literature review shows that there are effective ways to teach vocabulary both using traditional methods and computer technology. It also shows that explicit vocabulary teaching has been established as relevant when it comes to certain types of vocabulary such as academic vocabulary. As Cobb (1999) points out, considering the amount of time available and the number of words necessary in an academic environment, "acquisition through reading is too slow for the time available” (p. 345). Thus, in a situation when learners have a certain urgency to improve their vocabulary, explicit instruction will be a 
suitable alternative. The literature also reveals that to achieve a better understanding of the words, it is ideal to combine reading with other activities that provide opportunities for learners to encounter the words multiple times and use the words more actively. To actively use the words in writing and speech, learners will, among other things, need to understand the “company the words keep,” i.e., collocations.

Considering the amount of information learners need to process when learning vocabulary, it appeared to me that a combination of in-class and online environments would enable learners to make the most of class time and, at the same time, further develop one specific aspect of vocabulary acquisition via the online environment. The piece of the vocabulary puzzle to be studied online would be collocations.

The study design was inspired by Adair-Hauck, Willingham-McLain, and Youngs’ (2000) longitudinal “program evaluation project” at Carnegie Mellon University. Their project evaluated the development of L2 listening, speaking, reading, writing and culture, and “the integration of technology-enhanced language learning (TELL)” (p. 269). The participants were second-semester French students. At that university, language classes met four times a week. For the duration of the study, the treatment group met three times in the regular classroom, and "in lieu of the fourth class period, the students chose when and where to do the multimedia components” (Adair-Hauck, Willingham-McLain, \& Youngs, 2000, p. 277). During the multimedia sessions the students worked on computer-based tasks dealing with the four skills as well as culture, whereas the control group worked on similar activities but using paper and pencil. According to the researchers, "findings indicated that students in the treatment group performed equally well as the control group in listening and speaking and better on reading and writing achievement measures” (p. 269). 
The idea to teach words in groups, i.e., collocations or chunks, came from Lewis' (2002a) The Lexical Approach. As Lewis put it:

An important part of the language acquisition is the ability to produce lexical phrases as unanalyzed wholes or 'chunks', and that these chunks become the raw data by which the learner begins to perceive patterns, morphology, and those other features of language traditionally thought of as 'grammar'. (p. 95)

The reason for focusing on collocations was the fact that learners frequently struggled when using words actively, and one aspect which often caused problems for learners was collocation. In the process of learning academic vocabulary collocations, some of the essential principles of the Lexical Approach were "recognition, generation and effective recording of collocations” (Lewis, 1997, p. 257). The rationale for focusing on this aspect of vocabulary acquisition lay in the fact that, as Nesselhauf (2003) commented, “collocations [were] of particular importance for learners striving for a high degree of competence in the second language, but they [were] also of some importance for learners with less ambitious aspirations, as they not only enhance[d] accuracy but also fluency” (p. 223). In addition, learning such information about words would help learners to create more native-like texts (Nation 2001).

Since in the last few years I have been working with learners who were preparing to attend a university in the U.S., the logical vocabulary choice was the AWL. Considering learners' difficulty with writing in an academic setting, I deemed it important to focus on an aspect of vocabulary which would help students when completing academic assignments. Collocation “skills,” as Lewis (2001) said, “equip[ped] learners to expand their individual mental lexicons in a way which [was] relevant, personal and a skill which [could] be taken 
away as a tool for life” (p. 196). By helping learners to understand and encouraging them to use collocations, I aimed to provide a tool, i.e., knowledge of what collocation was and how to locate it, which students would be able to use in class and throughout their academic life.

To enhance the collocation information, I introduced online dictionaries and an online concordancer to the students. The concordance studies presented here revealed that exposing learners indirectly to collocation (via a concordancer and other online tools) could be beneficial to them. Kaur and Hegelheimer (2005) showed that these online tools could help students’ writing development.

Even though the concordance software proved to be beneficial, Kaur and Hegelheimer (2005) suggested (quoting Nation, 2001) that "instruction [was] necessary for learners to see the importance of the words and to be able to use them productively” (p. 298). Moreover, the studies indicated that students tended to prefer the other online activities (word bank, cloze exercises, and online dictionary, for instance) to the online concordancer.

Utilizing two environments, the present case study provided the instruction suggested by Kaur and Hegelheimer (2005). In the face-to-face environment, the class teacher actively taught the new vocabulary (academic words) as well as collocations. In addition, the online environment provided students with exercises to practice combining the words with their collocations as well as identifying collocations in both reading and listening exercises. In both environments, the students were encouraged to record information about the target words.

In the online environment, similar to Horst, Cobb, and Nicolae’s (2005) online “practice strategy,” the students worked on quizzes containing sentences, texts, and rational cloze exercises. Contrary to that study, I created the exercises instead of the students. By 
introducing diverse input and practice, the students had access to form, meaning, and usage of the word chunks, which might lead to better retention via deeper information processing. As in Kaur and Hegelheimer's (2005) study, I evaluated students' writing. Unlike Kaur and Hegelheimer (2005), I focused on explicitly teaching academic vocabulary and collocations in two different environments, whereas their study focused specifically on "the effectiveness of using an online concordancer and dictionary compared to the use of only an online dictionary” (Kaur and Hegelheimer, 2005, p. 287).

Finally, being a case study, it enabled me to obtain an in-depth understanding of the entire process: presenting collocations to the students, preparing them to use the online tools, observing their attitude in both environments, evaluating their outcomes, and learning directly from the students their perceptions of the whole process. 
Operational and Conceptual Definitions

Bilingual dictionary: a dictionary that provides a translation from words in a target language to words in a learner's L1.

CALL: Computer Assisted Language Learning

CASLA: Computer Applications in Second Language Acquisition

Collocation(s): "describe the way individual words co-occur with others” (Lewis, 2002a, p. 93).

Concordancing: "is a means of accessing a corpus of text to show how any given word or phrase in the text is used in the immediate contexts in which it appears" (Flowerdew, 1996, p. 87).

Context: a sentence, paragraph, or text in which the words studied are found.

EFL: English as a Foreign Language

ESL: English as a Second Language

Explicit Learning: learning that consists of consciously trying to come up with "rules" for a certain topic, in particular when referring to grammar (Hulstijn, 2005).

First Language: L1, also referred to as native language, "generally, a person's mother tongue or the language acquired first” (Richards, Platt, \& Platt, 1992, p. 140).

Foreign language: (FL) language not spoken in the country from which the learner is originally.

Incidental vocabulary learning: vocabulary “.... is learnt as a by-product of another activity, such as reading or communication, without the learner's conscious decision, or intention, to learn the word" (Laufer \& Hill, 2000, p. 58). 
Moodle: Modular Object Oriented Developmental Learning Environment. Course management software (CMS) designed for professors and teachers to add an online component to their courses (Cole, 2005).

NS: native speaker

NNS: non-native speaker

Productive vocabulary: words that the learner uses actively, i.e., words that the learner utilizes in conversation and writing.

Rational cloze exercise: "refers to [a cloze exercise] in which a specific type of word is deleted, for example verbs or adjectives” (Steinman, 2002, p. 293).

Receptive vocabulary: words that the learner understands in speech and reading yet does not utilize in his/her own speech or writing, i.e., words which are not part of the learner's idiolect.

Second language: "a native language in a country as learnt by people living there who have another first language” (Richards, Platt, \& Platt, 1992, p. 143).

SLA: Second Language Acquisition

Vocabulary notebook: a notebook or card that a learner uses to record an assortment of information about words he/she is studying.

Vocabulary Profiler: "Vocabulary Profilers break texts down by word frequencies in the language at large” (Cobb, n.d.).

Word families: "a word family consists of a headword, its inflected forms, and its closely related derived forms” (Nation, 2001, p. 8). 


\section{Chapter 3}

\section{Methodology}

This chapter includes the research questions, an overview of the research study, description of the participants and the blended instruction, and the data analysis procedures. Research Questions

This case study looked at how focusing on academic vocabulary collocations contributed to ESL learners' writing development. The study also examined the learners' perceptions of using a blended instruction approach to study academic vocabulary collocations.

Question \#1. How does focusing on academic vocabulary collocations contribute to ESL learners’ performance in academic writing?

Question \#2. What are learners' perceptions of blended instruction?

\section{Participants}

The participants were mid-to-high intermediate-level learners of English as a second language (ESL). Most of the learners had studied English in their home countries and came to the United States to improve their English skills. The majority intended to prepare to take classes and/or pursue a degree at an American university. They had different language (Arabic, Chinese, Japanese, and Korean) and cultural backgrounds. The students ranged in age from 18 years old and older.

Most of the students were taking classes on reading, writing, grammar, communication skills, and vocabulary in the Intensive English Program (IEP) at an American university. Some were also taking one or two electives, such as the TOEFL (Test of English as a Foreign Language) preparation, pronunciation, business English, and US popular 
culture. The class utilized in the study was an academic vocabulary class which had eight students, six of whom agreed to participate in the study. Their participation was voluntary. Instructor

The class teacher was a native speaker of English and had also studied various foreign languages. Moreover, she had a Master’s degree in TESOL (Teachers of English to Speakers of Other Languages) and had taken classes on CALL (Computer Assisted Language Learning) and linguistics. The class teacher had vast experience teaching ESL.

In the classroom, the teacher was in charge of the teaching and assisted students in developing their vocabulary. More specifically, she helped students develop strategies to study and review vocabulary, to recognize parts of speech, to utilize collocations, and to apply the academic vocabulary knowledge when listening, speaking, reading, and writing. Initially, the teacher planned to use two textbooks: Essential Academic Vocabulary: Mastering the Complete Academic Word List (Huntley, 2006) and All Clear! Idioms in Context (Fragiadakis, 1993). However, due to the students’ English level being lower than she expected, the teacher opted to use the former only. A more detailed description of how the class was designed can be found in the course syllabus (Appendix A).

\section{Course Design}

The instructional approach was divided into two parts: an in-class and an online component. In the classroom component, the students focused on various aspects of academic vocabulary, whereas in the online component for the study students concentrated solely on academic vocabulary collocations.

In class the students worked on various activities to develop their academic vocabulary knowledge in general. The teacher used the textbook to work on reading 
comprehension, vocabulary in context, word parts, parts of speech, dictionary use, and collocations. Students developed their reading, listening, writing, and speaking skills (see Appendix B for samples of speaking activities). In class the teacher also explained to the students that collocation comprised an essential part of L2 vocabulary development and that it could help them improve their fluency in writing and speaking. The objective of the inclass activities was to provide input and practice on the various aspects of vocabulary acquisition.

The online exercises provided further collocation practice for the students via Moodle and Hot Potatoes exercises. According to Cole (2005), Moodle stands for Modular Object Oriented Developmental Learning Environment. It consists of course management software (CMS) and has been designed for professors and teachers who want "to add web technology to their courses” (Cole, 2005, p. xiii). The program enables instructors to add a number of online resources to their courses. Some of the resources available are a web board (called Forum in Moodle), a chat room, various types of quizzes, assignments, and a wiki [“a web page everyone in your class can create together, right in the browser, without needing to know HTML” (Cole, 2005, p. 161)]. Hot Potatoes, on the other hand, consists of a downloadable tool which allows the user to create online exercises. Some of the exercise types available are multiple-choice, short answer, jumbled sentences, crossword, matching, and fill-in-the-gaps (see Appendix N for a sample of a Hot Potatoes quiz). The online vocabulary activities focused on supplying additional practice to collocate academic vocabulary with their appropriate counterparts.

Instructional materials. In class the group used one textbook: Essential Academic Vocabulary: Mastering the Complete Academic Word List (Huntley, 2006). Huntley’s 
textbook was designed to assist learners in developing their academic vocabulary. She utilized the AWL to organize the chapters and to design the exercises and activities found in the book. The textbook did not strictly follow the AWL sublists; rather, the author utilized words which fit the particular chapter theme. Consequently, words from multiple sublists could be found in each chapter. Huntley's textbook had a companion website which provided online quizzes. These quizzes consisted of true/false, fill-in-the-blanks, and multiple choice exercises.

Huntley's textbook provided the context for the in-class work material, and the teacher often supplemented the class with activities from newspapers, online articles, and flyers related to the chapter theme. Michael Lewis’ books, Implementing the Lexical Approach (2002b) and Teaching Collocation (2001), were used as resources for collocation activities/exercises for both the classroom and the online environments.

The words used in the online component were taken from the AWL (Coxhead, 2000). The AWL consists of the most recent compilation of academic words which are essential for those learners who intend to pursue undergraduate or graduate studies in an English-speaking country. The AWL is subdivided into 10 sublists. Coxhead (2000) points out that "the AWL accounts for $10 \%$ of the tokens [words] in the Academic Corpus” (p. 222). For the online components of the class, I utilized only sublists 1 through 3 (see Appendix C for sublists). According to Coxhead, "the words in the first three sublists occur with comparatively high frequency” (p. 228). Moreover, these sublists raise academic text coverage to 6.6\%. (Coxhead, 2000, p. 228). Nation (2001) points out that knowing high frequency words (first 2,000 most frequent words in English) gives learners about 80\% readability of a text. Adding the AWL to that list increases learners' readability another 10\%. Learning sublists 1 
through 3 can increase learners' readability of academic texts by $6.6 \%$ out of that $10 \%$. Such an increase would be significant for learners. The three sublists amount to 180 word families of the 570 included in the AWL.

I was responsible for creating the online activities, utilizing the Moodle course management software and Hot Potatoes software to do so. The Hot Potatoes software was utilized to create activities which were then imported into Moodle as well as made available on my website due to software licensing requirements. The online exercises did not contain all the words from the particular vocabulary sublist, yet the words included were predominantly chosen based on words that the students were learning in class. Also, the activities did not strictly follow the words chapter by chapter since these exercises were not meant to be used only for review but also for independent learning of vocabulary collocations. Students were instructed on how to work on some of the Moodle activities. In Moodle, the students found activities for reading, listening, and some writing. The speaking component was worked on solely in class.

For the online exercise sessions, I used themes resembling what the students found in their textbook. The words, sentences, and texts were related to these themes. This way the students were exposed to the target words several times in different combinations and yet in the same contexts.

Some of the sentences, short passages, and dialogues I created myself with the help of dictionaries. Students worked on matching synonymous collocations, identifying words which could not collocate with a target word, rational cloze exercises—a type of cloze exercise from which we delete specific words we want students to focus on; in the case of 
this study, the words deleted were AWL items — and locating collocations in reading and listening passages.

The passages used for reading and listening exercises came from articles on the Voice of America (VOA) website. The VOA articles were searched for specific words using the Web VocabProfiler (Cobb, n.d.). Students only worked with a few target words in these exercises. In these exercises I asked the students to locate possible collocations for the target words after having either read a text or listened to it (see Appendix M for a sample of a reading exercise). Considering that these activities would take more time, I allotted more time for students to do them (approximately 15 minutes).

The collocational information about the words came from the Online Concordancer (Greaves, n.d.), which is a tool that can provide a number of collocations for words (a concordancer sample can be found in Appendix D), and also Oxford Collocations (2002). This particular dictionary was chosen for its wealth of information regarding word collocations.

In addition to the Moodle activities, the students had access to my personal website (http://esl.nevesweb.info). It was via this website that the students accessed Moodle, the collocation activities, and online resources such as Merriam-Webster's online version, which provides definition, thesaurus, and pronunciation information; the Cambridge Advanced Learners Dictionary Online, which supplies definition and collocation information; and the Online Concordancer. Horst, Cobb and Nicolae (2005) explained that a concordancer enabled students to search “[a] corpus to find all occurrences of the selected words and display them in a format that allow[ed] the user to see the many different instances of the 
word in use” (p. 96). Students could also utilize any paper or online dictionaries and/or their personal bilingual dictionaries whenever they needed them.

Course Sequence

The blended instruction took place over the course of twelve weeks of the school semester. In the first three weeks, the teacher taught her regular classes, and I utilized 15 20 minutes of each class to give a demographic questionnaire, help students sign up with Moodle, and provide instruction for using Moodle. Table 1 illustrates the sequence of activities throughout the twelve weeks. Subsequently, I provide more detail of how the activities progressed.

Table 1

Summary of Blended Course

\begin{tabular}{|c|c|c|}
\hline Week/Day & Class & Online \\
\hline $\begin{array}{l}\text { Week } 1 \\
\text { Day \#0 }\end{array}$ & $\begin{array}{l}\text { - Students were invited to participate in } \\
\text { the study and answered questionnaire }\end{array}$ & N/A \\
\hline Day \#1 & 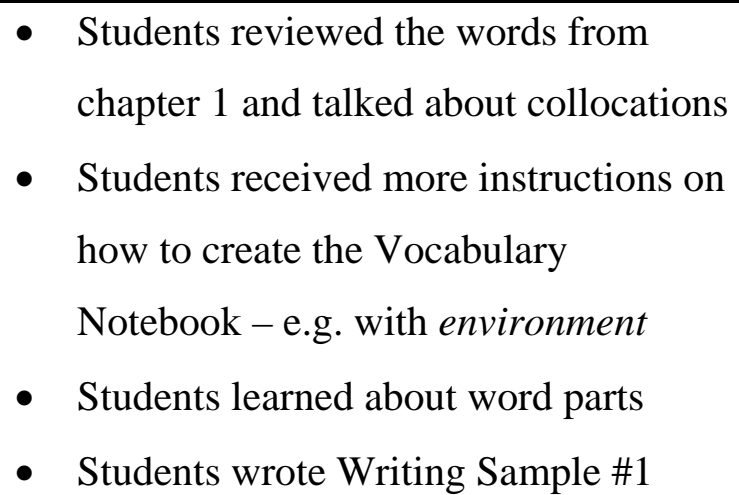 & N/A \\
\hline $\begin{array}{l}\text { Week } 2 \\
\text { Day \#2 }\end{array}$ & $\begin{array}{l}\text { - Students worked on reading and } \\
\text { speaking activities, and on parts of } \\
\text { speech } \\
\text { - Students received collocation input via } \\
\text { questions and the reading } \\
\text { comprehension }\end{array}$ & N/A \\
\hline
\end{tabular}




\begin{tabular}{|c|c|c|}
\hline Week/Day & Class & Online \\
\hline Day \#3 & 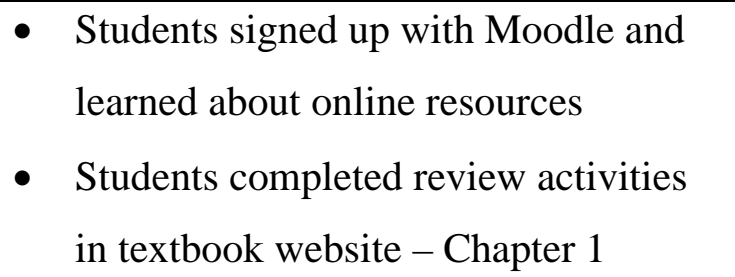 & N/A \\
\hline $\begin{array}{l}\text { Week } 3 \\
\text { Day \#4 }\end{array}$ & 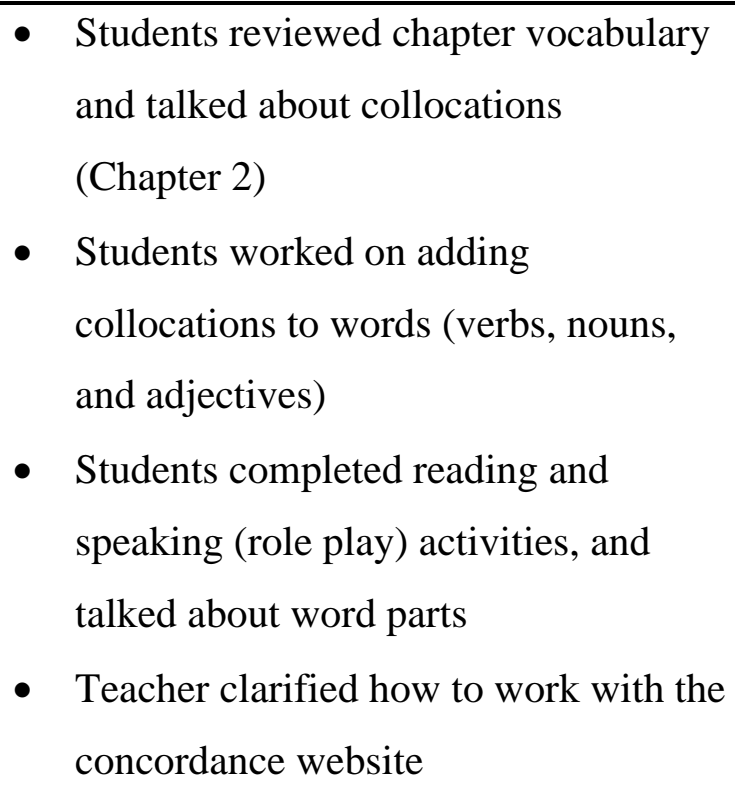 & N/A \\
\hline Day \#5 & $\begin{array}{l}\text { - Students practiced using the new } \\
\text { chapter vocabulary and worked on } \\
\text { reading comprehension } \\
\text { - There were examples of collocation in } \\
\text { questions asked in class (input) }\end{array}$ & $\begin{array}{l}\text { - Students received Moodle } \\
\text { instruction and had time to } \\
\text { practice and ask questions }\end{array}$ \\
\hline $\begin{array}{l}\text { Week } 4 \\
\text { Day \#6 }\end{array}$ & $\begin{array}{l}\text { - Students played a vocabulary review } \\
\text { game (true/false) (Chapter 3) } \\
\text { - They worked on the collocation } \\
\text { section of the textbook } \\
\text { - Students worked on reading } \\
\text { comprehension and word parts }\end{array}$ & 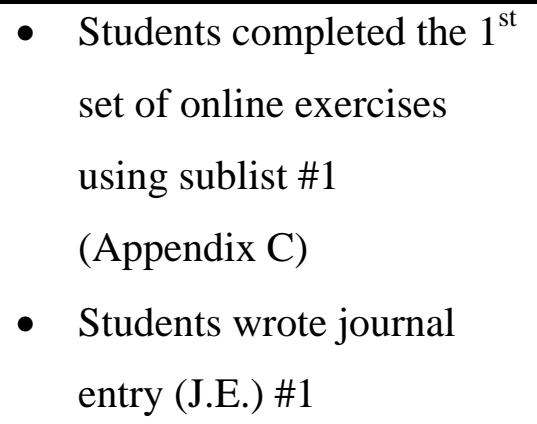 \\
\hline
\end{tabular}




\begin{tabular}{|c|c|c|}
\hline Week/Day & Class & Online \\
\hline Day \#7 & 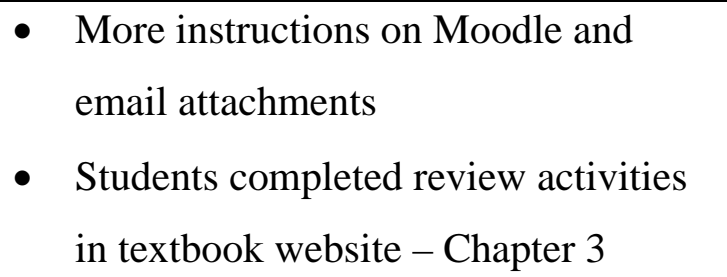 & - Same as above \\
\hline $\begin{array}{l}\text { Week } 5 \\
\text { Day \#8 }\end{array}$ & $\begin{array}{l}\text { - } \text { Teacher had students correct the } \\
\text { mistakes in some of their sentences } \\
\text { - Students reviewed words from } \\
\text { Chapter } 4 \\
\text { - Students worked on reading and } \\
\text { speaking activities }\end{array}$ & 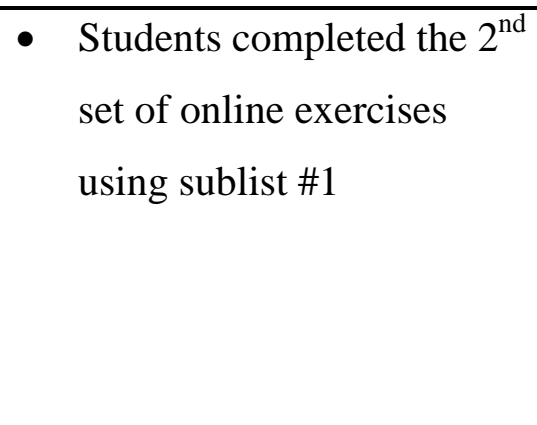 \\
\hline Day \#9 & $\begin{array}{l}\text { Students completed collocation } \\
\text { activities in their textbook: finding } \\
\text { example of things associated to } \\
\text { common collocations } \\
\text { - Students also did short presentation, } \\
\text { studied word parts, and played a } \\
\text { definition bingo }\end{array}$ & - Same as above \\
\hline $\begin{array}{l}\text { Week } 6 \\
\text { Day \#10 }\end{array}$ & $\begin{array}{l}\text { - Students reviewed for the Mid-term } \\
\text { exam (Chapter 5) } \\
\text { - They did a listening/fill-in-the-blanks } \\
\text { (knowledge of collocation was } \\
\text { relevant to do the task), reviewed } \\
\text { collocation, parts of speech, and word } \\
\text { parts } \\
\text { - Teacher submitted Journal \# } 1 \text { this } \\
\text { week }\end{array}$ & 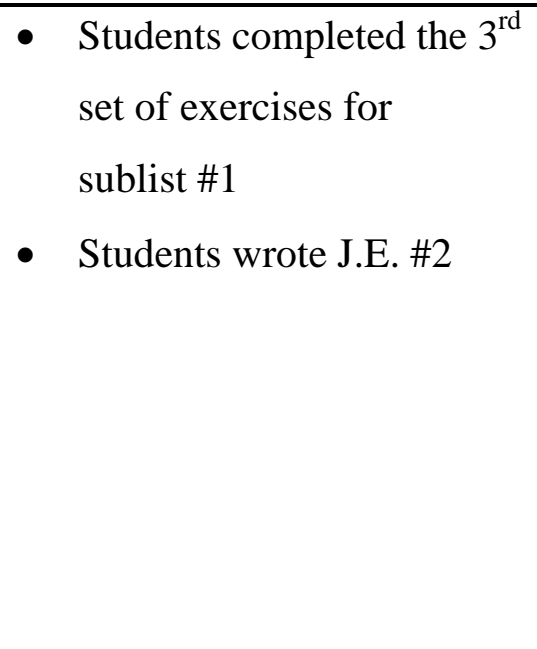 \\
\hline & - Mid-Term Exam & - Same as above \\
\hline
\end{tabular}




\begin{tabular}{|c|c|c|}
\hline Week/Day & Class & Online \\
\hline $\begin{array}{l}\text { Week } 7 \\
\text { Day \#11 }\end{array}$ & $\begin{array}{l}\text { - Students went over the exam - } \\
\text { collocation section } \\
\text { - The class started chapter } 6 \text { with } \\
\text { reading comprehension and creating } \\
\text { sentences } \\
\text { - Students used their vocabulary } \\
\text { notebook to teach words to each other } \\
\text { and worked on a speaking activity } \\
\text { They wrote Writing Sample \#2 }\end{array}$ & $\begin{array}{l}\text { - Students completed the } 1^{\text {st }} \\
\text { set of online exercises for } \\
\text { sublist \#2 (Appendix C) }\end{array}$ \\
\hline $\begin{array}{l}\text { Week } 8 \\
\text { Day \#12 }\end{array}$ & $\begin{array}{l}\text { - Teacher had students correct the } \\
\text { mistakes in some of their sentences } \\
\text { - Students reviewed the new } \\
\text { vocabulary, studied word parts, and } \\
\text { developed their dictionary skills and } \\
\text { collocation use (Chapter 6) } \\
\text { - Students wrote the mid-term reflection }\end{array}$ & 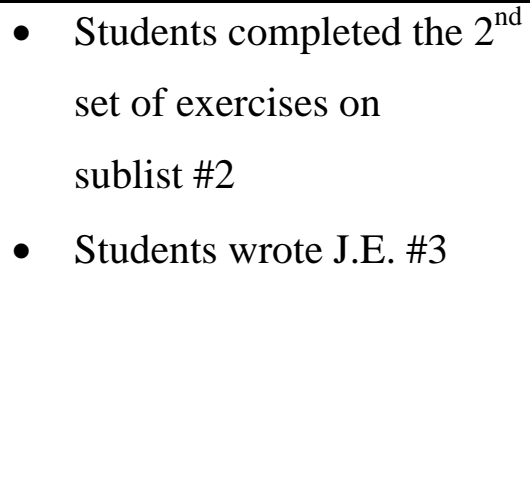 \\
\hline Day \#13 & $\begin{array}{l}\text { - Students reviewed vocabulary } \\
\text { - They studied collocation, parts of } \\
\text { speech, and also worked on reading } \\
\text { and speaking }\end{array}$ & - Same as above \\
\hline $\begin{array}{l}\text { Week } 9 \\
\text { Day \# } 14\end{array}$ & $\begin{array}{l}\text { - Students reviewed vocabulary } \\
\text { - They worked on dictionary skills, } \\
\text { word parts, and collocation }\end{array}$ & $\begin{array}{l}\text { - Students completed the } 3^{\text {rd }} \\
\text { set of exercises on } \\
\text { sublist \#2 }\end{array}$ \\
\hline Day \#15 & $\begin{array}{l}\text { Students completed review activities } \\
\text { on the textbook website - Chapter } 7 \text { as } \\
\text { well as Moodle exercises }\end{array}$ & - Same as above \\
\hline
\end{tabular}




\begin{tabular}{|c|c|c|}
\hline Week/Day & Class & Online \\
\hline $\begin{array}{l}\text { Week } 10 \\
\text { Day \#16 }\end{array}$ & $\begin{array}{l}\text { Students worked on Chapter } 8 \\
\text { vocabulary, reading comprehension, } \\
\text { dictation/ collocation, dictionary skills, } \\
\text { and speaking (discussion and short } \\
\text { speech) }\end{array}$ & $\begin{array}{l}\text { - Students completed the } 1^{\text {st }} \\
\text { set of online exercises for } \\
\text { sublist \#3 (Appendix C) } \\
\text { - Students wrote J.E. \#4 }\end{array}$ \\
\hline Day \#17 & $\begin{array}{l}\text { - Students played a game using their } \\
\text { vocabulary notebooks, worked on a } \\
\text { collocation game, and created } \\
\text { sentences using the new vocabulary } \\
\text { - Teacher submitted Journal \# } 2\end{array}$ & - Same as above \\
\hline Week 11 & $\begin{array}{l}\text { - A substitute teacher taught the class } \\
\text { (no observation) }\end{array}$ & 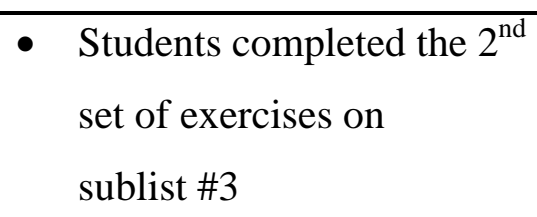 \\
\hline & - Students did assignments outside class & - Same as above \\
\hline $\begin{array}{l}\text { Week } 12 \\
\text { Day \#18 }\end{array}$ & $\begin{array}{l}\text { - Students reviewed the material taught } \\
\text { in the previous week (Chapter 9) } \\
\text { - They worked on speaking (discussion } \\
\text { and role play), reading } \\
\text { comprehension, and parts of speech }\end{array}$ & $\begin{array}{l}\text { - Students completed the } 3^{\text {rd }} \\
\text { set of exercises on } \\
\text { sublist \#3 } \\
\text { - Students wrote their final } \\
\text { J.E. \#5 }\end{array}$ \\
\hline Day \#19 & $\begin{array}{l}\text { - Students reviewed vocabulary, and } \\
\text { then did a collocation activity (See } \\
\text { Appendix K) based on their } \\
\text { vocabulary notebooks } \\
\text { - Students also worked on dictionary } \\
\text { skills, reading comprehension, and } \\
\text { speaking }\end{array}$ & - Same as above \\
\hline
\end{tabular}




\begin{tabular}{lll}
\hline Week/Day & \multicolumn{1}{c}{ Class } & \multicolumn{1}{c}{ Online } \\
\hline Week 13 & $\bullet$ & Students worked on collocation \\
Day \#20 & exercises: finding examples of things & \\
& associated to common collocations & N/A \\
& (Huntley, p. 97) \\
& - & \\
& They also studied word parts and parts & \\
& exam (Chapters 9 - 10) \\
\hline Day \#21 & Students wrote Writing Sample \#3 as \\
& part of the final exam \\
& Students participated in the interviews \\
& during week 13 \\
& Teacher was interviewed after the \\
& semester was over \\
\hline
\end{tabular}

At the beginning of week $\# 1$ of the project, students answered a questionnaire which focused on demographics and the students' level of comfort using computer technology and the Internet (see Appendix E). In addition, the students were asked to write a paragraph using some of the words from chapter 1 in the textbook (see Appendix I for instructions on writing sample \#1). This constituted their first writing sample, which was used to assess their ability to collocate the AWL items. During weeks \#1, \#2, and \#3, I prepared the students to use the online tools and exercises, and the students also participated in their regular classes.

The teacher allowed me to use approximately 20 minutes of three class sessions to familiarize the students with my website and the online tools in Moodle. The computer instructions aimed to familiarize the students with the various online resources. 
In the meantime, I observed the in-class sessions and kept a journal where I related what took place in the classroom. Moreover, I described the progress of the class activities and my perception of students' responses to the activities; I was not involved in any of the teaching. Initially, I considered asking the teacher to look over my class observations. However, because the project took more time than the teacher expected at first, I decided to only occasionally talk to her about the observations.

The instructor wrote two journals as well, in which she commented on the students' progress in their writing, evaluated the online activities, and talked about her overall perception of the blended instruction course. Originally, I thought about asking the instructor to write a final journal. However, at the end of the project, I opted to interview her because I believed I would obtain more information that way. During this interview, the instructor and I discussed what had happened both inside and outside the class and how the project had turned out.

In week \#4, the students were assigned exercises using the first sublist, which included 60 words (see Appendix C). For three weeks, the students completed online exercises on this sublist. I followed the same pattern with the other sublists (\#2 and \#3). The students were to access the Moodle website and complete three exercises each week. These exercises were created in a quiz format. For each exercise (see Appendix F for a sample Moodle exercise), the students were timed—allotted approximately 10 minutes — and graded. We covered sublists 1 through 3 in nine weeks of the semester.

The online activities consisted of exercises such as Odd One Out (see Appendix F). Students identified from four words the one which could not be combined with the target word. They also matched nouns to their corresponding verb collocations, read short 
dialogues and identified collocations, and completed fill-in-the-blanks activities with the appropriate collocations.

Twice a week the students attended their regular hour and 15 minute vocabulary classes, where they developed their vocabulary to improve their speaking, listening, reading, and writing skills. Another 30-minute session, outside class, was allotted to work on the online exercises specifically. During this time, students had the option of working with a classmate or individually. The majority chose to work alone.

After completing the online exercises, the students wrote a journal entry individually. The students' journals contained information about their experience while working on the online exercises. These journals were guided by questions (see Appendix G) and were to be written after every other online session. At first I had intended to ask the class teacher not to assign homework once a week so that the students would have time to work on the online exercises. However, that was not possible. The teacher had a great deal of material to cover and tended to assign homework on occasion to save in-class time.

About halfway into the blended course (week \# 7) the students were asked to write a second writing sample (see Appendix I for instructions on writing sample \#2). This sample came from an activity assigned by the teacher. In week \#8, students wrote a reflection which supplied information about their perception of the course and of their performance up to that point (see Appendix H for reflection questions). After I read and assessed the reflections, depending on the students' comments, I modified some of the online activities. Finally, at the end of the semester, students participated in an interview (see Appendix $\mathrm{J}$ for sample questions). As part of their final exam, the students wrote the last writing sample (see Appendix I for instructions on writing sample \#3). 
Data Description, Collection \& Analysis

Question \#1 (How does focusing on academic vocabulary collocations contribute to ESL learners' performance in academic writing?) was answered from the analysis of the researcher's journal, instructor's journals and interview, students' writing samples, students' journal entries, and the students' interviews. Question \#2 (What are learners' perceptions of blended instruction?) was answered by the researcher's journal entries, instructor's journals and interview, and the students' journal entries, mid-course reflections, interviews, and online exercises (Moodle logs). Table 2 identifies the data sources and describes the results for each of the two research questions.

Table 2

Summary of Research Questions, Data Sources, and Description of Results

\begin{tabular}{|c|c|c|}
\hline Research questions & Data Sources & Description of Results \\
\hline \multirow{5}{*}{$\begin{array}{l}\text { 1. How does focusing } \\
\text { on academic } \\
\text { vocabulary } \\
\text { collocations } \\
\text { contribute to ESL } \\
\text { learners' } \\
\text { performance in } \\
\text { academic writing? }\end{array}$} & - Researcher’s journal & $\begin{array}{l}\text { Comments on the writing - } \\
\text { students' performance on in-class } \\
\text { activities and assignments }\end{array}$ \\
\hline & $\begin{array}{l}\text { - Instructor's journal and } \\
\text { interview }\end{array}$ & $\begin{array}{l}\text { Comments on students' overall } \\
\text { performance in class - focus on } \\
\text { students' use of collocation in } \\
\text { class }\end{array}$ \\
\hline & - Students' journal entries & $\begin{array}{l}\text { Student Prompt \#2 - attention to } \\
\text { words and their combinations } \\
\text { Prompt \# } \mathbf{3} \text { - if students are } \\
\text { focusing on collocations and how. } \\
\text { Prompt \# } \mathbf{4} \text { - if students focus on } \\
\text { collocations, and if so, which ones }\end{array}$ \\
\hline & - Students' writing samples & $\begin{array}{l}\text { Use of target words (AWL items) } \\
\text { and accuracy collocating them }\end{array}$ \\
\hline & - Student interviews & Students' comments \\
\hline
\end{tabular}




\begin{tabular}{|c|c|c|}
\hline Research questions & Data Sources & Description of Results \\
\hline \multirow{6}{*}{$\begin{array}{l}\text { 2. What are learners' } \\
\text { perceptions of } \\
\text { blended } \\
\text { instruction? }\end{array}$} & - Researcher’s journal & $\begin{array}{l}\text { Overall comments - perception } \\
\text { of students' performance in class } \\
\text { and online }\end{array}$ \\
\hline & $\begin{array}{l}\text { - Instructor's journal and } \\
\text { interview }\end{array}$ & $\begin{array}{l}\text { Instructor's comments - } \\
\text { perception of the whole process of } \\
\text { instruction: in class performance } \\
\text { and online performance and } \\
\text { materials }\end{array}$ \\
\hline & - Students’ journal entries & $\begin{array}{l}\text { Prompt \# } \mathbf{1} \text { - check whether } \\
\text { technology is helping or hindering } \\
\text { Prompt \#5 - check level of } \\
\text { difficulty of activities } \\
\text { Prompt \#6 - check students' level } \\
\text { of interest } \\
\text { Prompt \#7 - opportunity for } \\
\text { further comments }\end{array}$ \\
\hline & - Mid-course reflection & $\begin{array}{l}\text { Prompts \#1 through \#5 - check } \\
\text { what works and what does not in } \\
\text { each environment } \\
\text { Prompts \#6 and \#7 - check the } \\
\text { students' perception of their } \\
\text { learning }\end{array}$ \\
\hline & - Online exercises & $\begin{array}{l}\text { Moodle logs, time spent on and } \\
\text { frequency using the exercises }\end{array}$ \\
\hline & - Student interviews & Students' comments \\
\hline
\end{tabular}

Researcher's journal. The researcher's journal entries consisted of classroom observations. While observing the classes, I took notes and later wrote a journal entry in which I documented what happened in the classroom, focusing on the students' reactions to and engagement in the collocation activities as well as the activities in general. I concentrated on the interaction level that the activity required and whether the intended goal had been achieved. Also, I observed whether the students followed the instructions. The 
level of engagement had an effect on an activity's success, and also the time an activity was introduced - beginning, middle or end of the class - could affect the students' interest and concentration. These points helped me to confirm students' comments in the mid-course reflection and the interview. Similar to the other data sources, I tried to identify what was working and what was not working in the classroom. Moreover, I looked at the students' progress in understanding, identifying, and utilizing collocations.

Instructor's journal and interview. The teacher was asked to write about the students’ performance in general as well as their performance in their writing. Additionally, she was asked to talk about her perception of blended instruction. Finally, she was asked to assess the online exercises. Her comments on the latter helped me to improve the online activities. She wrote two journal entries. To avoid overloading the instructor and to obtain more specific information, I invited her to participate in an interview after the semester ended.

Students' journal entries. The students were responsible for completing journal entries after finishing five of the nine sessions. These journal entries consisted of seven prompts that the students answered. Students' answers helped me to evaluate their online experience. The prompts related to the academic vocabulary itself as well as the use of online resources. A template for the journal entry (see Appendix G) was posted in Moodle together with the exercises for the particular week so the students knew exactly when they needed to write the entry.

While learning how to use Moodle and the online resources, the students were instructed on where to find the template, how to download it, how to label their work, and how to submit it to the researcher. After working on the week's online session, the students 
were to download the journal template from Moodle, answer the prompts on the computer, and email the entry to the researcher as an attachment. When I received the journal entries, I separated them in individual computer files. The students and researcher followed this procedure every other week.

The journal entries were read as they were submitted. I looked at whether the students were having problems accessing the material or working on the exercises. I also learned which exercise types appealed to them most and which ones did not. From the lexical perspective, I looked at the level of difficulty of the words and exercises (questions 2, 3, 4 and 5). Moreover, their answer to prompt \# 2 helped me to see whether the students were taking notes on the words, and, if so, what they were recording. Taking notes was not a requirement. However, the teacher required the students to keep a vocabulary notebook (see Figure 2 for a sample).

After reading the journal entries, I provided feedback and suggestions to the students whenever applicable. If a student provided a confusing answer, I talked to him/her after the class to try to clarify his/her answer. Around mid-course, to the students who had submitted the journals, I emailed comments about their journal entries and, when applicable, requested further explanation for certain comments they had made. 


\section{Vocabulary Notebook Example environment}

Meaning

Sentence

Pronunciation

Related word forms

Associations

Collocations
1. The surroundings and conditions that affect the growth and development of living things

2. The social and cultural conditions affecting the nature of a person or community

Animals adapt to the local environment.

en/vi/ran/mant

environmental (adi), environmentally (adv), environs (n. plu) nature, animals, endangered species, pollution, neighborhood

Safe/friendly/dangerous/economic environment Explore/adapt to/improve/protect the environment Damage to the environment

Conservation/protection/pollution of the environment

Harmful to the environment

Figure 2. A vocabulary notebook entry.

The objective was to learn from the students whether technology was assisting learning or getting in the way. The students' answers also helped me to adjust the exercises. Below, I elaborate on what information I obtained from each individual prompt.

Prompt 1 (What was it like to work on the online activities today? Describe.) provided information regarding the technology/software itself. I learned from the students whether it was easy to access and use the website and Moodle or if there were technical problems. I observed, as an instructor and as a student, that such difficulties might lead users to be discouraged from using technology. Ease of use of the online tool would create a more positive view of the software and would make learning more pleasant, whereas glitches would incur the opposite effect.

Prompt 2 (While doing the exercises, did you look up any words in a dictionary? If so, which words and in which dictionary? What did you read about the word? Did you take 
notes of anything about this word? If so, what did you write?) constituted a long question, yet its content was directly connected, which was why I decided to include it all in one prompt. This group of questions helped me to verify which words (nouns, verbs, adjectives, and adverbs) posed difficulty for the students. If the students needed to look a word up in a dictionary, it probably presented difficulty for them either because they did not know the meaning of the word or because they did not know how to use it. The type of dictionary the students used helped me see what sort of information they were seeking. Depending on what students said they read about the words, I had an idea of how much detail they were paying attention to and if they were considering collocations at all. Finally, note taking (translation, definition, examples, pronunciation, possible collocations, or no notes) told me what the students regarded as important about the words they looked up. This also gave me an idea of whether the students were thinking in terms of word collocations or not.

With prompts 3 and 4 (Did you notice any word combinations you were familiar with? Which one (s)? \& Did you notice any word combinations you were not familiar with? Which one (s)? ), I hoped to determine whether the exercises were being used as a review/reinforcement activity ("old" chunks) or if they were providing new input ("new" chunks). Provided that students fully answered the prompts and identified specific word combinations they were familiar with and the ones they were not, I was able to classify which collocations were being reinforced and which ones were new input. By observing “old” chunks, students enhanced their possibility of turning input into intake, i.e., bringing the group of words into their long-term memory; while encountering a chunk for the first time provided input, “...language presented to students through reading and listening” (Lewis, 2002a, p. 24). Furthermore, these questions would help me to verify if students 
could differentiate between a word chunk and a non-word chunk by observing what students wrote down as examples of word collocations.

Prompt 5 (How do you feel about your score on the exercises today?) consisted of a way for students to self-evaluate their performance. This question enabled students to talk about their successes and frustrations.

Prompt 6 (What did you enjoy about doing the activities presented?) provided information about engaging and non-engaging activities. Looking at the percentage of students who liked or disliked an activity could help me to improve the activities. When several of the students, or all of them, commented that a certain exercise was too complicated, boring, or repetitive, I either removed or modified the activity, attempting to make the exercise more engaging to students.

Finally, prompt 7 (Please add any other comments or suggestions you may have.) was an open-ended prompt that presented an opportunity for students to introduce a new topic or talk about a topic that may have escaped the researcher. Students also had a chance to use their creativity and perhaps feel like they were an active part of the learning process. If they noticed that what they said mattered and they were actively involved in the design process, they may have felt more inclined to do the online exercises.

Students' writing samples. The various writing samples helped me to verify the students’ progress during the semester. For their first writing sample, students were asked to write a paragraph in which they included six to eight words from chapter \#1 in the textbook. This sample was collected during week \#1 of the study. While reading their paragraphs, I concentrated on the AWL items studied in class and the students' accuracy when combining these words with their counterparts. At mid semester, a similar type of writing was assigned. 
These instructions came from chapter \#6 in their textbook. The second sample was compared to the first one and helped me to see how much the students had progressed (or not) up to that point. At the end of the semester, the students received an assignment in which they had to use at least 10 AWL items from the words they had studied. This final sample was also evaluated focusing on how well the students collocated the academic words studied (see Appendix I for writing sample instructions).

Mid-course reflection. The mid-course reflection (see Appendix $\mathrm{H}$ ) included questions regarding the in-class activities and the online exercises. At this point, the students evaluated not only the activities but also their own progress. Their feedback provided formative evaluation of the blended instruction. Their comments gave me the chance to make adjustments in the activities and exercises. The collection of this material took place at mid-semester. In class the students were handed the questions and allowed time to answer.

The mid-course reflection contained six questions. Prompts 1 and 2 (Which vocabulary activities/assignments do you think worked well in class? \& Which exercises worked well in Moodle? Explain.) provided information about how useful and beneficial students perceived in-class and Moodle activities to be. On the other hand, prompts 3 and 4 (Which vocabulary activities/assignments do you think have not worked well in class? \& Which exercises have not worked well in Moodle? Explain.) gave the students the opportunity to talk about activities they disliked. The students' comments were considered if/when modifying the online activities.

Prompt 5 (What have you learned about vocabulary?) helped me to obtain information regarding the students' perspectives of their own vocabulary learning. It also helped me to see whether the students were focusing on collocations. Lastly, prompt 6 (What 
do you think you have learned in this course?) provided an overall picture of how the students viewed the blended instruction course.

Online exercises. In Moodle, the students encountered various activities to practice using collocations (see Appendices $\mathrm{F}, \mathrm{M}$, and $\mathrm{N}$ for samples). While doing the online exercises, the students could take notes on the vocabulary studied. Note taking was observed through their journal entries. These exercises were timed and scored so I could have a sense for how long they took to complete the activity and how well they did. This information was automatically stored in Moodle and could be accessed and evaluated later. The students' results were compared to their comments in their journals. Both the researcher and the instructor had access to this information.

Every week I examined the students' results, their number of attempts when doing the exercises, and their time doing each exercise. This information, when analyzed with the corresponding journal entry, helped me to evaluate the level of difficulty when doing the exercises and to assess their progress.

Student interviews. Student interviews were conducted on the last week of classes. The students were asked open-ended questions about their perceived progress, the class tasks, and the online exercises. The interviews also provided an opportunity for me to address any questions that might have appeared during the semester. I talked to the students individually about their experience throughout the semester. Each interview lasted on average 30 minutes and was audio taped. While analyzing the students' responses, I looked for patterns in the comments on blended instruction. The categories I found included positive and negative comments on the use of technology in general and Moodle specifically, and positive and 
negative remarks concerning doing work outside the classroom. The students' comments about the in-class work was always positive.

In Table 3, I itemize the data collection and data analysis procedures used to answer the research questions.

Table 3

Data Description, Collection, and Analysis

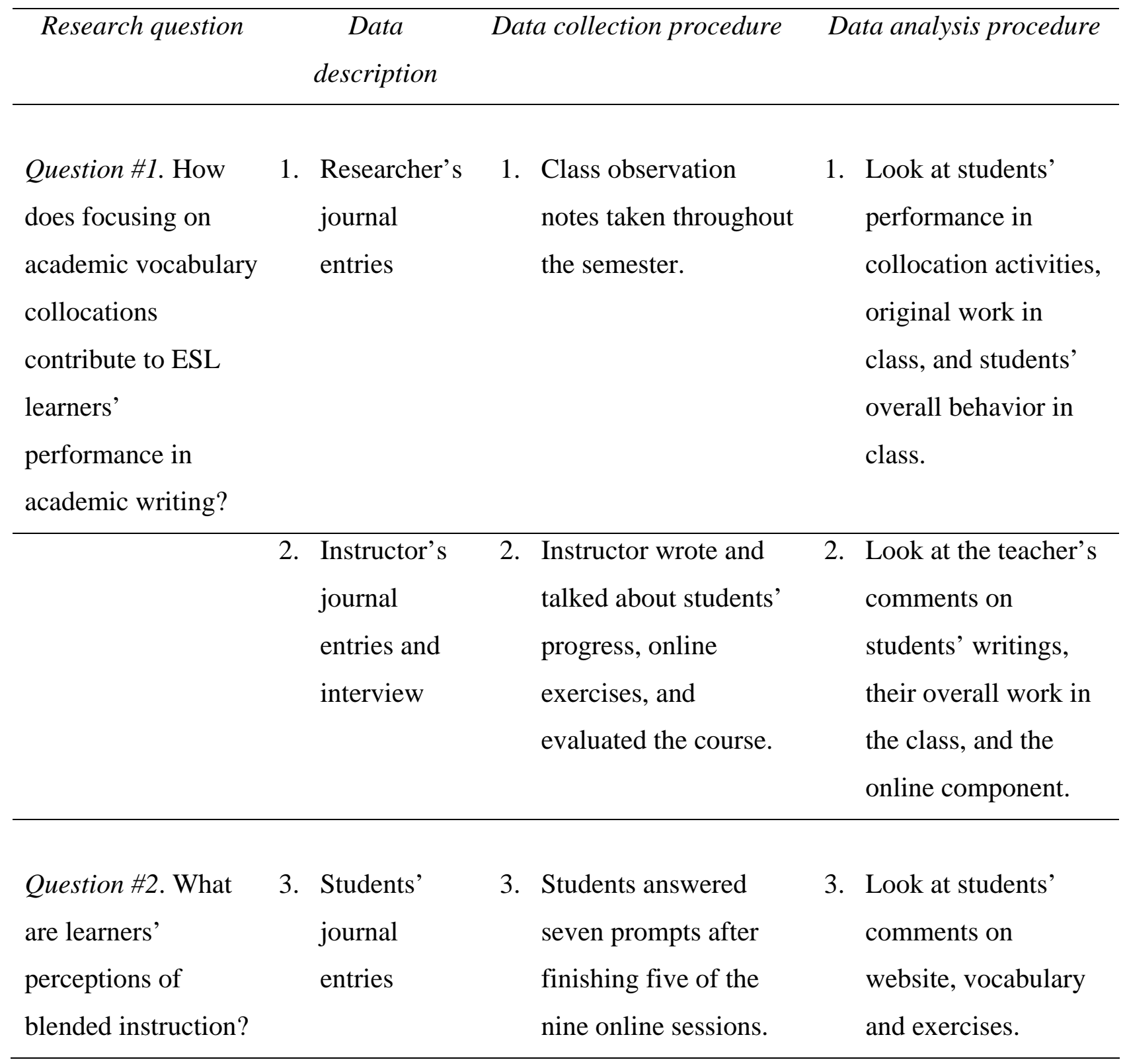




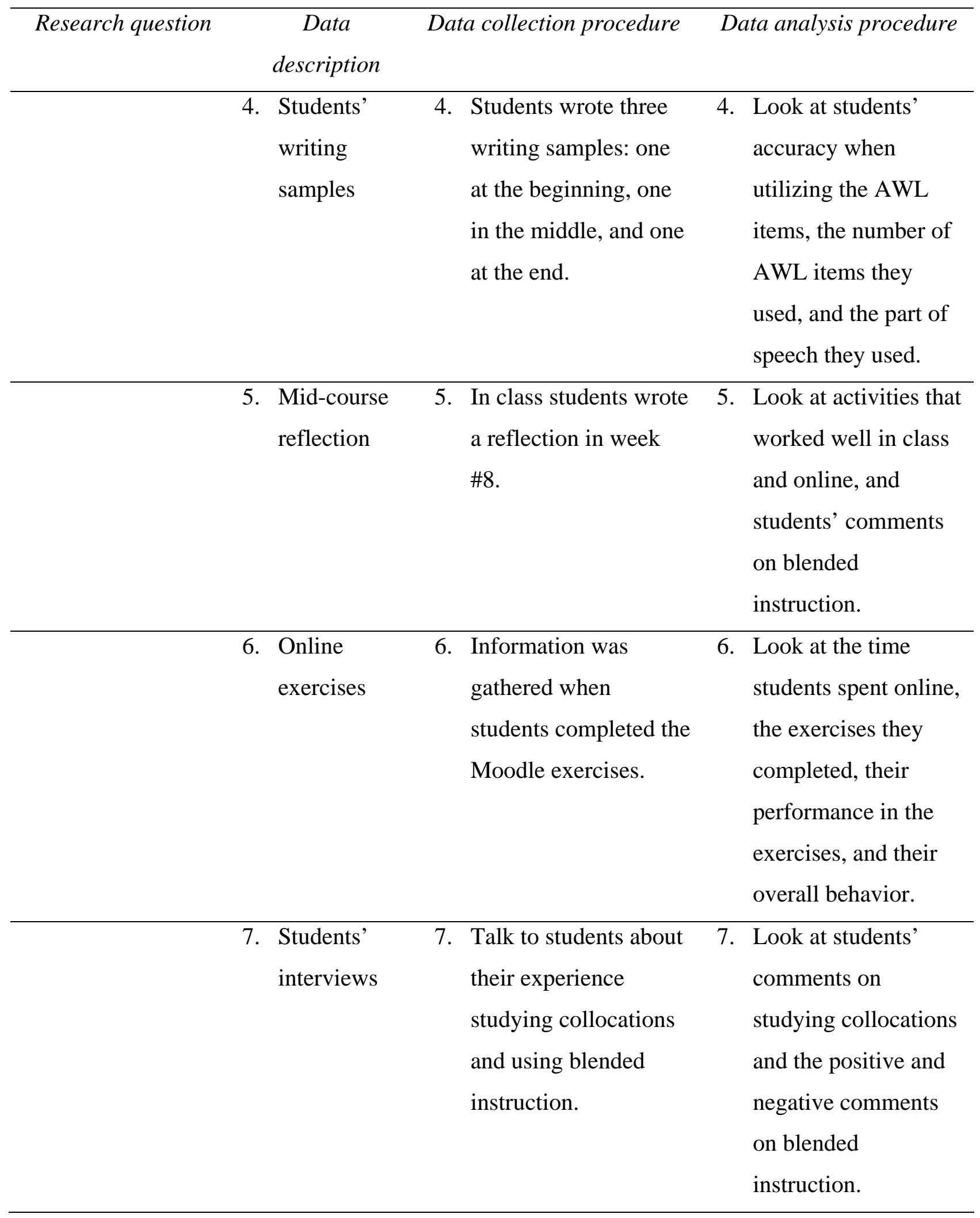




\section{Case Analysis Procedures}

The cases were first presented separately. For each student I composed a case in which I presented the student's background and then his/her attitude and performance in the classroom. Subsequently, I looked at his/her performance in the writing samples to answer question \#1. Finally, I analyzed the student's individual comments on the in-class and online component as well as the Moodle logs for that student to answer question \#2.

\section{Cross-Case Analysis Procedures}

When cross analyzing the cases, I focused on converging observations and comments from the students. I talked about the common points found in the students’ writing samples, including between two, three, or four students. For instance, while looking at the students' writing samples, I focused on vocabulary which had posed difficulty for the students, similar strategies that the students had used, and similar mistakes that they had made. The use of particular combinations by different students was also noted. In short, I drew attention to the commonalities found in the students' samples.

Moreover, I looked for matching comments that students made regarding the blended instruction experience, both the positive and negative points. In this section, I also included specific observations which were not shared by all students, yet I considered worth mentioning.

\section{Triangulation}

To enhance the internal validity of the study, I used triangulation when analyzing the results. The term triangulation, according to Patton (2002), came from the field of land surveying. Patton explained that having multiple markers would facilitate locating something or someone. He added that this term was used "metaphorically to call to mind the 
world’s strongest geometric shape - the triangle” (p. 555). Bringing the concept of triangulation to qualitative research meant that having multiple sources of data to analyze a single phenomenon would help the researcher to identify the results more accurately. Thus, triangulation, i.e., looking at varied data sources, helped increase the validity of a study as well as reduced its bias and permitted researchers to cross-check their data. Furthermore, Merriam (1988) stated that the researcher might utilize triangulation to ensure internal validity, or “how one’s findings match reality”. She added that in qualitative research “reality [was] holistic, multidimensional, and ever-changing...” (pp. 166 - 7).

Triangulating information from various sources did not mean obtaining the same results in all the sources. Inconsistencies in the results provided the "opportunity for deeper insight into the relationship between inquiry approach and the phenomenon under study” (Patton, 2002, p. 556). Triangulating data meant comparing the various data sources, i.e., comparing the points of view in different sources.

In this study, triangulation came from multiple sources of data such as observations (researcher), which according to Merriam (1998) “offer[ed] a first hand account of the situation under study” (p. 111). I also utilized journals (teacher and students) and interviews (teacher and students) as well as information in the online logs (Moodle logs). Merriam (1998) observed that combining observations, interviews, and “document analysis allow[ed] for a holistic interpretation of the phenomenon being investigated” (p. 111).

In analyzing the data to Question \#1, I compared students’ comments on collocation and their writing during the interview with their writing samples. I also looked at the teacher’s remarks about students' collocation use in their writing. In answering Question \#2, I compared my observation notes, the teacher's remarks - both in the journals and the 
interview - about the online component, and the students' comments in the interview as well as their behavior online (obtained in the Moodle logs). 


\section{Chapter 4}

\section{Results}

\section{Pilot Study}

Prior to conducting the study, I carried out a pilot study towards the end of fall 2005. Ten students participated in the pilot study: three from the Middle East, six from Asia, and one from South America. Regarding their age groups, 70\% were between 18 - 24 years old, $20 \%$ were over 37 , and $10 \%$ were between 31 - 36 years old. With this group I tested and received feedback on the background questionnaire (see Appendix E) which enabled me to reword a few of the questions. While the students were answering the background questionnaire, questions \#2 (Do you know other languages? If yes, which ones?) and \#5 (How do you like using computers and the Internet? What do you usually use them for? Which software programs are you familiar with?) caused difficulties. However, the adjustments in the questions did not prove to be as beneficial as I had hoped. Despite my changes, some students from the study still appeared to misunderstand some of the other questions.

During the pilot, I introduced the students to a few online resources (dictionaries and the Online Concordancer) which they could use while doing the online exercises. To complete the online exercises, the students needed to sign up with Moodle. A confirmation email enabled the students to enroll in the online "class," yet this email was not delivered quickly to all students. Some students were able to sign up and enroll in the class on the same day, whereas others did not receive the message at all.

The pilot study showed me that I had underestimated the time necessary for the enabling skills. In the pilot study I tried to introduce the online tools in one class, but it 
ended up being too much information for one day. The students who were not familiar with technology got frustrated when signing up as well as completing the exercises, so I decided to break the instructions into three smaller sections for the actual study. In the first session I introduced the students to the online resources (dictionaries and the Online Concordancer), and they created an account in Moodle. In the second session students practiced doing the Moodle exercises. In the third session students learned how to send email attachments. Time constraints required me to rush the third session a bit.

During the pilot study the students did not have the time to complete the exercises because the pilot was conducted towards the end of the semester, and the students were taking final exams and completing final assignments. Nevertheless, the pilot helped me to improve the questionnaire and better plan the technology instruction sessions.

\section{Class Observations}

During spring 2006, I collected data. I did not begin the data collection simultaneously with the beginning of classes. First, I discussed the details of the study with the class teacher. At that point, the teacher informed me that there were six students in the class, but there was a possibility of a few more joining the group towards the end of January and beginning of February. Aiming at having all students receive instructions at the same time, I began on January 24.

In the first meeting, there were five students in class. However, after looking at the background questionnaire completed that day, I learned that one student was a minor and could not participate in the study. Two other students joined the study in the following weeks. In the group, there were altogether eight students, six of whom agreed and could 
participate in the study. Of the two who did not participate one was a minor and the other declined to take part for personal reasons.

The academic vocabulary class observations began on January 26. Considering that the group was small, the teacher always asked the students to organize the desks in a circle so they could see each other and interact more easily. The students habitually organized the circle themselves before the teacher arrived. The classroom was of medium size with large windows on one side. There were two blackboards: one in the front of the room and another to the side, facing the windows. In the corner between the window and the blackboard, there was a small bookshelf with an assortment of books. Throughout the observation sessions, I did not notice students perusing the books on the bookshelf.

During the observations, I sat in the back of the room, so as not to interfere with the class. It appeared to have worked well because most of the students said they did not mind my being in the classroom. Moreover, the teacher mentioned she completely forgot that I was in the room and, at times, she even forgot to give me class handouts. In contrast, two of the students, who had been my students in the previous semester, seemed to have been somewhat affected by my presence. During their interviews both commented on being selfconscious of my presence and wanting to show me that their English had improved. According to them, this happened only on a few occasions.

Both the textbook and the online exercises were geared to more advanced students, yet the students were not as advanced as the teacher expected. In fact, the group differed from what the teacher expected in both language level and number of students. She pointed out that of "the students that were there, the levels were somewhat diverse and actually seemed to have been lower in the beginning than I'd expected.” In her first journal she 
commented that "The first chapter was quite a struggle and it quickly became evident that we were going to need more time on each chapter than I'd anticipated.” Thus, she made adjustments to the course to suit students' needs. Considering that the majority of the students were preparing to enter the university, one alteration the teacher made early on was to eliminate the idiom textbook and focus exclusively on the academic vocabulary one.

The teacher also commented that the activities she proposed in class were taking longer than she expected. As a result, they “didn't have time to do as much in the textbook as [she] would have liked to have done," she said. Another adjustment made was regarding writing assignments. She did not have students do as much in-class writing. The teacher said, "I would normally do more in-class writing than I did. But the class in general was slower. Everything took longer.”

Two activities which might have slowed the class down were learning to create a vocabulary notebook and getting the students ready for my study. The teacher pointed out that "things that took up a lot of time in the beginning were getting them ready for the vocabulary cards [notebooks], that seemed to be an ongoing effort for a while ... [and] getting them tuned to do Moodle exercises. So we did lose a bit of time there. And we lost a bit of momentum there.” After some instruction, the students understood how to create the notebook and how to handle Moodle, and as the teacher said, “things picked up pretty well and things went much better.”

The vocabulary notebook mentioned above consisted of 8 - 10 word entries that students wrote every two weeks. In this notebook the students wrote down detailed information about these words. The teacher insisted that the students included the following items about the words: (1) meaning, (2) sentence (from a dictionary), (3) pronunciation, (4) 
related word forms, (5) associations, (6) collocations, (7) original sentence (student's personal “creation”) (see Figure 2 for a notebook sample entry). During the first observation, the students completed a vocabulary notebook entry as a class using the word environment. The teacher called the students' attention to the examples of collocation with environment. She also showed the students how to locate collocation examples in a regular dictionary. In the notebooks, the students would have about three opportunities to work with collocations: the dictionary sentence, collocations, and the original sentence.

From the teacher's first journal I learned that the study was taking more time than she had expected, so I decided to make a few adjustments. I asked the teacher to read fewer of my journal entries from the observations than I had originally planned. I also avoided making announcements to the students in class, but rather I informed them about the Moodle exercises via email. Once students enrolled in the Moodle “class,” I automatically had their email addresses and could communicate with them via Moodle's message board, which directed messages to students’ email addresses. Occasionally, I would ask students to explain something they had written in a journal entry after class. In general, I tried to be as non-intrusive as possible.

The classes were fast paced and quite interactive, the activities were varied, and the students did not have any downtime. In every class students revised the words studied, read a variety of texts, and worked on speaking. Listening consisted mostly of listening to the teacher and to each other. The teacher informed me that the students worked on a listening activity with a substitute teacher, but I was not present for that lesson. Some students were quieter whereas others were quite vocal, yet they all seemed engaged in the class activities. 
In class the students focused on several aspects of the academic vocabulary such as word parts, words in context, synonyms, parts of speech, and collocation with other words (nouns, verbs, adjectives, and adverbs). Students also developed dictionary and reading comprehension skills. During the classes, the teacher gave considerable emphasis on collocations and selected the collocation activities herself; she utilized activities found in the textbook and brought a few others to class.

In general, the teacher provided a wide range of collocation examples while presenting and reviewing vocabulary, and while talking. Moreover, she called students' attention to collocations. In her first journal, the teacher pointed out that "in terms of how my own teaching has been affected by the study, I would say the positive factor is that I'm a lot more aware of using collocations myself and probably point them out more,” which ultimately seemed to have been necessary for students to understand the concept and make an effort to use them.

During the course of the semester, the students wrote three writing samples for the study in class. The first sample was written on January $26^{\text {th }}$, the second sample was written on March $9^{\text {th }}$, and the final writing sample came from students' final exams and was written on April $27^{\text {th }}$ (see Appendix I for writing assignment instructions). To provide more information to the study, the teacher gave me the students' collocation sections from their final exams (see Appendix L) in addition to their writing samples. She believed that it would help to demonstrate the students’ progress in using collocations. Agreeing that this information would be relevant, I decided to include their results here as well. 


\section{Case Analysis}

In this section, I present the criteria I used to analyze the students’ writing samples. When analyzing their writing samples, I utilized the Web Vocabprofiler (Cobb, n.d.). From the profiler I identified the total number of words in the samples and the number of academic words used. In the majority of the samples, I based the academic word count on the number of families rather than the number of tokens (individual words) because the students were studying the words as families; i.e., the teacher often asked students to identify the noun, verb, adjective, and adverb forms of particular words (e.g., environment, environmental, environmentalist, environmentalists, environmentally, environments) whenever applicable. Therefore, even if a word family was repeated, it would only count as one AWL.

In order to use the Web Vocabprofiler, I needed to transcribe the students’ writing to the profiler (Cobb n.d.). When transcribing I corrected the students' spelling so that the software could process the words. The Web Vocabprofiler broke down each writing sample into various word frequency levels. It separated the words into the first 1000 most frequent words, second 1000 most frequent words, AWL items, and words not included in any frequency list (low frequency words) using a color-coded system (see Figure 3 for Naomi’s first sample Web Vocabprofiler results). For this study I focused on the total number of words in each writing sample and the AWL items that each student used.

Subsequently, I confirmed that the academic words identified by the profiler had actually been taught in class. In the case of a mismatch between the Web Vocabprofiler and the textbook, I consulted the Academic Word List itself to confirm whether the word was included in the AWL or not. Only the academic words taught in class were considered when analyzing the students’ samples. 


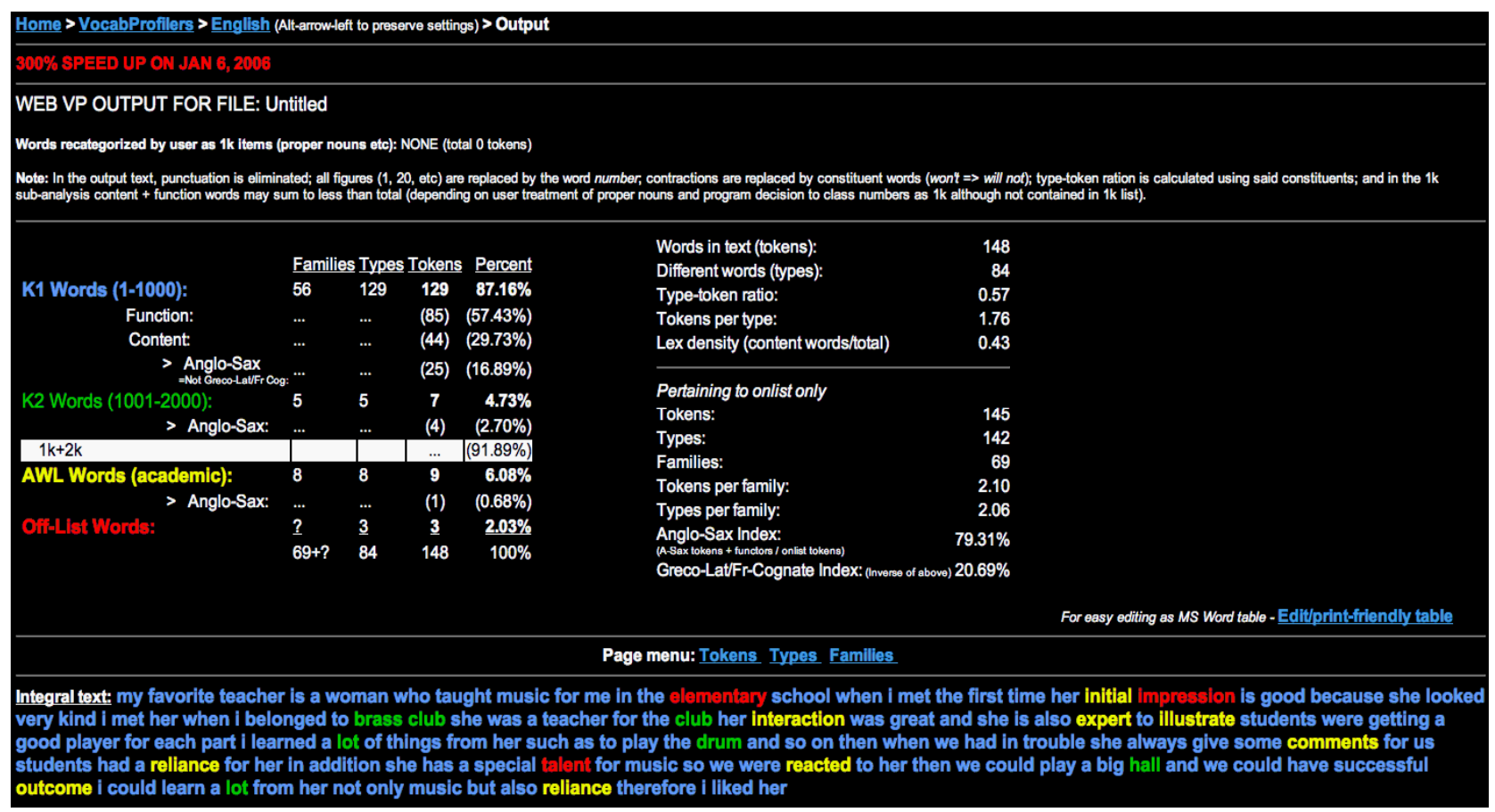

Figure 3. Web Vocabprofiler results from Naomi’s first writing sample.

To verify the acceptability of the collocations, I consulted online versions of the Cambridge and the Longman dictionaries, the Oxford Collocations (2002), and the Online Concordancer (Cobb, 2000). In the cases when I could not find information in these sources, I checked with native speakers. When assessing the students' use of collocations, I focused on their word choice around the target words (AWL items). When analyzing the students' use of academic vocabulary collocation in their writing samples, I considered the chunks they created using the academic words studied in class. Since I was evaluating their use of various parts of speech such as nouns, verbs, adjectives, and adverbs, I took into consideration whether the students used the appropriate part of speech when creating the chunk. In addition, the students were studying parts of speech, or word forms as it was referred to in their textbook, in class. Hence, if the students utilized the wrong part of speech when creating the chunk, the collocation use was considered incorrect. 
Given that when teaching words in chunks, the words would appear in an appropriate order, I also verified if the words used were in the correct order. When students did not organize the words in the appropriate order, the collocation was considered incorrect.

In class the teacher called the students' attention to both grammatical/syntactic and lexical/semantic collocations. In other words, she highlighted the use of prepositions after words as well as the noun + verb, verb + noun, adjective + noun, and noun + noun combinations. Because of that, when examining the students' use of the academic words, I considered the type of prepositions the students used after words, such as reacted to from Abbas or interaction with from Tariq. I also looked at the verb + noun, noun + noun, and adjective + noun combinations as in promote sales, judo techniques, challenging task, successful outcome, and ethnic diversities used by Atsushi and Naomi.

I looked at the students’ general use of collocations; I was not particular about the combined words being before or after the AWL items, but rather if their collocation of the academic word was in some way acceptable. At times, the students used the words in collocations that were possible but perhaps not appropriate for the context in which they were working. In these cases, I explained what was correct about the collocation and accepted it, and why the chunk was not suitable for the context.

When dealing with linking verbs and their nominal and adjective predicates as in “funds [were] insufficient,” I analyzed whether the noun or adjective after the linking verb could be collocated with the noun it qualified. When the combination was possible (as in “insufficient funds”), the collocation was considered correct. Moreover, I did not classify the type of collocation mistakes the students made because the purpose of my study was to verify the students' use of collocations in writing as opposed to classifying their mistakes. I did not 
evaluate the students' use of grammar (verb agreement and article use, for instance) even though I addressed grammar issues when they were connected to collocations of AWL items. Considering the language level of some of the students, I deemed it to be more productive to proceed this way when evaluating their work. To facilitate the identification of the AWL items in the analysis here, I italicized these words in the examples I provided.

The topic for sample \#1 came from a writing assignment in the textbook (see Appendix I). This task was carried out at the end of a class, and the students went beyond the class period.

When writing the first two samples, the students were allowed to use their textbook and dictionaries. The last sample was written as part of the final exam, so the students were allowed to consult their vocabulary notebooks and the exam itself.

For the online component, I examined the Moodle logs for the individual students. I verified the frequency with which they used the software, which exercises they chose to do, how long they stayed online each time, where they were when doing the exercises (in or outside class), and what their pattern of behavior online was. Since the exercises were used as a means for the students to get input, I disregarded the grades per se. The students also asked me to allow them to do the exercises more than three times as I had originally planned, which I did.

Below I introduce each individual case. To maintain anonymity, pseudonyms were used to refer to the students. These pseudonyms were chosen based on each student's cultural background. I talk about their background, their attitude and performance in class, their performance in the writing samples (RQ1), and their comments regarding their work in class and online (RQ2). 


\section{Student Cases}

Case \#1 - Abbas. Abbas, a middle-aged Saudi Arabian student, came to the U.S. to pursue a master's degree. At the beginning of the study, he had studied English for about two years, ten months of which was in the U.S.

Abbas participated in the pilot study as well. For a reason that the student did not discuss with me, he decided to take this academic vocabulary level class for two consecutive semesters. During the pilot study, the students did not complete the online exercises due to time constraints. Thus, Abbas was not much further ahead than the rest of the case study class.

Abbas demonstrated great interest in class. He was present at all of the classes I observed: $75 \%$ on time and 25\% late. This students always volunteered answers and worked actively during group or pair work activities. It did not matter if the activity was presented at the beginning, middle or end of the class. Even when he arrived late, the student quickly familiarized himself with what the class was doing and was ready to participate.

In class, Abbas performed relatively well when asked to complete collocation exercises. When asked to identify collocations for the word distribution in class, he gave the words film, board, economic, and business. His original sentences were simple yet accurate (“Children in the first decade get a great amount of knowledge” \& "In spring break I visited some locations in town.”).

His attitude in class, his written work, and the final exam results seemed to indicate that he understood the concept of collocations. His use of collocations in the samples, however, was variable: he performed better in the first and the last samples than in the 
second sample (See Table 4 for an analysis of his writing samples). (See Appendix O for the complete versions of Abbas' samples).

Table 4

Detailed Analysis of Abbas' Writing Samples

Sample \#1 • Wrote an 87-word passage

- Used 11 AWL items (6 nouns, 3 verbs, and 2 adjectives)

- Collocated somewhat correctly $90 \%$ of the AWL items used (10 out of 11)

- Made a mistake when using 1 verb (10\%)

Sample \#2 • Wrote a 65-word passage

- Used 10 AWL items (6 nouns, 1 verb, and 3 adjectives)

- Collocated fairly correctly $70 \%$ of the AWL items used (7 out of 10 )

- Made mistakes when using 2 nouns and 1 adjective (30\%)

Sample \#3 • Wrote a 103-word passage

- Used 10 AWL items (5 nouns, 3 verbs, and 2 adjectives)

- Collocated correctly $80 \%$ of the AWL items used (8 out of 10)

- Made mistake when using two verbs (20\%)

Below I present a detailed analysis of Abbas' writing samples and his results in the final exam collocation section. Abbas' first sample contained 87 words, and he utilized eleven AWL items (six nouns, three verbs, and two adjectives) when six to eight were required. It seems that the student made an effort to employ the new vocabulary and did so appropriately in most cases. For instance, he pointed out that "cooperative learning is good 
because it has many benefits for [him]" because he could "establish a new relationship with others.” Other accurate examples included "working as a team" and "get more data.” In "our analysis will be clear" and "in specific area," and "depends on the major," the student performance was acceptable. In terms of content, the readability was somewhat difficult. It appeared that the student was trying to include as many AWL items as possible, and he did so accurately at times. Nevertheless, the reader would have to do some interpreting to understand the overall meaning.

In "if we have research it," it was unclear whether the student was trying to use the verb or the noun. Although he had learned the word research as a noun, the structure seems to indicate that the student might have been trying to use a verb form as in "if we have to research it...," or perhaps "have researched it.” Thus, the word was counted as a verb. In either case, a correction would be necessary for grammatical accuracy. There were other language issues in his writing; however, I concentrated on collocations since that was the focus here. Overall, Abbas collocated 10 of the AWL items (90\%) well out of the 11 target words he used.

In writing sample \#2, the students talked about a favorite elementary or high school teacher (see Appendix I for instructions). This topic or perhaps the particular type of vocabulary appeared to have posed more difficulty for Abbas. His text was shorter (65 words), and he utilized fewer AWL items than the first sample (10 words: six nouns, one verb, and three adjectives). Once again he tried to include more words than required (six to eight words). This time seven (70\%) were used somewhat correctly.

He did not seem to have difficulty with some of the words. For instance, in " 45 students of one sex (male)" and "the funds [were] insufficient," Abbas combined the words 
accurately. Even though in the latter example the words were not used in a typical chunk, the possibility of creating the collocation "insufficient funds" existed. Hence, the collocation was considered appropriate. In addition, this was a collocation example presented in the textbook. In "he wanted to have outcome for students," and "the teacher has reacted to the demographic theories challenging,” Abbas had appropriate collocations as in the verb + noun have outcomes, verb + preposition react to, and theories challenging. Looking at the whole sentence, however, it could be seen that corrections would be necessary to clarify the meaning. The use of outcome would have been improved by the addition of the word positive: "[the teacher] wanted the students to have positive outcomes." Despite the need for revision, the specific collocations highlighted here were considered acceptable.

In “constant for other challengers,” Abbas used the words rather awkwardly and comprehension was hindered. A more uncommon noun, however, posed difficulty: "the core of student." Even though the combination "the core of" is possible, the word following the chunk indicated that the student might not have understood what the word meant. Usage in both cases was considered incorrect. It could be noticed that he worked hard to include new words, but he did not seem to fully understand how to use some of them.

The final sample came from a writing task in the final exam (see Appendix I for instructions). Abbas composed a 103-word passage. The students were required to utilize 10 words from the AWL, and Abbas followed this instruction. He included 10 academic words (five were nouns, three verbs, and two adjectives).

The nouns were used appropriately. In "the employee got a promotion," "don't have enough justification," “as a minority in,” and "get this kind of difficult job” his collocations were satisfactory. However, in the case of "enter my country with drugs or other bad goals," 
the collocation "bad goals" was a weak but acceptable example. His use of the verb and the adjective in "resolve a lot of illegal situations" was also adequate. The specific collocation “internal crimes” was possible. However, this collocation tended to be used in the context of crimes in a company rather than in a country as the student used. In spite of that, I decided to count this example as a correct item because my focus was on the students' use of collocation specifically.

His collocation of verbs were incorrect and needed revision in "thousands of them exclude of their countries” and “...government to innovate a good ways.” Overall, 80\% of word collocation use was correct, while $20 \%$ was incorrect. Despite his mistakes, Abbas seemed to have performed better when using nouns.

In more controlled exercises where the words to be combined were provided, Abbas did a better job. Provided with words to fill-in-the-blanks, he managed to collocate adjectives and verbs appropriately as well as understand collocations well enough to provide examples (see final exam collocation page in Appendix K). Out of 25 items, Abbas successfully completed 23 (92\% correct).

Abbas’ performance was variable, yet some improvement could be observed in his final sample as well as his exam results. He demonstrated a preference for using nouns and tended to employ them better than other parts of speech. Despite the improvement collocating some of the words, the student showed difficulty creating a cohesive and coherent text. Table 5 below presents an overall evaluation of Abbas' collocation performance in the writing samples and in the final exam. 
Table 5

Summary of Abbas’ Performance in Writing

\begin{tabular}{lll}
\hline Samples & $\bullet$ & Wrote a longer passage from first to last sample \\
& $\bullet$ & Varied in the number of AWL items \\
& $\bullet \quad$ Consistently used more AWL nouns than any other part of speech \\
& $\bullet \quad$ Made mistakes with nouns, verbs, and adjectives \\
\hline Collocations in & \\
the Final exam & $\bullet \quad 92 \%$ were correct (23 items out of 25)
\end{tabular}

The student displayed online a similar commitment to what he showed in class. He used Moodle regularly. He was also quite inquisitive and sought help when he had difficulty with the online exercises. Yet he did not complete the journal entries as frequently or thoroughly.

In his preliminary questionnaire, I learned that Abbas’ experience with computer technology and the Internet consisted of using a word processor, search/research tools, email, and news. Also, the student indicated liking to use computers and the Internet.

Indeed Abbas was quite active in both websites available for the vocabulary class. The Moodle logs showed that the student would spend over an hour working on the exercises at times. Furthermore, the logs indicated that he tried to complete certain exercises numerous times. The teacher also mentioned that he did the exercises from the textbook companion website until he obtained a perfect score. This pattern seemed to be followed in both the textbook companion website and Moodle. 
Observing his attitude in class and online, it seemed that Abbas would not be opposed to blended instruction. During the interview, however, he expressed a preference for the inclass component. He also underlined the positive and negative aspects of the online component (see Table 6 for a summary of his comments).

Table 6

Abbas' Perception of Blended Instruction

In class $\quad$ Liked to get feedback from the teacher

- Enjoyed working in class with classmates and the teacher

- Valued the vocabulary notebook

- Enjoyed the varied and interactive activities

Online $\quad$ Online exercises provided extra practice/ a review tool

Positive points - Helpful to memorize the words

- The websites complemented each other

Online

Negative points

- Encountered problematic exercises (Hot Potatoes rational cloze and

- Experienced technical problems

- Considered the time limit stressful

- Disliked the mismatch between the textbook and Moodle website vocabulary

Abbas seemed to prefer the in-class component because in this environment he could obtain immediate feedback from the instructor. Moreover, the vocabulary classes had varied 
and interactive activities, so the students worked with each other to complete activities. Cooperative work seemed to be a plus in his opinion.

On the other hand, the student considered the online component useful because it provided more practice. He accessed and used Moodle 12 times in the course of the semester. Abbas commented during the interview that the "website, it was, you know, useful. It's good and useful for me to have to improve my vocabularies.” As mentioned before, the student spent some time online doing and re-doing the exercises. Abbas seemed to have taken a comment the teacher made in class to heart. He said, "when I want to memorize the vocabulary, I should write it, as the teacher told us, 17 times till you memorize it very well.” So he believed that this repetition helped him memorize the words.

The Moodle logs, however, led me to question the student's efficacy when using the online resources. When analyzing the logs, I noticed that the student was spending two to three minutes in activities for which were allotted 10 to 15 minutes. Since I provided immediate feedback to the students, the information in the logs made me wonder whether the student might have been copying the correct answers instead of actually doing the activities, especially because he obtained perfect scores in very little time. For instance, he completed an exercise which involved reading an article and typing answers to four questions in three minutes.

By allowing multiple attempts, I might have created an opportunity for students to copy the answers. However, the exercises had been created to help instruction rather than to evaluate/grade the students, so feedback was necessary. This particular student might have been trying to impress the teacher. During the interview the teacher pointed out that "I know that they [Abbas and Tariq] wanted to impress me because the recommendations they get 
from me to their ... programs are very important.” There might have been some extrinsic motivation for the student to dedicate so much time and to want to get high scores on the online exercises.

Abbas spent a considerable amount of time completing the Moodle exercises. In spite of that, there were a few aspects of the exercises that he did not like. According to him, the drawbacks in Moodle included technical problems, problematic exercises, dissimilar words between Moodle and the textbook per chapter, and the time limit.

Technical problems frustrated this particular student at times. He mentioned having experienced technical problems with both websites. He pointed out that "I tried many times and it take a time for me ... I found out there's a problem with the website. I trust the website that everything is going good.” In this case, it seemed that he was referring to the textbook companion website. The teacher also pointed out in the interview that there were technical problems with that website, which had not been fixed. Nevertheless, the technical problems did not discourage Abbas from using the websites for long periods as mentioned above.

One problem Abbas had with Moodle was accessing the journal entry file. To eliminate the problem, I emailed him a copy of the journal entry file. He submitted two of the five entries, yet he provided very concise answers to the questions and not a great deal of comments on the exercises. Thus, the technical problem may not have been the main issue in this case.

This student had particular difficulty understanding two of the exercises in Moodle: a short answer exercise (see Appendix M for a sample) and the Hot Potatoes rational cloze (see Appendix $\mathrm{N}$ for a sample). The former exercise consisted of a reading or listening passage 
followed by collocation questions. When answering the questions, the students had to be extremely precise. Any typo or minor mistake would lead to an incorrect answer. The teacher also commented on this exercise as not being clear, which led me to provide examples on how the answer would be written out. However, contradicting Abbas’ complaint about the short answer exercise, the Moodle logs indicated that he obtained high scores within the time allotted when doing these exercises.

The Hot Potatoes rational cloze exercises (see Appendix N for a Hot Potatoes rational cloze sample) contained clues (the first two letters of the correct word) to help the students along. Abbas did not understand the purpose of the "clue" even though I met with him individually and explained how that exercise worked. During the interview, he once again asked me to explain what the "clue" was. The particular exercise was a complex one and required certain knowledge of the language. This student did not complete any of the rational cloze exercises.

Finally, the student mentioned during the interview that "the limited time it's confuse me a little bit.” However, when analyzing the Moodle logs and the time he spent to complete an exercise, the time limit did not seem to have posed a problem. Rarely did the student seem to need all the time allotted for the exercises. Thus, there was some inconsistency in his comment about this particular point.

To sum up, Abbas appreciated the online component as part of the class; however, he believed that the online component should be an in-class activity. In his view, the teacher should be in the computer laboratory with the students first. He commented, "CALL lab is good to practice with teacher sometime when the student is not close [to] the teacher when I have problem, I will stop.” According to him, the students should do all the online exercises 
with an instructor first, and then they would redo the exercises on their own as many times as they wanted. Lastly, the student wanted the words in the online exercises to match exactly the ones in the textbook chapter by chapter. In other words, he would like Moodle to be more like the textbook companion website.

Case \#2 - Tariq. Tariq, a Saudi Arabian student in his mid-to-late twenties, came to the U.S. to pursue a master's degree. At the time of the study, the student's exposure to English had been quite limited; he had studied English for about eight months. From a comment he made in class, I concluded that he had not studied English before coming to the U.S. He was one of two students in the class who had been my student the previous semester.

In class, Tariq was an active and attentive student, always volunteering answers and participating in group/pair discussion. Of the 20 observations, he was in class on time 18 times (90\%), late once (5\%), and absent from one class (5\%). According to the teacher, Tariq was one of the weaker students in the beginning, and he had difficulty understanding how to do the vocabulary notebook. She mentioned that he "...had no idea how to arrange them.” He sought help and "once [he] did get it, [he] outperformed some of the other students. [He] worked really hard on them. I was very impressed,” the teacher said. He also needed further explanation of the concept of collocation. During observation \#2, I noticed that the teacher explained to him what collocation was as well as provided examples. At that point, she was explaining to the students how to include collocation in their notebooks. Eventually, he understood the concept since during the interview he mentioned, "collocations how this word is used.” Even though he grasped the concept, he still had difficulty adding 
collocation examples to his notebook entries. The teacher commented that Tariq tried to include collocations, but they were not always good.

Creating isolated sentences in class did not seem as problematic for Tariq. On the other hand, composing longer pieces of writing was more of a challenge. In class, I observed that Tariq performed well when he had to provide definitions and synonyms. He worked well with collocations in more guided activities or when dealing with words which he would probably encounter more often because he was living in an American environment. For instance, when asked to find a collocation for consult, he replied "a doctor," whereas for academic he said "research,” and for financial he added "support.” When asked examples of collocation for the word utility, he mentioned "electric," "water," and "apartment."

Some of the sentences he composed in class were "her techniques are a good way for children to learn,” "The funds for my trip to Washington were sufficient,” and "I was very sad when I removed from my host family to my apartment.” In the eagerness to use the new words, the student sometimes created awkward sentences, such as the last example here. But mistakes did not prevent him from trying and volunteering in class.

Writing was a challenge for him, and Tariq knew it (see Appendix P for the complete versions of Tariq's writing samples). He was not $100 \%$ satisfied with his writing. He realized that it had improved in relation to when he first arrived. However, he demonstrated being aware that he still had problems when he commented, "But it’s improve[d] my writing ... But not as I want. I still need more time to improve.” The student mentioned having problems with organization and grammar. He expected to be further along because he planned to enter the university soon. Table 7 shows Tariq's performance in the writing samples. 
Table 7

Detailed Analysis of Tariq's Writing Samples

\begin{tabular}{|c|c|}
\hline Sample \#1 & $\begin{array}{l}\text { - Wrote a } 75 \text {-word passage } \\
\text { - Used } 11 \text { AWL items (8 nouns and } 3 \text { verbs) } \\
\text { - Collocated somewhat correctly about } 36 \% \text { of the AWL items used } \\
\text { (4 out of } 11 \text { ) } \\
\text { - Made mistakes when using } 5 \text { nouns and } 2 \text { verbs (about } 63 \% \text { ) }\end{array}$ \\
\hline Sample \#2 & $\begin{array}{l}\text { - Wrote an 82-word passage } \\
\text { - Used } 8 \text { AWL items new nouns } \\
\text { - } \quad \text { Collocated correctly about } 50 \% \text { of the AWL items used (4 out of 8) } \\
\text { - } \quad \text { Made mistakes when using } 4 \text { nouns (50\%) }\end{array}$ \\
\hline Sample \#3 & $\begin{array}{l}\text { - Wrote a } 107 \text {-word passage } \\
\text { - Used } 12 \text { AWL items (8 nouns and } 4 \text { verbs) } \\
\text { - Collocated somewhat correctly about } 66 \% \text { of the AWL items used } \\
\text { (8 out of } 12 \text { ) } \\
\text { - Made mistake when using } 2 \text { nouns and } 2 \text { verbs (about } 33 \% \text { ) }\end{array}$ \\
\hline
\end{tabular}

Looking at his writing, one could see that he needed more time to improve it. For his first sample, Tariq composed a 75-word passage on cooperative learning (see Appendix I for instructions), and he did make an effort to use the new vocabulary. He used eleven AWL items, eight nouns and three verbs. He appeared to understand the meaning of the words to some extent; however, his collocation use was poor. He alternated between proper and improper use of words, having more of the latter. Some of his successful attempts included 
“worked with other[s] on a project” (which came from the instruction), “...gave me a lot of benefits” and “...identify some variables.” Subsequently, he misused the word benefit in "this benefit told me."

In "how could I analysis some information and the method for them,” Tariq found potential "partners" for the word analysis; however, he made the mistake of using the noun, which he had studied in the textbook, instead of the verb. Because of the awkwardness of the sentence, I consider his use of the words incorrect.

When reading the passage, it appeared that the student was trying to include as many new words as possible, but some of the sentences ended up not making much sense (see Appendix P for the complete version of the sample). For instance, the following sentences contained several AWL items, yet none of them were adequately collocated: "this concept gave me process to involve many formula," and also "[This] information help[s] me to establish all of them by a good way.” Overall, he failed to collocate seven words (approximately 63\%) out of the eleven he attempted to use.

There was some improvement in Tariq's second sample. It could be that he chose to use more accessible words or he was more comfortable with the theme. The topic was to write about a favorite teacher (see Appendix I for instructions). He composed an 82-word passage which contained eight AWL items (all nouns). He tried to include the required number of new words this time. Out of the eight words he used, four (50\%) combinations were correct.

In this sample, the student did not venture to use too many complex words. He appeared to have chosen words he was probably more used to seeing and thus performed better. Some of the proper combinations were "got a good grade," “... [the teacher] did his 
task," and "he was [an] immigrant from Palestine.” In this sample Tariq misused the target words in "his major was Arabic language," "he was emphasis, but ...," "when he left the school leave big location," and "He had there decade." The errors seemed to indicate that he did not fully comprehend how to collocate those words.

In his final sample, Tariq composed a longer piece (107-word passage) as well as employed more AWL items (12 new words: 8 nouns and 4 verbs). Similar to his previous samples, Tariq tried hard to include academic words in his writing, yet he struggled to use some of the words. He employed somewhat successfully the words that he might hear/see/use more frequently, such as the AWL items in the sentences "get a good grade," "give [me a] promotion," and "I will register [for] some classes next semester." Even though the student did not include the preposition in the last example, I considered his collocation use correct because he utilized an appropriate noun complement for the verb register.

In "I had a lots of outcome for it," "interaction with student here and there," "Some of them correspondence with other[s]," and "I should implement my study," Tariq created acceptable collocations in "have outcome," "interaction with,” and "correspondence with.” However, when looking at the whole sentences, one realizes that the student would need to clarify them. In "implement my study," the student had a correct collocation, but if one considers what the student probably meant to say, his sentence would need revision.

The student had difficulty dealing with the AWL items in “... I will undergo this life to do my undertake with my job," which contain examples of inappropriate collocations. In the collocation section of the final exam, the student performed better. He successfully completed $74 \%$ of the items. Tariq was the student with the least exposure to English in class, which affected his performance in collocation use and writing. Despite his limited 
exposure to the language, he managed to perform better in structured exercises such as the exercises in the final exam. Even though he collocated some of the words correctly, looking at his texts as a whole it was clear that the student was not fully ready to actively use some of the AWL items studied. Table 8 shows a summary of the student's progress in his writing. Table 8

Overall Results of Tariq's Performance in Writing

\begin{tabular}{|c|c|}
\hline Samples & $\begin{array}{l}\text { - Progressively wrote longer passages } \\
\text { - Varied in the number of AWL items yet the last sample contained } \\
\text { the largest number of AWL } \\
\text { - Consistently had more AWL nouns than any other part of speech } \\
\text { nouns mistakes with nouns and verbs, yet most mistakes were using }\end{array}$ \\
\hline $\begin{array}{l}\text { Collocations in } \\
\text { the Final exam }\end{array}$ & - $74 \%$ were correct (18.5 items out of 25 ) \\
\hline
\end{tabular}

Although he showed some difficulty in collocating words appropriately, his comments during the interview led me to think that Tariq grasped the concept. When asked about collocations, Tariq explained, “collocation [is] word with other word, because this make[s] sense....” However, he did not yet possess sufficient language knowledge to easily transfer the understanding of the concept to his writing.

Not only did Tariq have limited exposure to English, he also had limited knowledge of using computers to study. Prior to the class, Tariq used computers for word processing and for accessing the Internet to do research and email. At the end of the semester, I learned 
that the class provided Tariq with the opportunity to develop his vocabulary knowledge as well as his computer skills. He commented during the interview that “... I improve my computer knowledge because I didn’t have before. I just used it a little bit. I just used for message or something. But also, this semester I be very, very useful with your website... Because now sometimes if I make something I remember when I cannot use this [the website], then [it] gives me some experience [to] use other [websites].” Table 9 presents the student's overall comments on blended instruction.

Table 9

Tariq’s Perception of Blended Instruction

In class

Online

Positive points

Online

Negative points
- $\quad$ Preferred the in-class environment

- Valued the vocabulary notebook

- Enjoyed getting teacher's immediate feedback

- Helped improve his computer skills

- Helped review the material studied in class at times

- Disliked the inability to talk to the teacher when he needed to

- Disliked the mismatch between the textbook and Moodle website vocabulary

- Had difficulty with certain exercises (Hot potatoes rational cloze)

- Disliked the fact that not all exercises were available at once

Similar to Abbas, Tariq utilized the online components often. In Moodle he did not follow the weeks as they had been planned, yet he completed several of the exercises and 
worked on Moodle about nine times during the semester. At times he spent over one hour online. The Moodle logs also showed that Tariq completed the exercises multiple times and attempted the exercises again even after he had obtained a perfect score. He seemed to avoid the rational cloze exercises; he viewed them but did not attempt them.

His Moodle logs also showed some inconsistencies between time spent on exercises and scores obtained. In reading and listening activities, the log showed that the student spent approximately 3 - 5 minutes to complete an exercise, when the listening/reading alone would probably take that amount of time to be done. Despite the inconsistencies and the student's limited proficiency, Tariq completed two of the journal entries and provided insightful comments which helped me to improve the Moodle exercises. He was quite candid in his comments, which helped me to fully understand how he felt about some of the exercises and led me to re-evaluate one exercise in particular. He specifically mentioned not liking a matching exercise which contained similar choices. After analyzing the exercise, I realized his comment made sense, and the exercise was substituted with a collocation synonym exercise.

He was one of the students who mentioned looking up words in the dictionary while working on the Moodle exercises. Even though he did not take any notes, the fact that he was actively looking up words appeared to indicate interest on the part of the student.

Tariq also preferred the in-class environment because "in the classroom it give me the chance to discuss with you [the teacher] if I have something wrong or if I [am] confuse[d] with something.” The student identified both benefits and drawbacks in the online component. One of the benefits was that he could review the material. He indicated particularly liking the exercises in week \#6 "because most of the vocabulary I used [learned] 
in class.” A personal benefit was improving his computer skills, as mentioned earlier. The student also enumerated a few drawbacks for the particular online tool I used. The drawbacks he mentioned were technical problems at times, not having the teacher to ask questions, Moodle not being closely related to the textbook, having difficulty with certain exercises, and not all exercises being available from the beginning of the semester.

The technical problem he mentioned happened only once and did not seem to have had a major impact because he mentioned it only during the interview. The fact that the teacher was not available for questions was an issue probably because this student had limited English proficiency and still seemed to depend more on the instructor. "Sometimes if I use the website [at home], if I make mistake or something, not mistake, if I can’t understand [a] question or exercise, I cannot discuss [it] with you.”

Another negative aspect of the Moodle exercises was that the words did not correspond to the exact ones being taught in a given chapter. Tariq would have preferred that the weekly exercises in Moodle followed the vocabulary in the textbook chapter by chapter, probably similar to what he saw on the textbook companion website.

Also, similar to the previous student, he had difficulty with the Hot Potatoes rational cloze exercises and, as a consequence, avoided doing them. Lastly, one item he mentioned, though he did not pursue it much further, was that the exercises were presented weekly as opposed to being available from the beginning of the semester, as the textbook exercises were.

Considering the amount of time the student dedicated to the Moodle online exercises, it appeared that he would not be opposed to doing online exercises provided that a few changes be made. Though his preferred medium seemed to be the classroom, his comments 
indicated that the online exercises would be worthwhile for him to review the material studied in class.

Case \#3 - Atsushi. Atsushi, a businessman from Japan in his mid-to-late 20s, came to the U.S. to improve his communicative ability in English. Atsushi pointed out in the interview that “...my purpose here taking IEP class [was] improve my English conversation ability,” and he had no intention of pursuing a degree at an American university. He had studied English for 13 years.

When I first invited the class to take part in the study, I noticed that Atsushi hesitated before saying “yes,” yet he ultimately did. I was left with the impression that he agreed to participate in part due to peer pressure. The teacher had encouraged the class to participate, and all his classmates had agreed to, so he may have felt like he had to say "yes” as well. His subsequent behavior corroborated this first impression. He never asked me to withdraw from the study nor declined to provide any work which was done in class. However, any outside class, research-related activity he was somewhat reluctant to do. One example of that was when I scheduled the interviews. Before agreeing to talk to me, he wanted to know what the purpose of the interview was. To "put him at ease” I explained briefly what we would talk about during the interview.

When the group went to receive instructions on using Moodle, about a week after signing up for the online component, Atsushi had forgotten his account information and had to create a new account. After that first day, he seldom completed the Moodle exercises. On the occasions he did, it was in class and at the teacher's request. He also did not submit any journal entries. 
At mid-semester, in an indirect conversation via the mid-term reflection, he admitted not having done any of the Moodle exercises and indicated he would do them. He said, “frankly speaking, I was not active for Moodle ever. However, I will do Moodle from now on.” Ultimately, he did not fulfill his promise. During the interview, he explained his reasons for not having done the exercises.

In class, Atsushi was a quiet but focused student. He was on time for 18 of the 20 observations (90\%) and late twice (10\%). He was not one to volunteer answers much, and at times he needed some encouragement from the teacher to participate.

Collocation was a new concept for him. During the interview he commented, "I have never learned collocation in the class in Japan, so it's very fresh [new] for me. I, we sometimes misuse vocabulary, so learning collocation makes me learn and use word[s] in the good way."

His writing samples showed he was more fluent than the other students in class (See Appendix Q for the complete versions of Atsushi’s writing samples). Table 10 presents a detailed analysis of his writing.

Table 10

Detailed Analysis of Atsushi's Writing Samples

Sample \#1 • Wrote a 76-word passage

- Used 12 AWL items (6 nouns, 2 verbs, 3 adjectives, and 1 adverb)

- Collocated correctly 75\% of the AWL items used (9 out of 12)

- Made mistakes when using 2 adjectives and 1 verb (25\% ) 


\begin{tabular}{lll}
\hline Sample \#2 & $\bullet$ & Wrote a 134-word passage \\
& - & Used 13 AWL items (8 nouns, 3 verbs, and 2 adjectives) \\
& - Collocated correctly about 92\% of the AWL items used (12 out of 13) \\
& - Made a mistake when using 1 noun (7\%) \\
\hline Sample \#3 & $\bullet$ & Wrote a 107-word passage \\
& - Used 17 AWL items (8 nouns, 7 verbs, and 2 adjectives) \\
& - Collocated correctly $100 \%$ of the AWL items used \\
& - No serious mistakes were found \\
\hline
\end{tabular}

In his first writing sample (see Appendix I for instructions), Atsushi composed a 76word passage and used 12 AWL items (six nouns, two verbs, three adjectives, and one adverb), some of which were from chapters other than the one the class had studied. Out of the words used, eight (75\%) were utilized appropriately.

He accurately collocated the nouns such as "the benefit of cooperative...," "negative aspects," "approaches for a project," and "variables that the other members established." He worked well with one of the verbs (see previous example). Occur posed difficulty to all students who tried to use it, and Atsushi was no exception. In "the situation not to occur bad problems," he made an error with occur. He identified a potential collocation yet used the words in an incorrect order. In the case of the adjectives, Atsushi appeared to have generalized a rule. Having been exposed to the combination "cooperative learning" in the textbook, he seemed to have applied the "rule" and created "cooperative working" and "individual working" in the place of the proper forms: "cooperative work" and "individual work," respectively. 
The student used information from the assignment instructions to create collocations. Such examples were seen in "working cooperatively," "benefit of cooperative...," and “negative aspects” found in Atsushi’s passage. In this particular sample, I counted cooperative (adjective) and cooperatively (adverb) separately. Although these words belong to the same word family, the student used different "rules" to work with them, succeeding in one case and not the other. I wanted to draw attention to the strategies the student seemed to have used to deal with these two words.

In sample two (for instructions see Appendix I), Atsushi created a longer piece (134 words) and introduced interesting examples of collocations. The student used 13 AWL items (eight nouns, two verbs, and three adjectives) in his text, of which 12 were accurately employed. Furthermore, he seemed to have cleverly utilized the textbook as a resource for collocations. The combinations “achieve successful outcomes” and “perform challenging

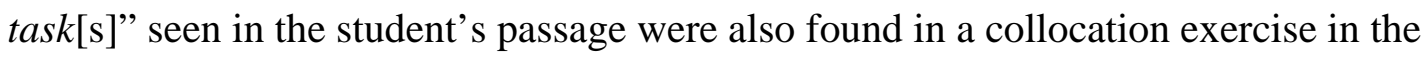
textbook (Huntley, 2006, p. 60). The majority of the nouns were employed well (see outcomes and task in examples above). He also talked about "judo techniques" and "each member of our team.” He collocated the verbs appropriately as in "[the] situation altered" and "he commented that it was important to achieve successful outcome[s]." An error appeared in the following sentence: "the circumstance of our judo club team was not good" where the word circumstance was somewhat poorly collocated. The students usually used the word circumstance in the singular when it tended to be used in the plural. The teacher pointed that out in class, but the students appeared to need more exposure to this word before being able to use it productively. 
Atsushi consistently increased the number of AWL items in his writing samples. In sample \#3 (see Appendix I for instructions), the student included 17 AWL items (eight nouns, seven verbs, and two adjectives). He used some of the examples from the exam in his writing, as suggested in the instructions, and did so accurately. Phrases such as "promote sales," “coordinate delivery schedule,” and “achieve a successful outcome” seemed to have been taken/adapted from the exam itself.

Atsushi consistently went beyond the AWL items required by the assignment. Furthermore, he demonstrated ability to employ the new vocabulary even in more subtle aspects of collocation such as the preposition in "imposed on me” (sample \#3).

There were no obvious collocation errors in his use of the AWL in this writing sample. In fact, this particular writing sample substantiated what the teacher said that "the writing activities that we did. ... [Atsushi] was very good at incorporating vocabulary very succinctly and actually very accurately as well,” and she added, "and certainly his ability to incorporate the vocabulary...correctly, improved tremendously.” His samples indicated that the teaching of collocations had a positive impact on his results. In the final exam, he obtained a perfect score in the collocation section. Table 11 summarizes his performance. Table 11

Overall Results of Atsushi's Performance in Writing

\begin{tabular}{|l|ll|}
\hline Samples & $\bullet$ Passages varied in length \\
$\bullet$ & Consistently included more AWL \\
$\bullet$ & Consistently had more AWL nouns than any other part of speech \\
$\bullet$ & Consistently improved collocation use \\
$\bullet$ & Most mistakes came from adjectives \\
\hline
\end{tabular}


Collocations in the

Final exam
- $100 \%$ were correct

Atsushi was not as dedicated to Moodle as he was to the class. His disinterest in doing the online exercises was not related to his lack of ability and computer knowledge, nor his dislike of computer technology. During the interview, the student commented that he frequently used computers for work and preferred computers to paper and pencil. Furthermore, according to the teacher, he always completed the exercises from the textbook website.

His reasons for not using Moodle seemed to have come from the inconsistency between Moodle and the textbook vocabulary in each chapter and, as he himself said, "so if this website [Moodle], doing this website is mandatory, and I mean, do every week.” He also commented that if the exercises had been compulsory, he would have done them. He appeared somewhat embarrassed to say that directly, though. After I verbalized it, he confirmed it. The student accessed Moodle twice, and both times he was in class and the teacher had asked the students to complete these online exercises. The second time he accessed the site he completed about six exercises and spent about 50 minutes online. His results were around $60 \%$ correct.

Since he did not do the online exercises consistently, he could not write the journal entries. His mid-term feedback was brief and vague, with the exception of the last question where he mentioned he planned on completing the Moodle exercises.

Some of the classes were used for students to do online exercises and review the material. However, this student did not seem to like that. He would prefer to do the online 
exercises outside class. He stated that in-class time should be used for conversation. In addition, he indicated that using computers in class would be somewhat ineffective because he believed that "if we study in classroom, the main point in the class should be talking, not writing, talking [to] each other," and he also said, “if we do computer, alone in the class, it’s kind like boring.” Table 12 shows a summary of Atsushi’s view of blended instruction.

\section{Table 12}

Atsushi’s Perception of Blended Instruction

\begin{tabular}{|l|ll|}
\hline In class & $\bullet$ & Preferred to work in class and interact with classmates and the \\
& $\bullet$ & teacher \\
\hline Online & $\bullet$ & Enjoyed the varied and interactive activities \\
Positive points & & homework \\
\hline Online & $\bullet$ & Textbook and Moodle website not directly connected \\
Negative points & $\bullet$ & Exercises not compulsory \\
& $\bullet$ & Doing it alone in class was boring \\
\hline
\end{tabular}

It appeared that this student would not be opposed to some sort of blended instruction provided that the in-class and online components were strictly related and that the online exercises were compulsory. Nevertheless, he did show preference for in-class work because “in the class activity... getting together with other student and share opinion share their opinion, it’s better, I think. Because ...we can meet each other in the class.”

Case \# 4 - Naomi. Naomi, a Japanese student in her early to mid twenties, came to the United States to improve her English and also to attend university. She had studied 
English for eight years when the study began. Naomi joined the group on February $7^{\text {th }}$. By the time she was invited to participate in the study, the students had already signed up with Moodle and received instructions on how to use it. Yet she agreed to participate and quickly got caught up with the class. Naomi demonstrated that she was a dedicated student. She was always on time and on task. Moreover, of the 17 observations from the time she arrived, Naomi was in class for fifteen and absent for two (approximately $88 \%$ and $11 \%$, respectively). A quiet yet attentive student, she did not frequently volunteer answers, but she would promptly participate when called upon. Also, when asked to work in pairs or in small groups, she appeared to contribute significantly.

Collocation was a new concept for this student. Her work in class and her writing seemed to indicate that she grasped it. In class, when the teacher asked her for some examples of collocations for the word “administration,” Naomi mentioned [administration] officer, [administration] policies, and regional [administration]. She also created sentences such as "Recently, Mexican immigrants c[a]me to the U. S." and "I went to Florida and there were ethnic groups there.” I also learned from the teacher that Naomi used to do a pretty good job including collocations in her notebook entries.

Naomi completed two of the writing samples. Since she joined the group later, she wrote samples \#2 and \#3 (See Appendix R for the complete versions of Naomi’s samples). Table 13 shows a detailed analysis of Naomi’s performance in the writing samples. 
Table 13

Detailed Analysis of Naomi’s Writing Samples

\begin{tabular}{|c|c|}
\hline Sample \#1 & - $\quad$ N/A \\
\hline Sample \#2 & $\begin{array}{l}\text { - Wrote a 148-word passage } \\
\text { - Used } 7 \text { AWL items (4 nouns, } 2 \text { verbs, and } 1 \text { adjective) } \\
\text { - Collocated correctly } 43 \% \text { of the AWL items used } \\
\text { ( } 2 \text { nouns and } 1 \text { adjective) } \\
\text { - Made mistakes when using } 2 \text { nouns and } 2 \text { verbs (approximately 57\%) }\end{array}$ \\
\hline Sample \#3 & $\begin{array}{l}\text { - Wrote a 190-word passage } \\
\text { - Used } 13 \text { AWL items (7 nouns, } 4 \text { verbs, } 1 \text { adjective, and } 1 \text { adverb) } \\
\text { - } \quad \text { Correctly utilized } 85 \% \text { of the AWL items used (11 out of } 13 \text { ) } \\
\text { - } \quad \text { Made mistakes when using } 2 \text { nouns (approximately } 15 \%)\end{array}$ \\
\hline
\end{tabular}

Her first sample (see Appendix I for sample \#2 instructions) consisted of a 148-word passage where she included seven AWL items (four nouns, two verbs, and one adjective) and appropriately collocated three of them. Considering the adjective + noun collocation in “initial impression,” it could be said that the specific collocation worked well. However, when considering the whole sentence, "When I met the first time, her initial impression is good because she looked very kind,” one would see that the sentence needed some revision so it would have the intended meaning.

The nouns outcome in "have successful outcome[s]" and comment in "she always give[s] some comments" were both collocated appropriately. The word reliance, on the other hand, posed difficulty. She used this word in "students had a reliance for her [the teacher]" 
and "I could learn a lot from her not only music, but also reliance." In these two instances Naomi misused the word. The word reliance is not typically collocated with learn and have, but rather with place and increase to name a few verbs. In the first case, she might have used the noun in the place of the verb (rely), whereas in the second she might have needed another word. One of the Moodle exercises indicated that Naomi's understanding of the word improved when she identified the collocation "reliance on" in a reading passage.

In "Her interaction was great, and she is also expert to illustrate...," Naomi collocated the words incorrectly. The word interaction is typically used in a context which implies a group of people. Also, one would say “an expert at illustrating.” Naomi’s sentences would need to be modified in order for the collocation to be considered correct. Finally, her use of the word react in "we were reacted by her" indicated that she had not quite grasped how to employ the word. In her last writing sample (see instructions for sample \#3 in Appendix I), Naomi appeared to have made an extra effort to use the new vocabulary and she also elaborated more on her answer. This time she wrote a 190-word passage including 13 AWL items (seven nouns, four verbs, one adjective, and one adverb) out of which approximately $85 \%$ were employed correctly. This seemed to indicate that she was becoming more comfortable with the language.

Five of the nouns were accurately used as in "I have a part-time job as a tutor," "teach as a professional," "they had [their] own objectives," "for instance,” and "went into partnership with coworkers.” The last example was collocationally correct even though the student appeared to have made a word choice error. Although she used the word partnership, the context indicated she meant team-teaching. 
The two remaining nouns were somewhat misused. She wrote "there were some diversity students" and "the circumstance was nice." In the first sentence the error was not so much a matter of wrong collocation but rather the wrong part of speech; she probably intended to say "diverse students." The second example was not so much a collocation error, but rather poor use of the word. This particular word, as the teacher mentioned in class, tended to be utilized in the plural form.

The four verbs, the adjective, and the adverb were properly employed. She said, "I could communicate with them," "the teacher emphasized the importance of studying hard," "Students were required to resolve questions by [themselves]," "I had sufficient reason to continue this job," and "initially they had to try themselves."

Both her samples contained different types of errors, yet the overall assessment showed that there was progress in her writing. From the first sample to the last, she practically doubled the number of AWL items and also obtained a higher percentage of correct items. In addition, her text sounded more fluent.

During the interview I asked her how she felt about her writing, and Naomi replied, "I hate it.” Her reasons for feeling this way were "I'm not good at grammar, so I don't know a lot of vocabularies, so I need to use the dictionary and, and I don't know how to write structure, organization. It's difficult.” In spite of that, Naomi herself noticed that the vocabulary class had affected her writing. She commented, "I can get more useful vocabularies, so I use it in the writing.” Her last sample showed she had progressively incorporated more new words in her writing. In the collocation section of the exam, Naomi answered $96 \%$ of the items correctly. Table 14 summarizes Naomi’s writing. 
Table 14

Overall Results of Naomi's Performance in Writing

\begin{tabular}{ll}
\hline Samples & Consistently wrote longer passages \\
$\bullet$ & Consistently included more AWL items \\
$\bullet$ & Consistently included more AWL nouns than any other part of speech \\
$\bullet$ & Improved collocation use \\
$\bullet$ & Made errors with nouns and verbs, yet most mistakes came from nouns
\end{tabular}

Collocations in

the Final exam • $\quad 96 \%$ were correct (24 items out of 25)

The class as a whole seemed to have made a good impression on her. In the midterm reflection, she commented that "It is very good for me to study in this class, because I have never taken a class like this class. I just memorized vocabularies before I took this class. But now I enjoy the class.” It appeared that the student realized that there was more to learning vocabulary than memorizing vocabulary lists.

Regarding blended instruction, Naomi liked the convenience of computers and the Internet. Table 15 summarizes Naomi’s comments on blended instruction. Like the other students, she used this technology for word processing, researching, and email. She also appeared comfortable with the technology. Even though she started late and missed the Moodle instructions, she was one of the more active students in Moodle and rarely asked for assistance. She signed up with Moodle on her own and also completed the exercises without much instruction. 
Table 15

Naomi's Perception of Blended Instruction

\begin{tabular}{lll}
\hline In class & $\bullet$ & Preferred to work in class with her classmates and the teacher \\
& $\bullet$ & Enjoyed the varied and interactive activities \\
\hline Online & $\bullet$ & Helpful for extra practice and review \\
Positive points & $\bullet$ Possibility to learn more words and collocation outside class \\
& $\bullet$ Flexibility as for where to study \\
\hline Online & Mismatch between textbook and Moodle words \\
Negative points & Level of difficulty of the exercises; contained too many new \\
& words
\end{tabular}

This student was one of the more regular Moodle users. She seemed to have taken her commitment to the study seriously. The logs showed that she did not complete every single exercise but completed them somewhat regularly. In her journal entries, the student indicated a preference for the matching and multiple choice exercises. She did work on some exercises which involved reading, yet she appeared to avoid the rational cloze exercises. The Moodle logs indicated that she viewed the rational cloze exercises, but there was no log of an actual attempt to do them.

Naomi took time outside class to do the exercises, and she would spend on average 30 minutes at a time. She submitted all the journals and they contained more thorough answers than the journals of any other student. From her journal entry \#1, I found out that she 
thought she was not supposed to use a dictionary while doing the exercises. In a subsequent class, I informed her that using a dictionary was permitted.

From her journal entries, I also found out that she thought “[Moodle was] a little difficult for me.” Nevertheless, she “enjoyed learning new collocations,” and she believed that "it's good for me to study collocations." She was the only student to mention occasionally writing down words she did not know and taking notes of their meaning and collocations. In her journal entry \#2, she commented, “I looked up household, worldwide and uneven”. I wrote about this word's meaning and collocations.” These words were being combined with the AWL items being studied. In journal entry \#3, she mentioned looking up and taking notes of the definitions of "systematic, scholarly, and adequate." Only the last word was part of the AWL.

During the interview, Naomi indicated a preference for the in-class component. She said she enjoyed working on the online exercises, but she would still prefer the majority of the work to be done in class. When I asked her what ration she would use for in-class and online work, she answered, "in the classroom is 60 or 70 outside 30 or 40 ."

From her journal entries and the interview, I learned about her view of the Moodle exercises. Naomi mentioned that the online exercises enabled her to review the material. She said, “They can help me to improve my English skill, and I can review the class by doing the exercise. So, it's good for me.” She also pointed out that the online exercises helped her to learn more vocabulary and provided flexibility as for where to study. Naomi said, "I can [learn] more vocabularies outside class and I can do anywhere, I can [study] the vocabularies, um, at home, anywhere.” Still referring to the Moodle exercises, in a few of her journal 
entries she mentioned that "I enjoyed learning new collocations." To the question regarding what she had enjoyed about doing the activities, she replied, "I enjoyed doing exercises.”

On the other hand, the online exercises were difficult and time-consuming, and the words did not follow the textbook chapter by chapter. Naomi believed that "this website [Moodle] was a little bit difficult for me.” Moreover, she pointed out that the vocabulary in Moodle did not correspond exactly to the vocabulary in the textbook chapters, so "there are more vocabularies which I don't know the words. So a little too much time to spend.” Similar to her classmates, Naomi would have preferred Moodle to follow the textbook chapters more closely.

Naomi did not seem to have had problems with the technology itself. In neither the journal entries nor the interview did she mention any technical problems. There were, however, comments about the level of difficulty of the exercises. In her journal she stressed this point, yet she also pointed out that the exercises were helpful.

Analyzing Naomi’s performance in class and her use of Moodle, one could see that this student would most likely appreciate doing online activities provided that a few changes be made to the online component. It seemed that she would like the online exercises to be an outside class tool to review the material studied in class. She commented, "I like to do activities outside class using computer... I enjoy it. [If] I always have to do in the class it's kind of boring." From Naomi's perspective, doing the online exercises in class was not a good alternative.

Case \#5 - Yunjin. Yunjin was a Korean student in her mid twenties. She had studied English for six years in Korea then stopped for five while she was in college. The student had come to the U.S. to improve her English. As she put it, "If I study English, I can get a 
good job in my country and wherever." She planned to take the Test of English for International Communication (TOEIC).

Yunjin considered vocabulary “the most important thing in learning English.” During the interview she referred to the vocabulary class as “My favorite class because I'm interested. I like to remember vocabulary. If I remember vocabulary, I can use a lot, and then I can get the result [quickly]. So I like to remember vocabulary.” However, she realized that "I didn't make effort well this semester in the vocabulary class." Her teacher seemed to agree with that when she said, "I don't think she’s [Yunjin] terribly motivated.” Her attendance showed that as well. She was in class for $12(60 \%)$ observations, late twice (15\%), and absent five times (25\%). The teacher seemed to attribute this student's lack of motivation in part to her not intending to go to the university. The teacher commented, "motivation there was very variable. [Yunjin] was one of the students who was not planning on going to university.”

When in class she seemed to enjoy participating. She engaged in discussions when working in small groups, but sometimes she seemed to prefer to do the assignments on her own. At times the teacher would pair the students up to do an activity, and I noticed that Yunjin would be working on her own.

Yunjin indicated that she liked the vocabulary class. Writing, however, was more of a challenge for the student. She said that "writing is the most difficult in all subject[s]." She also commented that "when I started writing in the beginning of the semester, it was so hard. But it was so hard at the end." Nevertheless, the student seemed to be aware of one possible way for her to improve her writing. She pointed out, "if I read lot book English ... It can be improve my writing ability.” 
Assessment of her writing indicated some progress (See Appendix S for the complete versions of Yunjin's writing samples). Her writing samples (see instructions in Appendix I) started with the minimum AWL items required but developed as the semester progressed. Table 16 summarizes Yunjin’s writing performance.

Table 16

Detailed Analysis of Yunjin’ Writing Samples

\begin{tabular}{|c|c|}
\hline Sample \#1 & $\begin{array}{l}\text { - Wrote an 88-word passage } \\
\text { - Used } 6 \text { AWL items (2 nouns, } 2 \text { verbs, and } 2 \text { adjectives) } \\
\text { - Collocated correctly } 50 \% \text { of the AWL items used (3 out of 6) } \\
\text { - Made mistake when using } 1 \text { noun, } 1 \text { adjective, and } 1 \text { verb (50\%) }\end{array}$ \\
\hline Sample \#2 & $\begin{array}{l}\text { - Wrote an 84-word passage } \\
\text { - Used } 11 \text { AWL items (7 nouns, } 1 \text { verb, } 2 \text { adjectives, and } 1 \text { adverb) } \\
\text { - Collocated correctly } 73 \% \text { of the AWL items used (8 out of } 11 \text { ) } \\
\text { - Made mistakes when using } 2 \text { nouns and } 1 \text { adverb (27\%) }\end{array}$ \\
\hline Sample \#3 & $\begin{array}{l}\text { - Wrote a 102-word passage } \\
\text { - Used } 10 \text { AWL items (5 nouns, } 2 \text { verbs, and } 3 \text { adjectives) } \\
\text { - Collocated correctly } 70 \% \text { of the AWL items used (7 out of 10) } \\
\text { - Made mistakes when using } 2 \text { nouns and } 1 \text { adjective (30\%) }\end{array}$ \\
\hline
\end{tabular}

Her first sample contained 88 words and six AWL items (two nouns, two verbs, and two adjectives). Yunjin's collocations needed improvement. She successfully used one of the nouns: "It has also benefit[s]," whereas the other was poorly used in both attempts: "So sometimes it can be fought when our issue is different to each other," and "We maybe spend 
a lot of time for making one issue.” In fact, the second attempt contained a collocation error. Better collocation for that sentence would be "raise one issue."

In the case of the verbs, she employed one appropriately in "we can establish [a] good relationship.” For the verb occur she found a suitable collocation but did not use it in the correct order: “it occur a lot of problems.” Because she did not place the words in an appropriate order, her use of occur was considered incorrect.

When using one of the adjectives, the student appeared to have generalized a collocation she found in the textbook. In several places in the textbook, the students encountered the combination “cooperative learning.” This might have led the students, including this student, to create cooperative working instead of cooperative work, which would be the more appropriate option. The instruction to the writing task asked the students to "describe the benefits and the negative aspects of working cooperatively [italics added]" (Huntley, 2006, p. 10), which might also have contributed to the transfer mentioned here. Using individual as an adjective, she first wrote “individual opinion,” which she crossed out and substituted with “individual thinking.” Either collocation would be acceptable.

In sample \#2 (see Appendix I for instructions), even though she wrote a shorter passage (84 words) than sample \#1, Yunjin managed to include eleven AWL items (seven nouns, one verb, two adjectives, and one adverb). Seven out of the eleven words were collocated adequately. In this sample, she included more AWL items and collocated them better. Longer chunks were found in her text, such as "carry out challenging task[s]" and "get good grades or get compensation." The former example of collocation could be found in a collocation exercise in the textbook. Four of the nouns were collocated adequately, for example, "various ethnic diversity," "carry out challenging task[s]," and "get good grades or 
get compensation.” In a few of these examples, one could see that she also utilized the two adjectives properly. In the case of "Some teachers were immigrants," the AWL item immigrant was found as part of a collocation with teachers - as one might in a phrase such as “minority immigrant teachers”—so I considered this collocation appropriate.

Similar to her classmates, she had difficulty with words such as core and circumstance. Yunjin misused these words in "he was remained core in my heart" and "my high school's circumstance was special compare with other schools.” She also misused the adverb as can be seen in "I believe he is constantly a good teacher." Her overall result was approximately 73\% of AWL items collocated correctly (8 out of 11).

In the $3^{\text {rd }}$ sample (see instructions in Appendix I), she wrote a longer passage (102 words) and elaborated more on her answer. Moreover, she took advantage of the collocations found in the exam itself and adequately incorporated them in her own writing such as “perform rewarding tasks,” and “achieve a successful outcome.” She also collocated the AWL items appropriately in “emphasized that...” and professional job.” This seemed to indicate that the student grasped the concept of collocation in the end.

Sample \#3 contained 10 AWL items (five nouns, three adjectives, and two verbs). The nouns which came from the exercise in the exam were used appropriately (see examples above). Others posed some difficulty. Reliance, for instance, was utilized in the place of the verb rely in "She also emphasized that don't reliance on my husband who will be in my future." It can be noticed that she even used the correct preposition after the word, yet chose the wrong part of speech. The student seemed to have retained some knowledge about the word family, but she did not yet know all of its members. She also incorrectly collocated the 
word challenge in "so now I am doing challenge to be.” In both cases, this student's use of collocation was considered incorrect.

Her use of adjectives still reflected the overgeneralization found in her first sample. She wrote, "the reason is that physical working is so harder than professional job.” She used this collocation twice in her text, and yet a more appropriate collocation would be "physical work." On the other hand, she did a better job with global in "I want to be a global business woman.”

Finally, the verbs did not pose difficulty for her as can be seen in "My mom always emphasized that I should perform rewarding tasks and try to achieve a successful outcome [in] my life.” Her overall performance in sample \#3 was 70\% of words collocated correctly (7 out of 10). Following the same pattern as her classmates, Yunjin performed quite well in the more structured exercises. She completed $98 \%$ of the exercises correctly in the collocation section of the final exam. Table 17 summarizes her overall writing performance. Table 17

Overall Results of Yunjin's Performance in Writing

Samples
$\bullet$ PWL items varied according to topic
$\bullet$ Used more nouns in the last two samples
$\bullet$ Collocation accuracy varied
Made mistakes using nouns, verbs, and adjectives, yet most
mistakes came from nouns

Collocations in the

Final exam

- $\quad 98 \%$ were correct (24.5 items out of 25) 
Initially, Yunjin did not seem to grasp what collocation was, and she needed further explanation before she understood it. But in the end she seemed to understand the concept and made an effort to include the targeted collocations in her writing, as can be seen in her final sample. During the interview, she confirmed that she had grasped the concept and also understood its importance. When asked about collocation, she commented, "Vocabulary collocations. I didn't think about that, so I just remember one word and I didn't try to put another word that can go together.” She also said, "I didn't think about the vocabulary collocations before but during, according to this semester of vocabulary class, I, I could think about that.” Despite her absences, the work done in the class seemed to have contributed favorably to her results. Ultimately, Yunjin made some progress when using collocations. Even though the teacher pointed out that Yunjin was not always successful with her collocation examples in her vocabulary notebook.

Regarding the Internet, Yunjin was familiar with the standard tools (email, news, and dictionaries) and that was the extent to which she used the Internet. She mentioned liking to use the Internet, but she did not seem to enjoy doing exercises online. During the interview, she commented, "But I don't like this Internet with homework.” Indeed, she admitted that she did not like any type of homework. So it was no surprise that she seldom utilized Moodle.

After I introduced the Moodle exercises, Yunjin tried to do them, but she was confused. She did not understand what she had to do, nor why some of the combinations were not possible. Not understanding the assignments might have been a pattern for this student. Her teacher told me that "[Yun-jin] was interesting. She often didn't get the idea of what she was supposed to do in the exercises and did something completely different.” 
During the Moodle instruction, Yunjin asked me if there was a rule for collocations and when I explained that there was no rule, she appeared disappointed. Even after she grasped the concept of collocation, she still considered the exercises difficult. She mentioned that "because is there a lot of words which I don't know. ... But if I study constantly, it's very good. I think it’s very helpful.” Another reason for not doing the Moodle exercises was “Recently I'm so lazy.”

Soon after the enabling skills class, Yunjin spent approximately $1 \mathrm{~h}$ and 45 minutes on Moodle and completed some of the exercises outside class, yet that happened only once. After that she used Moodle mainly when the teacher took the students to the computer laboratory.

Yunjin was not very active with the journal entries either. She submitted only one entry. In this journal entry she commented that the exercises in Moodle were "so difficult, but it was very helpful to studying English.” Yunjin did mention enjoying one of the exercises entitled “Odd One Out 2,” which was a multiple choice exercise to identify wrong collocations. It may have been the novelty of the task that encouraged her to even look up words in an electronic dictionary. She mentioned looking up "cooperate, negotiate, lucrative, boost, and acute.” She did not talk about taking notes of any aspect of the words but just checking the meaning. Lastly, she said that she "want[ed] more comment below the incorrect answer.” At that point, I was not allowing the students to see the correct answers immediately after doing the exercise. Upon this request, I started designing the exercises so that students would have access to the correct answers. Even though she only completed one journal entry, she did provide some useful feedback. 
When doing the Moodle exercises, Yunjin did not follow the sequence of weeks, but picked the exercises at random. She was one of the students who seemed to want to get a perfect score and often would attempt the exercises multiple times. The first attempt always took the longest. In subsequent attempts, she spent considerably less time on the exercise. March $30^{\text {th }}$ was the last time she attempted any quiz and that was during class time. Her use of Moodle somewhat reflected her behavior in class, i.e., not always focused or consistent.

Yunjin was not particularly fond of blended instruction, yet she made a few positive comments about the online component. One positive aspect she identified was that the online environment was less stressful than the classroom. She said, "if I do all activity, it make me feel more comfortable because I don't need to care about anybody. And during class I have to concentrate more. I have to be nervous.” Another positive point was that the exercises were helpful.

Nevertheless, the negative points surpassed the positive ones. Yunjin mentioned that the exercises contained several new words and that the words did not match the textbook chapter by chapter. She wanted Moodle to have explanations for the words prior to the quizzes. "Textbook website [had] more detail. Because ... they based on textbook, and we have textbook... [the teacher] teach, and then textbook, and then site. So it's more easy, easy to understand.” In other words, she wanted Moodle to be more connected to the textbook. She especially liked the flashcards found in the textbook website. She said, "[the textbook] site there are flashcards to use. So and then we do quiz. And then the quiz is based on the flashcards.” These flashcards provided the definition and the part of the speech of a word, so the students could quickly review the vocabulary before attempting a quiz. Yunjin also wanted Moodle to provide explanations for the collocations. One last comment 
she made about Moodle regarded time spent on it. It did not appeal to her the fact that "if I do this activity, I usually take a long time.”

During the interview, I learned that this student considered herself to be "too old" to have to deal with computers, the Internet, and online exercises. She pointed out "because it's new. These days most of middle [school] students, they start learning from [the] Internet. But they use. Maybe they are familiar. I'm not.” One could see that she believed that the Internet is for people who grew up with computers and were more used to dealing with this type of environment. Furthermore, she stated that she would rather be in a face-to-face environment because she “...like[d] teacher with classmate.” In the case of this particular student, what added yet another downside to the online exercises was that they were part of her homework. She “[doesn’t] like this Internet with homework” and added "I just want to do during class. Spend a lot of time...but I don't like homework.” She would prefer to do all the work in the classroom and not have any homework assignment. Table 18 summarizes her comments regarding the in-class and online environments.

\section{Table 18}

Yunjin's Perception of Blended Instruction

\begin{tabular}{lll}
\hline In class & $\bullet$ Enjoyed the interaction with classmates and the teacher \\
& $\bullet$ Enjoyed the varied and interactive activities \\
& $\bullet$ Considered the classroom environment stressful at times \\
\hline Online & $\bullet$ Online exercises provided extra practice/ a review tool \\
Positive points & $\bullet$ Presented a less stressful environment \\
\hline
\end{tabular}


Online

Negative points

- Mismatch between textbook and Moodle words chapter by chapter

- Level of difficulty of the exercises; contained too many new words and not enough explanations

- $\quad$ Time consuming

- Technology itself stressful

- Too much homework

Case \#6 - Ziyi. Ziyi was a Chinese student in her early to mid 20s who had studied English for three years. She was one of the students who planned to study at an American university.

In class, Ziyi demonstrated that she was a dedicated student. She was always on time for class and had perfect attendance while I was observing the class. In addition, she always volunteered answers, asked questions, and gave her opinion. She was quite vocal in class and usually was the first one to refer to collocation exercises as difficult.

Prior to this class, Ziyi was not familiar with the idea of collocations but found the concept helpful. She also thought that "it was not really difficult, but it depends [on] how much vocabulary you know about that type of vocabulary ... if you know a lot you can ... combine all the words together. But if you don't know a lot of words, you just have to learn.”

She seemed to quickly understand the concept and be able to transfer this knowledge to her vocabulary notebook. According to the teacher, Ziyi created thorough vocabulary notebook entries, and "her journals [i.e., notebook entries] were the best. They were outstanding." The teacher added that "she was the one who did the best job including collocations in the journals. She must have had a good source.” Indeed, she had a very good 
source. From her journal entries and the interview, I learned that she used the Longman Dictionary of Contemporary English Online (see Figure 3 for a sample entry), which provides a section entitled "collocations” at times. Even when it does not provide this specific section, the dictionary highlights how to utilize the words and gives examples.

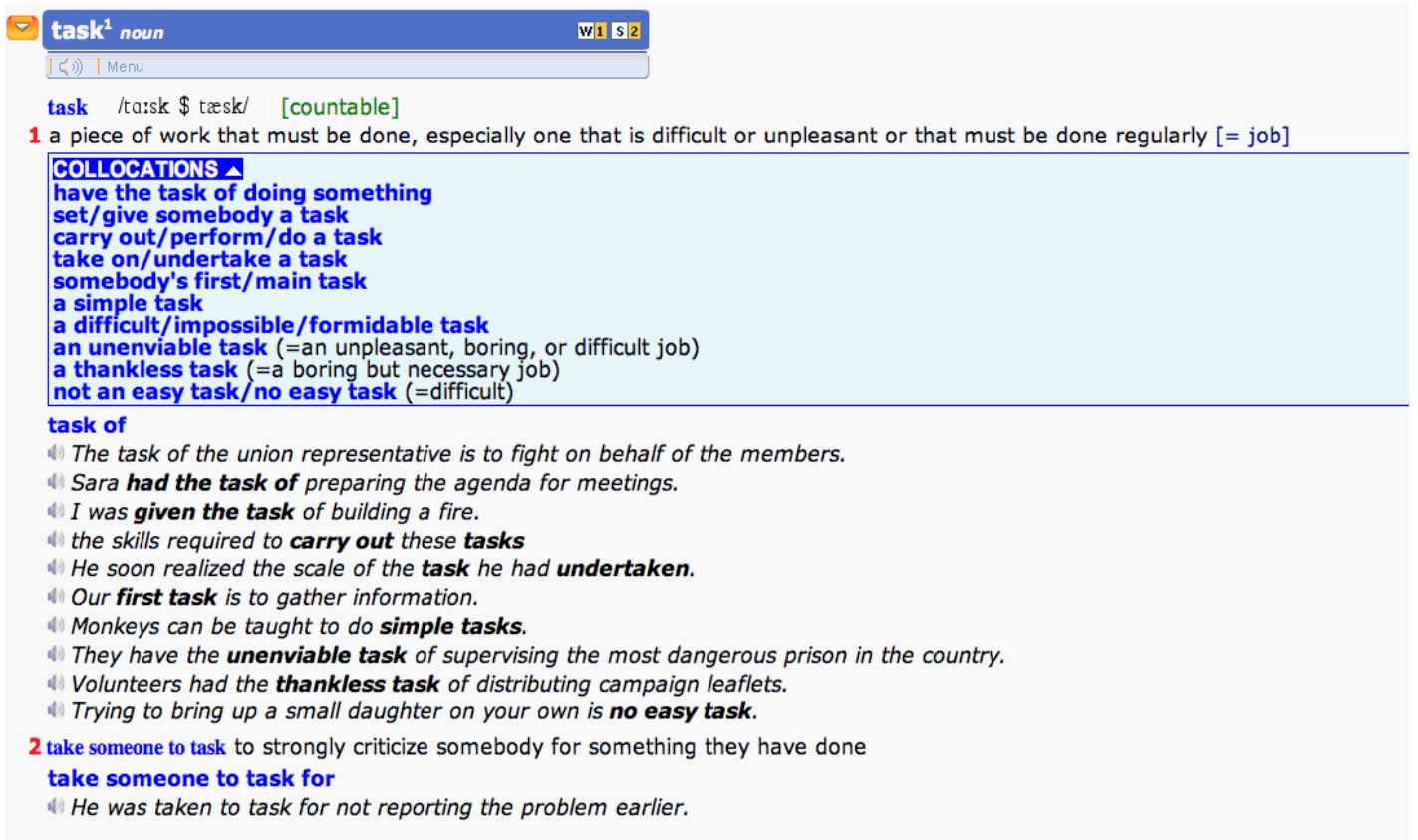

Figure 4. An entry in Longman Dictionary of Contemporary English Online

At the beginning of the semester, Ziyi considered that in her writing "[her] grammar is wrong all time, and the vocabulary is very simple, simple and no academic word. And just everything is a mess.” Yet she said that towards the end “at least I can figure out my grammar things. And then I can I ... use some word and I can think about another word [synonym] from the book. And I can check it out...I can use academic word instead of another word," indicating that she believed that the vocabulary class had helped her in her writing skills.

Her sample did show that she was making an effort to utilize the vocabulary studied (see Appendix T for a complete versions of Ziyi’s writing samples). Table 19 presents an 
analysis of her writing samples. As her first sample (see assignment instructions in Appendix I), Ziyi wrote a 75-word passage and included nine AWL items (six nouns, two verbs, and one adjective). Of the words used, she employed the adjective well: “cooperative learning is $\mathrm{a}[\mathrm{n}]$ approach for study." The combination “cooperative learning” was found in the textbook several times, so she had had multiple exposures to the collocation. She did not seem to have difficulty using some of the nouns: "put off finishing the project" and "to work hard in the team."

Table 19

Detailed Analysis of Ziyi’s Writing Samples
Sample \#1
- Wrote a 75-word passage
- Used 9 AWL items (6 nouns, 2, verbs, and 1 adjective)
- Collocated correctly about 77\% of the AWL items used (7 out of 9)
- Made mistakes when using 1 noun and 1 verb (about 22\%)

Sample \#2

- Wrote an 89-word passage

- Used 12 AWL items (10 nouns and 2 adjectives)

- Collocated correctly 50\% of the AWL items used (6 out of 12)

- Made mistakes when using 6 nouns (50\%)

Sample \#3

- Wrote a 180-word passage

- Used 13 AWL items (8 nouns, 3 verbs, and 2 adjectives)

- Collocated correctly $77 \%$ of the AWL items used (10 out of 13 )

- Made mistakes when using 1 noun and 2 adjectives (about 23\%) 
However, some words posed more difficulty. In a sentence such as "people can’t identified several method[s]," Ziyi seemed to combine the words adequately and yet made a grammar mistake, supporting her comment about her writing at the beginning of the semester. In "but sometimes also occur problems," she had a potential collocation yet in the wrong order, so her collocation was considered incorrect. As can be seen, both verbs caused problems for different reasons.

In addition, Ziyi wrote "people work together always have good concepts." Even though the verb + noun collocation was acceptable, a reader might have difficulty fully understanding what she meant. Comparing Ziyi's example to "Teachers should have a clear concept of what a multiracial society is" (Oxford Collocation Dictionary, 2002, p. 146), it could be said that Ziyi used the collocation somewhat correctly.

In the case of the word approach, it was unclear whether she fully grasped how to use it. In most cases, she appeared to understand the words and use them properly. Overall, she collocated approximately $77 \%$ correctly and $22 \%$ incorrectly (7 out of 9).

In sample \#2 (see instructions in Appendix I), the student wrote an 89-word passage and included $12 \mathrm{AWL}$ items (ten nouns and two adjectives). When combining adjective + noun, she performed quite well: "do not have good compensation," "completed some challenging tasks," "good environment," and "gave us a fair grade." In the case of tasks, the combination she utilized was presented in a collocation exercise in the textbook. The adjectives were also collocated appropriately as in the use of the word challenging above and "ethnic dances."

In other instances, she did not seem to fully understand how to use the words, and as a consequence, she misused them. For instance, she created combinations such as "we 
sometimes completed some challenging tasks of dancing by his constraint," "our core of the class,” and "give us a good environment and circumstance.” Ziyi might have understood the words in context, but these words were not yet part of her active vocabulary. Finally, in the case of interaction and diversities in "in his class we were always in interaction. He seems knew all the diversities between all ethnic dances,” she utilized these words poorly. She did not succeed in using some of the new words, yet she was not afraid of trying. Ziyi was not as successful in sample \#2 as she was in \#1. Overall, she collocated approximately 50\% correctly (6 out of 12). Yet she did venture to use rather complex words.

Ziyi progressively wrote longer passages and included more AWL items. The third sample (see instructions in Appendix I) contained 180 words and 13 AWL items (8 nouns, 3 verbs, and 2 adjectives). She maintained a similar pattern in her last sample. She utilized mostly new nouns and did a good job with those. Some of the nouns she utilized tended to be taught in combinations, such as "in contrast" and "for instance." Ziyi also collocated the nouns accurately in "face many challenges" and "have a good potential to be a teacher."

Certain nouns seemed to be adequately employed when we focused on the word immediately adjacent to the target words as in "different aspects" and "compensation from." However, when considering the whole sentence, it was noticed that the student did not utilize the most suitable words for the context: “...the most dominant thing are compensation from the company and techniques of myself” and "I used different aspects to teach them.” It seemed that she confused the meaning of words such as technique, aspect, and approach, or perhaps she thought she could use them interchangeably. Since my focus was collocations, I considered the collocation use correct in the case of aspects and compensation, but not in the case of technique. 
With the verbs she had no difficulty as can be seen in "different commercial required different type[s] of ...," “demonstrate the movements of a particular part of [a] dance,” and “I tried to illustrate every thing for them.” These are examples of what Nesseuhalf (2003) called "free combinations," i.e., verbs which require a complement which is not restricted to specific words. From this perspective the combinations Ziyi used were accurate.

The adjectives she chose to utilize in this sample posed difficulty for her. She talked about "the most dominant thing are compensation from the company ..." and "they told me about major idea of commercial.” In both cases, she appeared to be thinking of synonymous words to the ones used such as "important and main,” respectively. Her overall results were approximately $77 \%$ words correctly collocated and 23\% were poorly used (10 out of 13).

Similar to her classmates, she obtained a better result when doing more structured exercises. Ninety-six percent of her answers were correct in the collocation section of the final exam. Table 20 presents a summary of Ziyi’s performance in writing.

Table 20

Overall Results of Ziyi’s Performance in Writing
Samples
- $\quad$ Progressively wrote longer passages
- Consistently included more AWL items
- Consistently used more AWL nouns than any other part of speech
- Collocation accuracy varied
- Made mistakes using nouns, verbs, and adjectives, yet most mistakes came from nouns

Collocations in

the Final exam

- $\quad 96 \%$ were correct (24 items out of 25) 
Her writing samples showed that she appeared to progressively become more comfortable with academic vocabulary and in every writing sample she included more AWL items. Also, the student included in her writing samples a few of the combinations studied in class, which might be an indication that she was attending to what was being taught in class.

Computers did not seem to be a challenge to Ziyi. She said that she enjoyed using computers, and she used them basically to do research and e-mail. She mentioned using online dictionaries, and as seen previously, she used a very good online dictionary.

Her activity in Moodle somewhat reflected a comment the teacher made during the interview: "[Ziyi] seemed like one of the students in the beginning who would make a lot of progress, but I think she, um, I think her effort leveled off in the second half of the semester.” In the first part of the semester, she attempted to do a few of the Moodle exercises. At that point, she completed a few of the exercises and also wrote a journal entry. In this entry, she indicated that she worked on the exercises and consulted a dictionary to check the meaning and collocation of a word (procedure). In the second half, however, she worked in Moodle once during class time (March $30^{\text {th }}$ ) for which she also wrote a journal entry. On this day, she spent almost an hour in Moodle. In general, it appeared that Ziyi looked for the matching exercises and skipped the others. She opened two of the Hot Potatoes rational cloze exercises yet did not attempt to do them.

Her journal entries were brief, yet she provided some feedback. From her journal I learned that she considered the time limit stressful, a comment that she reiterated during the interview.

The student did not seem opposed to having blended instruction. Online exercises would be fine provided that a few criteria were met. Considering the exercises as they were, 
Ziyi found the online exercises helpful. She also liked the fact that she could learn new collocations in Moodle. She mentioned, "some of the collocations we haven't seen in the book, we haven’t learn in the book, so we can learn online.” Ziyi enjoyed doing the matching exercises because she wrote "the one activity, match the collocations. It was fun." Nevertheless, she would prefer the online component to be used for review. Some of the drawbacks she saw in the online component included the level of difficulty of the exercises, the time limit, the fact that the exercises were time-consuming, the mismatch between textbook and Moodle words, and having too much information.

The fact that the combinations did not closely match the ones in the textbook chapter made the Moodle exercises time consuming, difficult, and overwhelming in the student's opinion. That might have been aggravated by the time limit. She pointed out that "maybe I prefer to learn it this week from chapter one, and I prefer to review it on Moodle. It's like to make me like remember it. But it's just [that] online activities, it different from the textbook. It's a lot of new things to learn. And I also learn from the book. And all the things come to me and it's just cannot take it.” Finally, she preferred the in-class work because she enjoyed interacting with and learning from her classmates.

To sum up, Ziyi preferred the online component of blended instruction to be a review component for the class. Table 21 summarizes her comments on blended instruction.

Table 21

Ziyi's Perception of Blended Instruction
In class
- $\quad$ Preferred to work in class and interact with classmates
- Enjoyed the varied and interactive activities 


\begin{tabular}{lll}
\hline Online & $\bullet$ & Online exercises helpful/useful as extra practice or a review tool \\
Positive points & $\bullet$ & Contained new collocations \\
\hline Online & $\bullet$ & Mismatch between textbook and Moodle words \\
Negative points & $\bullet \quad$ Level of difficulty of the exercises; contained too many new \\
& words \\
& Time-consuming exercises \\
& Time limit - stressful
\end{tabular}

Cross-case Analysis

In this section, I first present a summary of the students’ backgrounds. Table 22 below includes who the students were, what their L1 was, how long they studied English and their reasons for studying it. Subsequently, I bring together all the cases described in the previous section to answer questions \#1 and \#2. In the first part of the section, I summarize the challenges of teaching collocations (both the concept and collocations themselves) and describe how this knowledge affected students' writing. 
Table 22

Summary of Students’ Backgrounds

\begin{tabular}{|c|c|c|c|c|}
\hline Name & Age & $\begin{array}{c}\text { First } \\
\text { Language }\end{array}$ & $\begin{array}{l}\text { Number of years } \\
\text { learning English }\end{array}$ & $\begin{array}{c}\text { Reason for studying } \\
\text { English }\end{array}$ \\
\hline Abbas & mid 40s & Arabic & about two years & $\begin{array}{l}\text { Studying at a } \\
\text { university }\end{array}$ \\
\hline Tariq & mid-to-late 20s & Arabic & about eight months & $\begin{array}{l}\text { Studying at a } \\
\text { university }\end{array}$ \\
\hline Atsushi & mid-to-late 20s & Japanese & 13 years & For work \\
\hline Naomi & early-to-mid 20s & Japanese & eight years & $\begin{array}{l}\text { Studying at a } \\
\text { university }\end{array}$ \\
\hline Yunjin & mid 20s & Korean & about six years & For work \\
\hline Ziyi & early-to-mid 20s & Chinese & three years & $\begin{array}{l}\text { Studying at a } \\
\text { university }\end{array}$ \\
\hline
\end{tabular}

In Table 23, I report the main findings regarding collocation teaching and collocation in writing. In the second part of this section, I give details about the students' perceptions of the in-class and the online components combined to teach vocabulary collocations. 
Table 23

Summary of Students' Performance in Collocation

Research Question \#1

How does focusing on academic vocabulary collocations contribute to ESL learners' performance in academic writing?

- Difficulty understanding the concept initially

- Grasped the concept of collocation

- Improvement of collocation use as the semester progressed

- Difficulty with certain words remained

- More advanced students integrated longer chunks in their writing

\section{Difficulty Understanding the Concept}

In order to address the question of how focusing on collocations contributed to the students' writing performance, it was important to look at the students' overall process of learning collocations. It was also essential to refer to the students' typical attitude toward vocabulary learning and their attitude toward collocations since these factors might ultimately affect the students’ outcomes.

Prior to teaching the collocations themselves, it was necessary that the students understood what was meant by collocation and why it was important. According to the teacher, the textbook was designed to expose students to collocation, so studying that aspect of vocabulary was already part of the plan. Understanding the concept, however, was the first challenge that the students faced. The teacher commented that she believed most people 
were not aware of what the word collocation meant, and she added that "it's not an easy concept.” Indeed, it was not easy for the students here.

In general, L2 learners study vocabulary using word lists, looking up a new word and memorizing its translation in the students' L1. Naomi’s comment in the mid-term reflection showed that. She said that she "just memorized vocabularies before [she] took this class."

Laufer and Shmueli (1997) pointed out that 75\% of language learners use bilingual dictionaries (p. 93). It was very common to see the students in this group with electronic dictionaries. The majority of these dictionaries contained a bilingual side which the students very often used. However, bilingual dictionaries do not provide the necessary information for students to "upgrade" a word from a passive to an active stage or to actually use that word. Thus, teachers tend to need to break the habit of students to only look up a translation or definition of new words. Teachers need to educate students that there is more to a word than knowing its meaning.

In this class, the teacher was doing so by having the students periodically add words to a vocabulary notebook. These vocabulary notebooks contained several pieces of information about the words, including a sentence (from a dictionary), collocations, and an original sentence (student’s personal “creation”) (see Figure 2 for vocabulary notebook sample entry). In fact, the teacher informed me that "[the students had to] include 3 collocations for each of the words they [chose].”

Learning what collocations meant and how to locate them took some time. Even though I started observing the classes a few weeks into the semester, I noticed that the teacher still used class time to clarify the term to the students. The teacher herself mentioned that they "had to do more classwork than usual to go over collocations so that they could 
enter them correctly in their vocabulary journals [i.e., notebooks]” (teacher’s journal \#1). Furthermore, during the online session with the Moodle exercises, a student (Yunjin) asked me what collocation was and if there was a rule for that. I explained to her that there were no universal rules for collocations, and she seemed disappointed.

\section{Grasping the Concept}

Eventually, the students did understand what collocation was and were able to use it in their vocabulary notebooks and their writing samples. One day in class, I observed that, while studying word parts, a student mentioned the word collocation as an example of a word which contained a variation of the prefix con (= with). This demonstrated that the students were gradually getting used to the word and its meaning. Regarding the students adding collocations to their notebooks, the teacher pointed out that "some of them were better than others, but I would say after we directly talked about that and we had examples on the blackboard, they got better at it. So everybody was including collocations regularly.”

Effectiveness in adding collocations to the vocabulary notebooks depended in part on the dictionary that the student utilized. One student (Ziyi) did an excellent job with collocations in her vocabulary notebook. According to the teacher, "[Ziyi] was the one who did the best job including collocations in the journals [i.e., notebook]. She must have had a good source.” As mentioned previously, I learned from Ziyi that she used the Longman Dictionary of Contemporary English Online, which, at times, provided specific collocation examples for the words (see Figure 3 for a sample entry).

Slowly all students started including collocations in their notebooks. At the end of the semester, the teacher commented that Naomi, Ziyi, and Atsushi tended to do a pretty 
good job with that, whereas Abbas tried with some success. She also said that Tariq and Yunjin were not so good with collocations in their notebooks, but they tried.

The focus on collocation led one of the students to take notes about collocations while doing the Moodle exercises. In one of her journal entries, Naomi said that "I looked up household, worldwide and uneven. I wrote about this word's meaning and collocations.” In the interview she pointed out that "when I find the collocations in the reading or newspaper, something like that, I am glad to see the words.” It appeared that finding the collocation examples in a newspaper showed her that her vocabulary was improving.

During the interviews, all students confirmed that the idea of collocation was a new concept to them and that they had never studied vocabulary the way they were studying in the class. Moreover, when asked about studying collocations, they mentioned that it made sense to study collocations (the students' comments regarding collocations can be found in their case descriptions).

Going from the concept to being able to locate collocations and understand them was part of a longer process. When working in more directed activities such as locating collocations for specific words in a text, the students performed well. However, when the teacher worked with textbook exercises which contained collocations such as corporate image, annual meeting, registered mail, occupational hazards and prime number, for instance, students tended to struggle with some of the combinations. The teacher typically needed to explain certain individual pairs before proceeding to the exercises. Furthermore, transferring their knowledge of collocation to their writing was yet another challenge. Nevertheless, I could observe that the transfer was occurring gradually, more effectively in the case of some students than others. 
Improvement of Collocation Use as the Semester Progressed

During the first observation, the teacher corrected paraphrasing exercises which contained the collocation cooperative learning several times. In this exercise, the students were also exposed to have major benefits, team members, encourage positive relationships, and others. As a follow-up activity, the class reviewed collocations.

On the board, the teacher wrote a few nouns and noun-adjective combinations taken from the particular paraphrasing exercise. Then she asked the students which verbs could be used with the words or phrases. The teacher drew a line to indicate where the verb should be placed (either before or after the words or phrases). The students had difficulty coming up with verbs for some of the combinations. When the students could no longer think of verbs, the teacher told them to look the verbs up in the textbook. With the help of the textbook, the students identified the appropriate verbs. The collocations written on the board are listed below. The underlined verbs were originally the marks to indicate where the verbs would go. At the end of the activity, the teacher highlighted the importance of learning collocations.

- $\quad$ Reach high academic standing

- Have major benefits

- Encourages (build) positive relationships

- Complete (do) an assignment

- Problems arise (occur) - When talking about this combination, the teacher pointed out that a combination such as problems happen was not a good collocation. 
At the end of this class, the students wrote their first writing sample (see Appendix I for instructions), and a few of the collocations reviewed in the exercise above were found in the students' writings.

An attempt at using the combination problems occur was observed in three of the samples (Atsushi, Ziyi, and Yunjin). In all three cases the students seemed to have remembered that the words could occur together, but they did not remember the appropriate word order in which they occurred. Atsushi used the words in "we have to use the working method according to the situation not to occur bad problems," whereas Ziyi created "but sometimes also occurred problems," and Yunjin wrote "it is not bad, but it occur a lot of problems." It was interesting to notice that the three used the combination in a similar way. It should be pointed out that this collocation was mentioned in class but not stressed. In the subsequent class, the teacher explained that occur was an intransitive verb and did not take a complement.

It was also noticed that two students (Abbas and Yunjin) effectively employed the combination have benefit in their own personal variations: "it has many benefits for me" and “it also has benefits” (Abbas’ and Yunjin’s, respectively). Tariq tried to employ the word benefit twice and was successful in the first example but not in the second: "this project gave me a lot of benefits” and "so, this benefit told me.” Tariq demonstrated more difficulty using the words. Looking at Tariq's sample, one had the impression that he was trying to "cram" as many of the new words as possible but did not succeed in collocating them well. The other students in the group obtained better results in sample \#1.

All students included at least the minimum number of new words required (6 to 8 words), and four out of five obtained a positive score of $50 \%$ or higher in collocation use in 
this sample. Tariq's score was lower than 50\% (see Table 8 for Tariq's detailed scores). At this point, the students were becoming familiar with the concept of collocation. Naomi had not joined the group yet.

In sample \#1, I noticed that a few of the students seemed to have “overgeneralized” a collocation pattern. The students encountered the combination cooperative learning several times in the chapter and went on to create similar collocations. Ziyi and Abbas employed this combination appropriately in their samples. Yunjin and Atsuhi, on the other hand, seemed to have gone on to create cooperative working and individual working, respectively, which constituted examples of incorrect collocations.

I also observed that a few of the students had difficulty with parts of speech. Tariq, for instance, utilized the noun analysis in the place of the verb analyze in "how could I analysis some information and the method.” Abbas attempted to use the word research, yet it was not clear whether he was trying to use the noun or the verb in "if we have research it is will be better than one person working on it.” Other students committed this type of error in the other samples as we will see later.

Around mid-term, it was observed that some students had difficulty coming up with adjectives to complete phrases found in the collocation section of the mid-term exam. The phrases included the following:

1. collect data

2. understand concepts

3. provide benefits

4. use a formula

5. conduct a analysis 
I did not have access to the students' collocation section in the mid-term exam, yet in class I learned that the students had often used the "general purpose" adjective good to complete the phrases. To show the students a few other possibilities, the teacher asked them for other examples, and the students came up with most of them. The teacher pointed out that this exercise was similar to what they were seeing in Moodle. Below are the examples created in class:

1. collect accurate / financial / statistical data

2. understand basic / simple / economic concepts

3. provide educational / great / major benefits

4. use a complicated / simple formula

5. conduct a useful / careful / brief analysis

A similar phenomenon was observed in Granger's (1998) study and the use of adverbs. Granger commented that "[the students] tend[ed] to use some amplifiers as 'general-purpose' items, a tendency confirmed by the use of the amplifier very....' She added, “the analysis [of her samples] showed a highly significant overuse of very, the allround amplifier par excellence” (p. 151).

Not only did the academic vocabulary students use the "general purpose" good in the mid-term exam, they also utilized it (and its counterpart bad) in their samples. For instance, Abbas mentioned bad goals in his samples, whereas Ziyi used good compensation, good environment, and good potential. Such examples might come from the students’ lack of specific vocabulary or perhaps reliance on a "safer" alternative. At times the students seemed to rely on the simpler adjective in their spontaneous writing. 
Sample \#2 revealed that a few students were venturing further in their use of new academic words. Some students showed improvement in their work and included longer examples of collocations. Tariq, Atsushi, and Yunjin obtained a higher percentage of correct combinations in the second sample. Ziyi and Abbas, on the other hand, showed a decline. Naomi presented her first sample.

In sample \#2 I observed that certain words presented problems for the students. Three students (Atsushi, Ziyi, and Yunjin) used the word circumstance somewhat unsuccessfully. They all tended to use the word in the singular when this word tends to be used in the plural. Atsushi wrote, "the circumstance of our judo club team was not good." Ziyi’s use was rather confusing: "he was trying hard to give us a good environment and circumstance." In her case, it was unclear what she meant. Yunjin's use also made the sentence unclear: "my high school's circumstance was special compare with other schools." These students might have been thinking about the word situation, which was listed as a synonym for circumstance.

Ziyi, Yunjin, and Abbas poorly employed the word core. Whereas Ziyi wrote, "we see him as our core of the class," Yunjin said, "he was remained core in my heart.” In Abbas' sample we found "the core of student in my [class] between 40 and 45 students." The students might have been trying to refer to someone or something as the most important or center, but the collocation they chose was not accurate. Even though these words were found in sublist \#3, which would indicate a relatively high frequency within the AWL, they posed difficulty for the students.

In addition, I observed in sample \#2 that some of the students were using the wrong part of speech at times. They seemed to use the exact word that they had studied in class. 
Naomi attempted to use the word reliance when what she needed was the word rely in "students had a reliance for her [the teacher].” Tariq used a noun in the place of a verb in “he was emphasis but all the student[s] got a good grade.” Despite certain students’ difficulties with specific words, sample \#2 revealed that four of the six students (Ziyi, Yunjin, Atsushi, and Naomi) might have been utilizing in their writing the collocation information provided in the textbook.

In the textbook, the students had an exercise in which they found a table containing verbs, adjectives, and nouns that could be used together. The table also indicated the sequence in which the words were to be used (Huntley, 2006, p. 60). Examples of these combinations appeared in these four students' samples. The examples were “completed some challenging tasks” from Ziyi, “carry out challenging task” from Yunjin, and "to perform challenging task" and "achieve successful outcome” from Atsushi. Naomi presented an example that contained two of the words: "have successful outcome." The verb she used was not listed in the exercise. Abbas' sample also contained words from this table, but he created his own sentence with the words in "funds [were] insufficient." In Tariq's samples such examples were not found.

The above examples indicated that directing the students' attention to this aspect of vocabulary acquisition had some impact on their writing. A remark from the teacher corroborated this observation. In her early April journal, she reported that the students were doing better in the class and had also made progress with their writing. She mentioned that “the students have got collocations figured out now and have found sources to locate collocations. [She thought] they [were] much more aware of collocations than they used to 
be," and she added that "I think the students are incorporating this vocabulary better into their written and oral activities.”

The last sample showed a similar result to the second. At this point, the majority of the students were including more AWL items in their writing and some continued to employ longer chunks.

In his last sample, Atsushi correctly collocated all the items he utilized. Naomi and Tariq showed improvement from their first drafts. Ziyi performed similarly to her first draft. Abbas and Yunjin had a slight decline in the percentage of correct use of collocations in comparison to previous samples.

Atsushi kept up his good performance, incorporating “a global company," "promote sales and coordinate delivery schedule," and "achieve a successful outcome.” Even though these examples seemed to have been taken from or inspired by the collocations presented in the exam, the student was able to successfully use them in his own text. His performance was probably what led the teacher to comment that "[Atsushi] ended up being a star performer at the end. He got the highest score on the test.” Ziyi also included longer chunks not necessarily from the exam yet accurate and more fluent: "I had to face many challenges," "I had to demonstrate the movements of that particular part of [the] dance," " I tried to illustrate every thing for them to make them understand," and "I think I have a good potential to be a teacher or model."

Naomi used longer chunks as well, as could be seen in "I have a part-time job as a tutor," "went into partnership with coworkers to teach our children," and "students were required to resolve questions by [themselves].” Yunjin continued to show the ability to employ longer pieces of collocation accurately in her text: “a global business woman” and 
“perform rewarding tasks and try to achieve a successful outcome [in] my life.” Abbas' sample had a couple of longer chunks: "got a promotion from [the] Saudi government” and “don't have enough justification.” Tariq’s did not contain such long chunks. Even though this student utilized the required number of AWL items in the task, he did not seem ready yet to actively use longer chunks as the ones shown above.

It appeared that for some students transferring their collocation knowledge to their writing would require more time. This finding reiterated Laufer and Paribakht’s (2000) conclusion that free-active vocabulary developed the slowest. By the end of the semester, most of the students showed some development in their use of collocations in their writing samples. The teacher deemed that, relatively speaking, all of the students improved their writing regarding their use of collocations, some more than others. All of the students performed well in the final exam's structured exercises. Some of them performed better in these exercises than in a more independent type of writing. Abbas had $92 \%$ of the items correct, while Tariq 74\%, Atsushi 100\%, Naomi 96\%, Yunjin 98\%, and Ziyi 96\%.

A few interesting factors were observed in the samples. The students consistently used more AWL nouns than any other part of speech in all of their writing, which brought to mind a comment from Rodgers (1969) that nouns were more easily learned than any other part of speech. The weakest student (Tariq) used three times as many nouns as verbs. It was true that the majority of the AWL items taught in this class were nouns. It was not clear why the students tended to prefer to utilize the new nouns to the other parts of speech. The fact that the students used the nouns did not necessarily mean that they were making fewer mistakes using them, but perhaps they felt more comfortable or thought it was easier to utilize the nouns than the other parts of speech. 
The second most common part of speech that the students used was verbs, which was the second largest group of AWL items taught in this class. According to Rodgers (1969), nouns followed by adjectives were more easily learned than verbs and adverbs. The students' overall choices differed from this pattern: the most used words were nouns, followed by verbs, then adjectives and adverbs.

\section{Difficulty with Certain Combinations Remained}

During observation 19, the teacher assigned collocation exercises based on the students’ vocabulary notebooks. The students were to share the information from their notebooks with a group in order to complete the exercises. The teacher told the students that they could not use their dictionaries. The only "dictionaries” that they were allowed to use were their notebooks. There were three activities on the handout (see Appendix K for handout); the last two of which dealt with collocation and were quite challenging to the students. Activity \#2 required the students to identify nouns which would follow verbs. The students had difficulty coming up with words to follow the verbs. In some cases they would end up using the noun form instead and realize that certain combinations would not work. At one point, the teacher had to explain that they had to use the word "challenge" as a verb and not a noun. With the help of the teacher, the students came up with "a regime," "a person," and "the government." The students seemed to be struggling to complete the collocations. Another word in the exercise was "grant,” and students came up with “scholarship,” “assistance,” and “wish.” The expression "grant a wish” needed to be explained. The students took some time to complete this exercise.

Eventually, the teacher corrected this exercise, but she was not able to finish the activity. Despite it being towards the end of the semester, the students were still struggling 
with one certain type of collocation: verb + noun. In this particular exercise, the students were dealing with a type of combination which seemed to pose difficulty in general. This event supported other studies on collocation which indicated that students had difficulty with verb + noun combinations (Gitsaki, 1996, cited in Shei and Pain (2002); Nesselhauf, 2003).

More advanced students integrated longer chunks in their writing

In addition, I observed that students who had more experience with English were able to explore the resources available more effectively. These students also performed better, but even the ones with less experience seemed to have at least learned what collocations were. The more advanced students accurately included longer chunks in their writing. Examples could be found in the writings of Atsushi, Naomi, Yunjin, and Ziyi. Collocation chunks studied in class were found in their samples, and some of the students used these chunks in multiple samples. These students' texts also appeared to flow better. The two students who had the least exposure to English, Abbas and Tariq, showed less improvement. This could also be observed in their final exam collocation section.

Even though the students who used Moodle more actively were exposed to new examples of collocations, I did not find any connection between the students completing the online exercises and their performance in their writing samples. The in-class work, on the other hand, did appear to have had an impact on the students' writing. This impact could be seen in the students successfully using the phrases learned in class in different writing samples.

One impact this study had was that the teacher focused more on collocation, mentioning the topic more often in class, and exposing students to more examples of collocations online. The teacher's comment in her second journal reported that "I notice 
myself using them more often and I try to highlight them a little in my speech.” She considered it a positive effect, and she commented that "the project has served to make both myself and my students more attuned to collocation use.”

\section{Students’ Perceptions of Blended Instruction}

When answering question \#2, I first discuss the students’ perceptions of the in-class work. Then I talk about their positive and subsequently their negative comments regarding the particular technology component I used. When discussing each individual item, I start from the comments that were unanimous and proceed to the comments from specific students. Table 24 summarizes comments on perceptions.

Table 24

Summary of Students’ Comments on Blended Instruction

Question \#2

What are learners' perceptions of blended instruction?

In class

- $\quad$ Preference for the in-class component (all students)

- Enjoyed interacting with classmates and the teacher (all students)

- More conscientious with in-class than online work (all students)

- $\quad$ More stressful (Yunjin)

Online - positive points

- Online component as a review tool, very useful/helpful (Abbas, Tariq,Yunjin, Ziyi, and Naomi)

- Learning new collocations (Ziyi and Naomi) 
Online - negative points

- Mismatch between textbook and Moodle vocabulary (all students)

- Online component time-consuming (Yunjin, Ziyi, and Naomi)

- Wanted to do the online exercises $\mathrm{w} /$ the teacher (Abbas and Tariq) vs. did not want to do the exercises in class (Atsushi and Naomi)

- Time limit stressful (Ziyi and Abbas)

The original design for the blended instruction differed from what was ultimately implemented. Initially, the online component was to be used as part of the instruction where students would work on exercises more independently. The online component would add to the content of the class. However, the way the vocabulary class was designed led to the online component being perceived as an extra activity, one to be done only periodically to vary the activities in class and review the material taught. This supplementary use influenced the students' perceptions of the blended instruction component.

In-class component. The in-class component was the core of the course. From the very beginning it was noticed that the online exercises were not an integral part of the course. The students' behavior in class, their comments at mid-term, and their comments in the interviews indicated that they all preferred it to be that way. Moreover, all six students, including the ones more comfortable with technology, indicated preferring the in-class component to the online one. The classes were interactive and varied, and students seemed to have fun working together with the teacher and each other, and during their interviews the students confirmed that.

Abbas, for instance, liked “the classroom many activities it’s good too ... and I work with a partner and it’s good.” Tariq appreciated the fact that he could discuss with the teacher when he had difficulties. He said that "in the classroom it give me the chance to 
discuss with you if I have something wrong or if I confuse with something.” Atsushi enjoyed working with his classmates because "in the class activity ... getting together with other student[s] and ...share their opinion, it's better I think. Because the class we can meet each other in the class.” Yunjin agreed with her classmates. She commented feeling more stressed in class because she felt like she needed to talk properly in front of her classmates. She said that “during class I have to concentrate more. I have to be nervous.” Despite feeling a bit nervous in class, she still "like[d] teacher with classmate.”

Naomi indicated her preference when she pointed out that she would prefer that the majority of the work be done in class. She said she would divide time percentage-wise as "in the classroom is 60 or 70 [and] outside [online] 30 or 40.” Finally, Ziyi commented that doing the online exercises was more difficult, but "if I do the activity in [the] classroom with a partner, with classmate, it help and we can learn from each other.” Later in the interview she added that she liked the way the class was designed.

The students’ comments supported what I observed in class. Even the quieter students were engaged in class. They all seemed to be enjoying the time spent in the face-toface environment. Rarely did I notice the students looking at their watches or the classroom clock to see if the class was close to finishing. What I did observe was the students actively participating in the activities that their teacher proposed, even when it meant going a little beyond the class period.

In addition to liking the interactive environment, a few of the students preferred to be with a teacher. These students felt that if they had questions, they could get immediate help and feedback. The two less advanced students (Abbas and Tariq) in particular made such comments. Furthermore, these two students also commented that they wanted to have the 
teacher available when doing the online exercises. Abbas said that the "CALL lab is good to practice with [the] teacher. Sometime when the student is not close [to] the teacher when I have problem, I will stop.”

Online component. Due to the students’ perception of the online component as a review tool for the class, the online activities were not done as conscientiously as the ones assigned in class. The teacher pointed out that the students worked better on the online exercises if she went to a computer laboratory with them, and they were more reluctant when they had to do the exercises on their own. The teacher commented that "when you actually went to the lab, I think it was successful," and "I think the students really liked the online portion of the class, and I ended up devoting more attention to it than I originally had expected to.”

Having the students work on the online component outside class was a challenge. During the semester there was constant prodding on both my and the teacher's part, reminding the students about the exercises. Initially, the students were exposed to three websites, including the teacher's website, the textbook companion website, and Moodle. Ultimately, Moodle and the textbook website were used more regularly. During the interview, Naomi said that it was “a bit too much,” whereas a few students reported that the exercises were different and complemented each other.

Despite the flaws, Naomi, Abbas, and Tariq (half the students) took time to complete the exercises and write the journal entries. The group as a whole identified positive and negative aspects in the online component proposed. Below I describe their comments in terms of positive and negative aspects. 
Positive aspects of the online component. Five out of the six students (Abbas, Tariq,Yunjin, Ziyi, and Naomi) pointed out that the Moodle online exercises were helpful and useful for reviewing the vocabulary studied. Their spoken and written comments tended to revolve around "it's helpful" and "it's useful." Abbas referred to the websites as being "good and useful for me to have to improve my vocabularies," and Tariq said that "these activities gave to me opportunity to remember some vocabulary I [had] forgot[ten].” Yunjin thought that if she had dedicated herself more to the class and if she had "stud[ied] constantly, [the exercises would be] very good. I think it’s very helpful.”

Ziyi and Naomi considered the Moodle exercises good for reviewing vocabulary; these two students also commented that the exercises helped them to learn new collocations. Ziyi pointed out that "maybe I prefer to learn it this week from chapter one and I prefer to review it on Moodle. It's like to make me like remember it.” She realized that Moodle contained "some of the collocations we haven't seen in the book, we haven't learn[ed] in the book, so we can learn online.” Naomi said that "I can review the class by doing the exercise. So, it’s good for me.” When talking about the Moodle exercises, Naomi also commented in one journal that "I enjoyed learning new collocations." Both in the journals and in the interview, Naomi indicated that "I can do the exercise in the computer lab now. It's good for me. I enjoy it.”

The teacher agreed with the students that the online component was a good review tool. The textbook companion website was presented as a review tool, and the students seemed to have embraced the idea and transferred it to Moodle as well. The teacher commented, "I think a lot of people use it for homework, which seems ideal because it doesn't waste class time... class time is so valuable.” The teacher also commented that 
Moodle "was great for review, because you were actually a couple of chapters behind where I was."

Negative aspects of the online component. The students did not consider the online component as an actual part of the class. A comment the teacher made during the interview reiterated that: "I think the students worked harder on it when they were in class doing it than when they were supposedly doing it for homework. I think it was just something they thought, you know, not really bother with, whereas when we went to the lab, they all work really hard.” The Moodle logs from Atsushi, Ziyi, and Yunjin supported this comment. The Moodle logs showed that these three students rarely used Moodle. In fact, these students tended to use Moodle only when in class with the teacher. Referring to Moodle, one student (Atsushi) said, “we don't need [it].”

It was also observed that in general the students tended to pick and choose the exercises they worked on, even though the weekly exercises had been designed as a unit. They tended to select the one which would take less time and disregard exercises which seemed difficult such as the Hot Potatoes rational cloze exercises.

The comments regarding the drawbacks in Moodle might also explain the students' attitude toward it. One of the main complaints was the mismatch between the textbook and online vocabulary in Moodle. All students made comments in that regard, and they all would prefer Moodle to follow the textbook just like the companion website did. Atsushi said that “we learned new words from [the] textbook. We expect [to] meet those new words. But it's different.” Abbas talked about the textbook and the companion website being related: “website is easy to have the book also same time ... there’s a relation between the book and the website.” Tariq reinforced this point when he commented, “it’s good, but the 
[companion] website for it's relating for the book.” Ziyi also expressed a similar opinion when she said that "this is not [based] on the book, right?"

The majority of the AWL items used in the Moodle exercises were the ones in the textbook. What differed was the way the AWL items were organized, i.e., it did not follow the organization in the textbook chapter by chapter. The Moodle exercises also used different themes from the ones in the textbook. The intention was to present the words in different contexts and in different combinations from the textbook. In fact, when the students reported the words that they looked up in their dictionaries while doing the Moodle exercises, these words were typically not AWL items. Thus, the problematic words might have been the words being collocated with the AWL items rather than the AWL items themselves.

Some of the students (Yunjin, Ziyi, and Naomi) pointed out that the online component was time-consuming. New words had to be looked up in a dictionary. There were also comments regarding the level of difficulty of the exercises. Both the teacher and the students made comments to that effect. As soon as those comments were made, I started changing the exercises to make them more accessible, taking into account the teacher's suggestions and the students' comments. However, as seen earlier, comments about the difficulty of collocation exercises also emerged in class. This made me wonder whether the issue was that the online exercises were difficult or that collocations were complex in general. Also, it appeared that the level of difficulty of the Moodle exercises may have contributed to the students considering the exercises time-consuming.

One aspect that divided the group was where to do the exercises: in or outside class. Whereas two of the students (Abbas and Tariq) wanted to do the exercises in class with the teacher, two other students (Atsushi and Naomi) wanted to do the exercises outside class. 
The former students were probably not ready to take on a more independent way of learning. Their language knowledge was somewhat limited at that point. The latter students, on the other hand, had had more exposure to English, so they were more comfortable working on the language on their own. These two students believed that the class time should be used for interactive activities. In addition, they seemed to be more comfortable with the technology. The two remaining students (Yunjin and Ziyi) did not raise this issue at all.

Finally, the time limit appeared to be stressful for two of the students (Ziyi and Abbas). Ziyi said that "the bad thing is that it has the time limit," whereas Abbas said that “the time limit sometime it make me confuse. I keep writing, just check the time.” Both students seemed to feel under pressure because of the time limit. Contrary to Moodle, the textbook companion website did not have a time limit. In Ziyi’s case, the time limit may have discouraged her from working on the exercises. She did not pursue the Moodle exercises very often. In Abbas' case, as mentioned earlier, the time limit did not seem to affect his result, so his comments appeared somewhat inconsistent with what the Moodle logs showed.

To sum up, the students' comments and behavior in the in-class and online environments indicated that the students preferred the classroom environment. In the next chapter, I draw conclusions from the cases in relation to the students' writings and consider the students' suggestions and comments for a possibly more refined online component to teach academic vocabulary collocations. 


\section{Chapter 5}

\section{Conclusions}

The first research question looked at the students' use of collocation in their writing after being explicitly taught what collocations were and examples of them. The samples that the students produced indicated that directing the students' attention to collocations had a positive impact on their results. The second research question regarded the students’ perceptions of blended instruction. In that regard, it was observed that the students preferred the in-class environment and would prefer to use the online exercises to review the material studied in class. In this chapter I present the conclusions drawn from the data regarding these two research questions. In addition, I suggest improvements for blended instruction on collocation teaching, present the limitations of the study, and suggest future research.

The SLA literature indicates that L2 learners have difficulty when writing in the L2. One of the problems in L2 writing is a lack of vocabulary. The learners themselves are aware of this limitation. Nation (2001) stated that Leki and Carson (1994) "found that second language learners see lack of vocabulary as the major factor affecting the quality of their writing” (p. 178). The students in this study also referred to grammar, sentence structure, and organization as being problematic. Nesselhauf (2003) and Kaur and Hegelheimer (2005) would probably add that lack of collocation knowledge also impacts on L2 learners’ writing ability.

\section{Question \#1}

In my case study, difficulties with academic vocabulary, collocation, and writing were observed. In the students’ writing samples I noticed that the students at times had some understanding of the words, and yet they could not use the words appropriately. In addition, 
I observed that collocation was one of the problems. The students also had difficulty distinguishing words with similar meanings and different nuances and usage. The teaching of collocations might not necessarily help in those cases, yet a more explicit teaching approach might facilitate understanding of both collocations and other aspects of vocabulary.

This case study showed that the teaching of the collocations themselves was not enough. First the teacher needed to clarify to the students what collocations were. The results indicated that had the teacher not addressed the issue of collocation as a concept, the students may not have paid attention to it. This point led me to conclude that the students needed explicit instruction on what collocation was and how they could identify and use it before they could learn the collocations themselves. In other words, the students needed guidance identifying collocations before they could successfully include the chunks in their texts.

Brown (1974), Gitsaki (1996) (cited in Shei and Pain, 2002), and Nesselhauf (2003) talked about students having difficulty collocating verbs. They referred specifically to the words which come after the verbs. In my study, the students appeared to have such difficulty also. They demonstrated such difficulty with the verb + noun combinations when doing an in-class activity (see Appendix K for this activity). They struggled particularly with item \#2 which entailed adding a complement to a verb. In their writing samples, such difficulty was not perceived. A certain preference for using AWL nouns was observed, though. At times the students would use the noun form of a word when they really needed the verb form. Being aware of such phenomenon could help teachers to attend to the verb + noun combinations so as to help students to be more comfortable with them. 
Nation (2001) pointed out that "while it is possible to make significant changes in vocabulary knowledge, it is not easy to move this knowledge to productive use” (p. 182). Nation's comment was observed in the students' use of academic words in their samples. In some cases, while the students seemed to understand the meaning of the words, they sometimes struggled to collocate some of them. In addition, they did not know the appropriate context in which to use certain words. The context occasionally showed that the students understood what the words meant, but using them actively was still problematic.

Despite their difficulty with certain words, some of the students learned to use the tools available in their textbook, and with this confirmed Hinkel's (2004) comment. Referring to research done by N. Ellis (1997), Lewis (1997), Nattinger and DeCarrio (1992), Hinkel concluded that "stock grammatical and lexical chunks can become an efficient means to expand L2 writers’ arsenals particularly when learners are also taught how to substitute discrete elements appropriately and in practical ways” (p. 38). One activity in the textbook provided the students with an assortment of words to be combined. As shown earlier, Atsushi, Naomi, Yunjin, and Ziyi made use of the chunks presented in the textbook and that added fluency to their texts. The teaching of this "lexical arsenal” helped these students improve their writing and made their texts more fluent.

Another point observed in the students' writings was the transfer of a certain collocation pattern to others. In his study, Howarth (1998) noticed that his learners transferred knowledge of certain combinations to others. For instance, Howarth's students came up with “draw a conclusive comments” from “draw a conclusion.” The students also created "reach a high achievement" which appeared to be a combination of "high achiever" and "a high level of achievement” (p. 180). A similar type of transfer was observed in the 
present study in the use of "cooperative working," "physical working," and "individual working." Even though one collocation example led the students to create inappropriate combinations, the fact that they were creating combinations was an indication that they were attending to the collocations.

In the case of more advanced students such as Naomi, Atsushi, Yunjin, and Ziyi, showing them collocations seemed to have helped to encourage them to bring it from passive to active use. For the less advanced students, however, the input was not enough. It could have been that these students were still dealing with other aspects of the language and of vocabulary, and it may have been overwhelming for them to process this much information at once.

Getting students ready and attuned to collocation may take a little time. Yet the study indicated that it was worthwhile, especially when dealing with the type of vocabulary focused on here. For students wanting to pursue a degree at an English speaking university or college, "knowing academic vocabulary is a high priority goal" and "productive use of academic vocabulary is an important component of academic success” (Nation, 2001, p. 197). Being aware of longer chunks can help to improve students’ productive use of academic vocabulary.

In the students' writing samples it was clear that there was more to vocabulary than collocation, and teaching collocations did not radically change the students' writing. In the students' writings it could be seen that, on occasion, the students used the correct collocation and yet failed to attend to the context. Nevertheless, being aware of and being able to handle this aspect of vocabulary gave the students a tool which they could take with them through their academic life and beyond. Finally, as Kennedy (1990) commented: 
What text-based collocation studies do suggest is that the description of grammar is, from the teacher's point of view, an essential part of methodology, but it needs to be based on more than the orthodox grammatical and lexical description. Just as the teacher of botany does not take students into the jungle and expect them to learn all the plants by simply being exposed to them, so the language curriculum designer and classroom teacher can facilitate learning by systematic presentation of the role of important language items and their linguistic ecology - the company words keep (p. 228).

\section{Question \#2}

In relation to the blended instruction, the results led me to conclude that both the instructor and the students were still in the process of getting used to the idea of combining a face-to-face environment with an online environment. They seemed to view online resources as something extra and not necessarily having the potential to be an integral part of the class.

Contrary to Adair-Hauck, Willingham-McLain, and Youngs’ (1999) study in which blended instruction was compulsory in the course, the online component in this study was perceived as an add-on. So the students in this case did not take it as seriously as the students in that study.

Different from the French course in Adair-Hauck, Willingham-McLain, and Youngs’ (1999) study, in an Intensive English Program situation, students tend to be overwhelmed with the amount of L2 studying that they need to do. Considering that the majority of the students were taking on average five to six courses in the program and also had regular homework from the other classes, it was understandable that some of the students would not take as much time to work on the online activities. 
In order for blended instruction to work, it is necessary to budget the time for the activities used. If students have assignments from different classes and the online component is not a graded portion of the class, the latter component will most likely be forgotten. Furthermore, certain students will only complete the online exercises if there is a percentage of the grade attached to it. Referring to Chapelle (2003), Kaur and Hegelheimer (2005) point out that "students using tools to enhance their learning need guidance and motivation. It is found that learners are not consistent in employing tools when left on their own to complete the tasks” (p. 298 - 9). Even though Kaur and Hegelheimer were referring to the concordancer, a similar behavior was observed when having the students in this study complete the online exercises.

The students' preference for the in-class component was also understandable. When students are used to a dynamic classroom environment, having them work in an online environment may be a challenge. For an online component to be acceptable, the exercises would need to be proposed as part of the class from the very beginning and also structured to match and complement the class work closely.

Contrary to the online studies presented in the literature review, the online exercises in this case study did not seem to have much impact on the students' writing. What contributed to their development was the in-class work. The online component might have helped the students who completed the online exercises to understand collocations because they were exposed to several extra examples of collocations in the exercises provided.

In this study, similar to Kaur and Hegelheimer (2005), the students were very comfortable with online dictionaries and consistently mentioned using them. On the other hand, they did not refer to the Online Concordancer at all. One reason may be what Cobb 
(1999) commented about; namely, the fact that a low-level student would have difficulty understanding this type of list. He pointed out that "the lexical information seems vast and confusing” (p. 347). The teacher confirmed this when she mentioned that the students had attempted to use the concordancer. When talking about the Online Concordancer, she commented that "we went over that again as a way to find collocations. Some of them put down [words] that obviously were next to each other on the collocation sheet but didn't make any sense. So they hadn't quite grasped that not all of those were collocations.” The teacher said that she "tended to think that unless [she] spent a lot of time on the concordances, they would get confused with them rather than unconfused, so [she] didn't address it again.” Similar to Adair-Hauck, Willingham-McLain, and Youngs' (1999) study in which one student commented that the online component helped to reduce anxiety, Yunjin commented that it was less stressful to do the online exercises. However, Yunjin still preferred the interaction in the face-to-face environment because she did not seem to like using computers. In the case of Adair-Hauck, Willingham-McLain, and Youngs' study, "the multimedia activities challenged students to take greater responsibility in working toward their goals in learning French” (p. 282). In the case of the Moodle activities, such a result was not observed. Moreover, the results indicated that certain learners might not be ready for this type of responsibility. Lower-level learners, who were still struggling with the language, would most likely prefer to be in a face-to-face environment. Because of the interactivity present in the Intensive English courses, students prefer to work in that environment. In order to transfer to an online environment, the material would need to be revised and turned into something more interactive. 
Even though the particular group who participated in this case study preferred the inclass environment, the attitude of some of the students seemed to indicate that, provided some modification be made, they would be willing to make use of an online component. Moreover, most of them did comment that the online component was useful and helpful. Given that, I still believe that the Moodle online tool, with some adjustments, can be utilized to enhance students' learning of collocations. In addition, this component can be used to provide students with extra practice and input. Finally, the online component can also be used to maximize their in-class time.

In other words, teaching academic vocabulary collocation via blended instruction may be feasible provided that the online component undergoes changes to meet some of the students’ expectations. As Horst, Cobb, and Nicolae (2005) point out, “...in our work the Internet is more than a source; it is also a medium through which to learn” (p. 107). Course Improvements for Teaching Collocations via Blended Instruction

After analyzing the students’ comments and suggestions, I concluded that for blended instruction to work, adjustments would need to be made to the online component I proposed. To make the online exercises more accessible and interesting for the students, I would include the following modifications to the Moodle exercises.

First, the students indicated that they expected the online component to be an extension of the textbook. Thus, the online exercises would be modified to follow the textbook vocabulary and chapter themes more closely so as not to overwhelm the students with too many new words. The journals from some of the students indicated that they had difficulty with low-frequency words collocated with the AWL items. In the case of such 
words, I would explain them in a glossary or the like to make it easier for the students to focus on the use of collocations.

Second, the class teacher pointed out in one of her journal entries that there were too many options in the multiple choice exercises. I would use "three [because it would be] much easier for the students to handle” the exercises as the teacher suggested. Since it was observed that collocations were difficult, reducing the number of options would probably be more encouraging and helpful as well as less time-consuming and confusing for students.

Third, during the interview, Yunjin suggested including more explanations for the words. I would take her suggestion and start the series of activities with exercises which would provide an explanation or definition to the collocation pairs utilized in the particular online session.

Fourth, exercises such as the rational cloze would initially contain a word bank for students to use to complete the passage. The gaps would be more spaced out so that students would have more context with which to work. As the semester progressed and the students became more comfortable with the idea of collocation, I could gradually increase the complexity level of the cloze exercises. Another exercise that caused difficulty was the Moodle short answers. This exercise would also be further explained to try to reduce the students' stress when dealing with it. In the case of the two exercises mentioned above, it would be relevant to work on them with the students in-class to make sure that the students understood what the exercises entailed.

Fifth, the online component could be used for activities and exercises which might take too much in-class time to complete (such as listening and reading, for instance). The teacher commented that “one thing I realized I haven’t done in the class is any kind of 
listening activities... associated with collocation.” The online environment would give the teacher an opportunity to provide this type of activity.

Finally, some students expected to do the online component in class, which in my opinion is counterproductive, especially when, as the teacher put it, "class time is so valuable.” Horst, Cobb, and Nicolae (2005) agreed with that. They commented that “computerized exercises clearly serve varying rehearsal needs well since learners can work on activities independently without taking up valuable class time” (p. 91). Therefore, using class time for online practice exercises like the one I proposed did not make sense. One of the reasons to use an online environment was to maximize class time. The in-class time could be used to familiarize students with the online exercises and also to help students to understand how to use the technology components and to participate in interactive activities.

While teaching students how to use the technology, the teacher could still have interaction among the students by having more computer savvy students help those who were not as comfortable with technology. To try to minimize the students' anxiety, I would initially work on more complex exercises in a computer laboratory with the students to familiarize them with the types of activities. Once the students understood what was expected of them, the students could work on the exercises on their own.

To attempt to emulate the class environment, since part of the class would take place online, the teacher could provide "online office hours" via the chat room, enabling students to get immediate feedback if they needed as well as providing an environment for students to communicate with the teacher and with each other.

Even though a few of the students in the study were not pleased with the time limit used, this feature would be important when the teacher's objective was to evaluate the 
students. This would reduce the chance for students to try to look up information. Cole (2005) commented that "timed quizzes [were] a single most effective tool for eliminating this strategy” (p. 93).

\section{Limitations of the Study}

- The number of students was limited (6). However, there was enough variety in the group to create a microcosm of what a teacher might have in class. Also, this particular group had only non-romance language speakers, which was informative considering the vocabulary with which we were working. Finally, this number was sufficient to identify the effectiveness of a vocabulary teaching strategy and to learn about the students’ perceptions of blended instruction when studying vocabulary collocation.

- The group of students ended up working with two websites. The two websites turned out to be advantageous because the students had something with which to compare Moodle. This comparison led students to give me ideas and make comments that enabled me to improve the exercises in Moodle.

- The online component was supposed to be completed outside class, which led some students not to do it. However, the fact that some students did not complete the exercise was informative in itself when they explained their reasons.

- Certain students' inability to express themselves in English at times made it difficult to get clear, detailed information. To get the most out of the students, I had to restructure some questions several times during the interviews. When dealing with their written journals, I would ask them to try to explain better next time. In the end, I managed to get the information necessary to answer the research questions. 
- The instructor had a curriculum to attend to and could not eliminate certain homework assignments as I had hoped. Thus, the students could not always dedicate homework time to the online exercises.

\section{Future Research}

- Teaching academic vocabulary collocations would be useful in an ESL reading/writing course. The academic vocabulary found in the textbook could be used to create online exercises employing a revised version of the blended instruction presented here. In this case, collocation would be one of the vocabulary aspects included in addition to definitions and synonyms. This way the students could study the target vocabulary independently, while the teacher could utilize the class time to work on reading and writing specifically as well as encourage the students to utilize the AWL items in their writing. Such a study could evaluate the improvement of the students' academic vocabulary use in their writings.

- In her article, Granger (1998) suggested that more studies were needed to pinpoint which collocations to teach. Such studies on academic vocabulary collocation would be helpful because it would enable us to teach students more relevant combinations.

- The students in this case study worked on collocations for a semester and some transference of collocations could be observed in their writing. How much more effective would a revised version of blended instruction over a longer period of time be?

- It appeared that there was a threshold for students to study collocation. Is that really the case? Or would students be more comfortable with collocations if they were exposed to them from the early stages of acquisition? 


\section{References}

Adair-Hauck, B., Willingham-McLain, L., \& Youngs, B. E. (1999). Evaluating the integration of technology and second language learning. CALICO Journal, 17(2), 269-306.

Brown, D. (1974). Advanced vocabulary teaching: The problem of collocation. RELC Journal, 5(2), $1-11$.

Cambridge Advanced Learners Dictionary ONLINE. (2004). http://dictionary.cambridge.org

Chapelle, C. A. (2001). Computer applications in second language acquisition:

Foundations for teaching, testing and research. Cambridge, UK: Cambridge University Press.

Cobb, T. (n.d.) Web Vocabprofile [accessed June 2006 from http://www.lextutor.ca/vp/ ], an adaptation of Heatley \& Nation's (1994) Range.

Cobb, T. (1999). Breadth and depth of lexical acquisition with hands-on concordancing. Computer Assisted Language Learning, 12(4), 345-360.

Cole, J. (2005). Using Moodle: Teaching with the Popular Open Source Course Management System. O’Reilly Community Press.

Coxhead, A. (2000). A new academic word list. TESOL Quarterly, 34(2), 213-238.

Coxhead, A. \& Nation, P. (2001). The specialised vocabulary of English for academic purposes. In J. Flowerdew \& M. Peacock (Eds.), Research perspectives on English for academic purposes (pp. 252-267). Cambridge, UK: Cambridge University Press.

Craik, F. I. M., \& Lockhart, R. S. (1972). Levels of processing: A framework for memory research. Journal of Verbal Learning and Verbal Behavior, 11, 671-684. 
Ellis, N. C. (1997). Vocabulary acquisition: Word structure, collocation, word-class and meaning. In N. Schmitt \& M. McCarthy (Eds.), Vocabulary: Description, Acquisition, and Pedagogy (pp. 122-139). Cambridge, UK: Cambridge University Press.

Ellis, R. (1994). Factors in the incidental acquisition of second language vocabulary from oral input: a review essay. Applied Language Learning, 5(1), 1-32.

Flowerdew, J. (1996). Concordancing in language learning. In The Power of CALL. Martha C. Pennington (Ed.). Retrieved August 1st, 2006 from http://sunzi1.lib.hku.hk/hkjo/view/10/1000064.pdf

Fragiadakis, H. K. (1993). All Clear! Idioms in context. Boston, MA: Heinle \& Heinle.

Gass, S. M., \& Selinker, L. (2001) Second language acquisition: An introductory course. Mahwah, NJ: Lawrence Erlbaum Associates.

Granger, S. (1998). Prefabricated Patterns in Advanced EFL writing: Collocations and Formulae. In A. P. Cowie (Ed.), Phraseology: Theory, Analysis, and Applications (pp. 145 - 160). Oxford: Clarendon Press.

Greaves, C. (n.d.). Online Concordancer [Web site]. Available at http://www.lextutor.ca/concordancers/concord_e.html

Heatley, A. and Nation, P. (1994). Range. Victoria University of Wellington, NZ. [Computer program, available at http://www.vuw.ac.nz/lals/.]

Hinkel, E. (2004). Teaching Academic ESL writing: Practical techniques in vocabulary and grammar. Mahwah, NJ: Lawrence Erlbaum Associates, Inc. Publishers. 
Horst, M., Cobb, T., \& Nicolae, I. (2005). Expanding academic vocabulary with an interactive on-line database. Language Learning and Technology, 9(2), 90-110. Retrieved from http://lt.msu.edu/vol9num2/horst.

Howarth, P. (1998). The phraseology of learners’ academic writing. In A. P. Cowie (Ed.), Phraseology: Theory, Analysis, and Applications (pp. 161 - 186). Oxford: Clarendon Press.

Hulstijn, J. H. (2001). Intentional and incidental second language vocabulary learning: a reappraisal of elaboration, rehearsal and automation. In P. Robinson (Ed.), Cognition and Second Language Instruction (pp. 258-286). Cambridge, UK: Cambridge University Press.

Hulstijn, J. H. (2005). Theoretical and empirical issue in the study of implicit and explicit second-language learning. Studies in Second Language Acquisition,27 (2), 129-140.

Huntley, H. (2006). Essential academic vocabulary: mastering the complete academic word list. Boston, MA: Houghton Mifflin.

Kaur, J. \& Hegelheimer, V. (2005). ESL students’ use of concordance in the transfer of academic vocabulary knowledge: An exploratory study. Computer Assisted Language Learning, 18(4), 287-310.

Kennedy, G. D. (1990). Collocations: Where grammar and vocabulary teaching meet. In S. Anivan (Ed.), Language Teaching Methodology for the Nineties. pp. 215-229. SEAMEO.

Kitajima, R. (2001). The effect of instructional conditions on students' vocabulary retention. Foreign Language Annals, 34(5), 470-482. 
Laufer, B. (1994). The lexical profile of second language writing: does it change over time? RELC Journal, 25(2), 21-33.

Laufer, B. (1998). The development of passive and active vocabulary in second language: same or different. Applied Linguistics, 19(2), 255-271.

Laufer, B. \& Hulstijn, J. (2001). Incidental vocabulary acquisition in a second language: The construct of task-induced involvement. Applied Linguistics, 22(1), 1-26.

Laufer, B. \& Nation, P. (1995). Vocabulary size and use: Lexical richness in L2 writing production. Applied Linguistics, 16(3), 307-322.

Laufer, B., \& Shmueli, K. (1997). Memorizing new words: Does teaching have anything to do with it? RELC Journal, 28, 89-108.

Laufer, B. \& Hill, M. (2000). What lexical information do L2 learners select in a CALL dictionary and how does it affect word retention? Language Learning \& Technology 3(2), 58-76.

Laufer, B. \& Paribakht, T. S. (2000). The relationship between passive and active vocabularies: Effects of language learning context. Language Learning, 48 (3), 365391.

Lewis, M. (1997). Pedagogical implications of the lexical approach. In J. Coady \& T. Huckin (Eds.), Second Language Vocabulary Acquisition (pp. 255-270). New York: Cambridge University Press.

Lewis, M. (2001). Teaching collocation: Further developments in the lexical approach. Hove, England: Thompson - Heinle Publications.

Lewis, M. (2002a). The lexical approach: State of ELT and a way forward. Boston, MA: Thompson - Heinle Publications. 
Lewis, M. (2002b). Implementing the lexical approach: Putting theory into practice. Boston, MA: Thompson - Heinle Publications.

Longman Dictionary of Contemporary English ONLINE. (n.d.). http://pewebdic2.cw.idm.fr/ Merriam, S. B. (1988). Case study research in education: A qualitative approach. JosseyBass Publishers.

Merriam, S. B. (1998). Qualitative research \& case study application in education. San Francisco, CA: Jossey-Bass Publishers.

Merriam-Webster Online. (n.d.). http://www.m-w.com/home.htm

Nation, I.S.P. (1990). Teaching and learning vocabulary. Boston, MA: Heinle \& Heinle Publishers.

Nation, I. S. P. (2001). Learning vocabulary in another language. Cambridge, UK: Cambridge University Press.

Nation, P. \& Newton, J. (1997). Vocabulary teaching. In J. Coady \& T. Huckin (Eds.), Second Language Vocabulary Acquisition (pp. 239-254). New York: Cambridge University Press.

Nattinger, J. R. (1980). A lexical phrase grammar for ESL. TESOL Quarterly, 16(3), 337344.

Nesselhauf, N. (2003). The use of collocations by advanced learners of English and some implications for teaching. Applied Linguistics, 24(2), 223-242.

Oxford Advanced Learner's Dictionary. (2000). Oxford, UK: Oxford University Press. Oxford: Collocations dictionary for students of English (2002). Oxford, UK: Oxford University Press. 
Paribakht, T.S. \& Wesche, M. (1997). Vocabulary enhancement activities and reading for meaning in second language vocabulary acquisition. In J. Coady \& T. Huckin (Eds.), Second Language Vocabulary Acquisition (pp. 174-200). New York: Cambridge University Press.

Patton, M. Q. (2002). Qualitative Research \& Education Methods (3 ${ }^{\text {rd }}$ ed.). Thousand Oaks, CA: Sage Publications.

Read, J. (2000). Research on vocabulary acquisition and use. In Assessing Vocabulary. (pp. 38-73). Cambridge: Cambridge University Press.

Richards, J. C. (1976). The role of vocabulary teaching. TESOL Quarterly, 10, 77-89.

Richards, J.C., Platt, J. \& Platt H. (1992). Longman Dictionary of Language Teaching and Applied Linguistics. Essex, UK: Longman Group UK.

Santos, T. (1988). Professors' reactions to the academic writing of nonnative speakers students. TESOL Quarterly, 22(1), 69-90.

Schmidt, R. (2001). Attention. In P. Robinson (Ed.), Cognition and Second Language Instruction. (pp. 3-32). Cambridge, UK: Cambridge University Press.

Schmitt, N., (1997). Vocabulary Learning Strategies. In N. Schmitt \& M. McCarthy (Eds.), Vocabulary: Description, Acquisition and Pedagogy (pp. 199-227). Cambridge, UK: Cambridge University Press.

Schmitt, N., (2000). Vocabulary in Language Teaching. Cambridge, UK: Cambridge University Press.

Shei. C.-C. \& Pain H. (2002). An ESL writing's collocational aid. Computer Assisted Language Learning, 13(2), 167-182. 
Sinclair, J. (Ed.). (2001). Collins Cobuild: English dictionary for advanced learners. $\left(3^{\text {rd }}\right.$ ed.). Glasgow: HarperCollins Publishers.

Sökmen, A. (1997). Current trends in teaching second language vocabulary. In N. Schmitt \& M. McCarthy (Eds.), Vocabulary: Description, Acquisition, and Pedagogy (pp. 237-257). Cambridge, UK: Cambridge University Press.

Steinman, L. (2002). A touch of ...class! The Canadian Modern Language Review, 59(2), 291-301.

Stevens, V. (1995). Concordancing with language learners: Why? When? What? CAELL, $6(2), 2-10$.

Stoller, F. \& Grabe, W. (1993). Implications for L2 vocabulary acquistion and instruction from L1 vocabulary research. In T. Huckin, M. Haynes \& J. Coady (Eds.), Second Language Reading and Vocabulary Learning (pp. 24-45). Norwood, NJ: Ablex Publishing Corporation.

Svenconis, D. J., \& Kerst, S. (1994). Investigating the teaching of second-language vocabulary through semantic mapping in a hypertext environment. CALICO Journal, 12(2-3), 33-57.

Warschauer, M., \& Healey, D. (1998). Computer and language learning: An overview. Language Teaching, 31, 57-71.

Wesche, M., \& Paribakht, T. S. (1996). Assessing second language vocabulary knowledge: Depth versus breadth. The Canadian Modern Language Review, 53, 13-40.

Wray, A. (2002). Formulaic language and the lexicon. Cambridge, UK: Cambridge University Press 
Zimmerman, C. B. (1997a). Historical trends in second language vocabulary instruction. In J. Coady \& T. Huckin (Eds.), Second Language Vocabulary Acquisition (pp. 5-19). New York: Cambridge University Press.

Zimmerman, C. B. (1997b). Do Reading and interactive vocabulary instruction make a difference? An empirical study. TESOL Quarterly, 31(1), pp.121-140. 


\section{Appendix A}

\section{Academic Vocabulary Syllabus}

\begin{tabular}{|c|}
\hline ACADEMIC VOCABULARY \\
Semester: Spring 2006 \\
Days/Time: Tues/Thurs, 1:00 pm \\
Room: 503B Eiesland \\
\hline
\end{tabular}

Instructor:

Office: 116 Eiesland Hall

Office Hours: 11:00-1:00, Tues/Thurs

Tel: $304-293-3604 \times 1102$

Email:

Course Texts/Materials

Essential Academic Vocabulary by Helen Huntley

An English-English dictionary

(preferred) The American Heritage English as a Second Language Dictionary, Houghton Mifflin Company, 1998. ISBN: 0-395-81873-7 (paperback)

Course Website

Textbook Website

http://college.hmco.com/esl/huntley/essential academic vocabulary/1e/students/inde $\underline{x \cdot h t m l}$

Course Objectives

You will participate in activities designed to enable you:

- to comprehend and use the 570 words on the Academic Word List

- to become aware of techniques for remembering new vocabulary

- to develop personal strategies for learning and reviewing new vocabulary

- to use an English-English dictionary to aid in word pronunciation, to determine the part of speech of a word, to choose from multiple meanings in the dictionary according to context, and to recognize and analyze related word forms, roots, and affixes.

- to utilize learned vocabulary in a variety of academic speaking, listening, writing, and reading activities

- to recognize and use the different forms of a word (noun, verb, adjective, adverb)

- to learn the meanings of word parts (roots, prefixes, and suffixes) and apply them to interpret unknown words in a text.

- to learn and use common phrases (collocations) associated with the Academic Word List

- to read and understand a variety of academic texts which contain words from the Academic Word List

- to use context clues to deduce the meaning of new vocabulary items without the aid of a dictionary in order to facilitate comprehension

- to become knowledgeable of the computer resources available for vocabulary building (the Houghton Mifflin website and other academic vocabulary Internet sites) 
- to distinguish between formal and informal vocabulary and idioms

- to learn and use vocabulary in your own academic field

- to learn and use common idioms

\section{Course Activities}

You will combine independent study and classroom activities to learn and practice the academic vocabulary in each chapter, which is focused on a specific academic field. You are expected to prepare for class sessions by looking up unknown words in each chapter and recording them in a detailed vocabulary journal. Class time will be spent actively reviewing and practicing these words in a variety of activities which will include the following:

- Preview questions on the chapter topic

- Academic reading from an undergraduate textbook

- Vocabulary in context

- Reading Comprehension: Text analysis and inferences

- Dictionary skills

- Word forms: Chart completion and word forms in sentences

- Collocation identification and practice

- Word parts analysis and application

- Personal and academic writing: summaries, paraphrases, definitions, reports

- Academic speaking activities: role plays, surveys, interviews, presentations, discussions

\section{Participation and Attendance}

You must be prepared in advance for each class session, attend each class, and participate actively in individual, pair, and group activities. You are expected to observe the IEP attendance policies.

\section{Homework}

All assignments are due on the day indicated. It is also expected that you review vocabulary independently on a daily basis.

\section{Grading}

- Vocabulary journals $\quad 30 \%$

- Homework activities and quizzes $30 \%$

- Tests (mid-term and final) $\quad 30 \%$

- Preparation for and participation $10 \%$ in class activities

NOTE: This class requires extensive personal study outside class in order for you to learn a great deal of vocabulary which will help you to be successful in your academic fields as well as in the TOEFL exam. 
Academic Vocabulary 3C Course Schedule Spring 2006

\begin{tabular}{|c|c|c|}
\hline Week 1 & $\begin{array}{l}\text { January } 10 \\
\text { January } 12\end{array}$ & $\begin{array}{l}\text { Introduction } \\
\text { Introduction to course website }\end{array}$ \\
\hline Week 2 & $\begin{array}{l}\text { January } 17 \\
\text { January } 19\end{array}$ & $\begin{array}{l}\text { Chapter } 1 \\
\text { Chapter } 1\end{array}$ \\
\hline Week 3 & $\begin{array}{l}\text { January } 24 \\
\text { January } 26\end{array}$ & $\begin{array}{l}\text { Idioms/Word Parts/CALL Lab } \\
\text { Chapter } 2\end{array}$ \\
\hline Week 4 & $\begin{array}{l}\text { January } 31 \\
\text { February } 2\end{array}$ & $\begin{array}{l}\text { Chapter } 2 \\
\text { Idioms/Word Parts/CALL Lab }\end{array}$ \\
\hline Week 5 & $\begin{array}{l}\text { February } 7 \\
\text { February } 9\end{array}$ & $\begin{array}{l}\text { Chapter } 3 \\
\text { Chapter } 3\end{array}$ \\
\hline Week 6 & $\begin{array}{l}\text { February } 14 \\
\text { February } 16\end{array}$ & $\begin{array}{l}\text { Idioms/Word Parts/CALL Lab } \\
\text { Chapter } 4\end{array}$ \\
\hline Week 7 & $\begin{array}{l}\text { February } 21 \\
\text { February } 23\end{array}$ & $\begin{array}{l}\text { Chapter } 4 \\
\text { Idioms/Word Parts/CALL Lab }\end{array}$ \\
\hline Week 8 & $\begin{array}{l}\text { February } 28 \\
\text { March } 2\end{array}$ & $\begin{array}{l}\text { Chapter } 5 \text { Review } \\
\text { Chapter } 5 \text { Test }\end{array}$ \\
\hline Week 9 & $\begin{array}{l}\text { March } 7 \\
\text { March } 9\end{array}$ & $\begin{array}{l}\text { Chapter } 6 \\
\text { Chapter } 6\end{array}$ \\
\hline & March 14/16 & Spring Break: No classes \\
\hline Week 10 & $\begin{array}{l}\text { March } 21 \\
\text { March } 23\end{array}$ & $\begin{array}{l}\text { Idioms/Word Parts/CALL Lab } \\
\text { Chapter } 7\end{array}$ \\
\hline Week 11 & $\begin{array}{l}\text { March } 28 \\
\text { March } 30\end{array}$ & $\begin{array}{l}\text { Chapter } 7 \\
\text { Idioms/Word Parts/CALL Lab }\end{array}$ \\
\hline Week 12 & $\begin{array}{l}\text { April } 4 \\
\text { April } 6\end{array}$ & $\begin{array}{l}\text { Chapter } 8 \\
\text { Chapter } 8\end{array}$ \\
\hline Week 13 & $\begin{array}{l}\text { April } 11 \\
\text { April } 13\end{array}$ & $\begin{array}{l}\text { Idioms/Word Parts/CALL Lab } \\
\text { Chapter } 9\end{array}$ \\
\hline Week 14 & $\begin{array}{l}\text { April } 18 \\
\text { April } 20\end{array}$ & $\begin{array}{l}\text { Chapter } 9 \\
\text { Idioms/Word Parts/CALL Lab }\end{array}$ \\
\hline Week 15 & $\begin{array}{l}\text { April } 25 \\
\text { April } 27\end{array}$ & $\begin{array}{l}\text { Chapter } 10 \text { Review } \\
\text { Chapter 10: Test }\end{array}$ \\
\hline Week 16 & May 1-5 & Finals Week: no classes \\
\hline
\end{tabular}




\section{Appendix B}

\section{Classroom Speaking Activities}

Role Plays - A speaking activity in which students would use collocation while talking. “At the beginning of the semester, you decided to join the band, the soccer team, the campus events committee, the chess club, and the french club. Initially, it was fun, and you have met a lot of new people. However, you are now falling behind in your studies, and you realize that you should eliminate some of these activities. The problem is that you like them all. You decided to discuss this problem with a friend who seems to be better at time management than you are. Your friend advises you about which activities to keep and which ones to drop” (Huntley, 2006, p. 45).

\section{Group Discussion: To Be a Teacher... or Not}

"In small groups, discuss and write down the pros and cons (advantages and disadvantages) of becoming a teacher. Consider such factors as status, compensation, benefits, vacation time, classroom management, student motivation, and school environment. When you have finished, summarize your notes orally to another group or the whole class” (Huntley, 2006, $8 B$, p. $64-5)$ 


\section{Appendix C}

\section{Coxhead (2000) AWL Sublists}

\begin{tabular}{|c|c|c|}
\hline analysis & established & occur \\
\hline approach & estimate & percent \\
\hline area & evidence & period \\
\hline assessment & export & policy \\
\hline assume & factors & principle \\
\hline authority & financial & procedure \\
\hline available & formula & process \\
\hline benefit & function & required \\
\hline concept & identified & research \\
\hline consistent & income & response \\
\hline constitutional & indicate & role \\
\hline context & individual & section \\
\hline contract & interpretation & sector \\
\hline create & involved & significant \\
\hline data & issues & similar \\
\hline definition & labour & source \\
\hline derived & legal & specific \\
\hline distribution & legislation & structure \\
\hline economic & major & theory \\
\hline environment & method & variable \\
\hline
\end{tabular}


Sublist \# 2 includes the second most frequent words of the AWL.

\begin{tabular}{|c|c|c|}
\hline achieve & distinction & potential \\
\hline acquisition & elements & previous \\
\hline administration & equation & primary \\
\hline affect & evaluation & purchase \\
\hline appropriate & features & range \\
\hline aspects & final & region \\
\hline assistance & focus & regulations \\
\hline categories & impact & relevant \\
\hline chapter & injury & resident \\
\hline commission & institute & resources \\
\hline community & investment & restricted \\
\hline complex & items & security \\
\hline computer & journal & sought \\
\hline conclusion & maintenance & select \\
\hline conduct & normal & site \\
\hline consequences & obtained & strategies \\
\hline construction & participation & survey \\
\hline consumer & perceived & text \\
\hline credit & positive & traditional \\
\hline cultural & & transfer \\
\hline
\end{tabular}


Sublist \# 3 includes the third most frequent words of the AWL.

\begin{tabular}{|c|c|c|}
\hline alternative & emphasis & philosophy \\
\hline circumstances & ensure & physical \\
\hline comments & excluded & proportion \\
\hline compensation & framework & published \\
\hline components & funds & reaction \\
\hline consent & illustrated & registered \\
\hline considerable & immigration & reliance \\
\hline constant & implies & removed \\
\hline constraints & initial & scheme \\
\hline contribution & instance & sequence \\
\hline convention & interaction & sex \\
\hline coordination & justification & shift \\
\hline core & layer & specified \\
\hline corporate & link & sufficient \\
\hline corresponding & location & task \\
\hline criteria & maximum & technical \\
\hline deduction & minorities & techniques \\
\hline demonstrate & negative & technology \\
\hline document & outcomes & validity \\
\hline dominant & partnership & volume \\
\hline
\end{tabular}




\section{Appendix D}

\section{Concordances of research from the Online Concordancer using the}

\section{University Word List corpus}

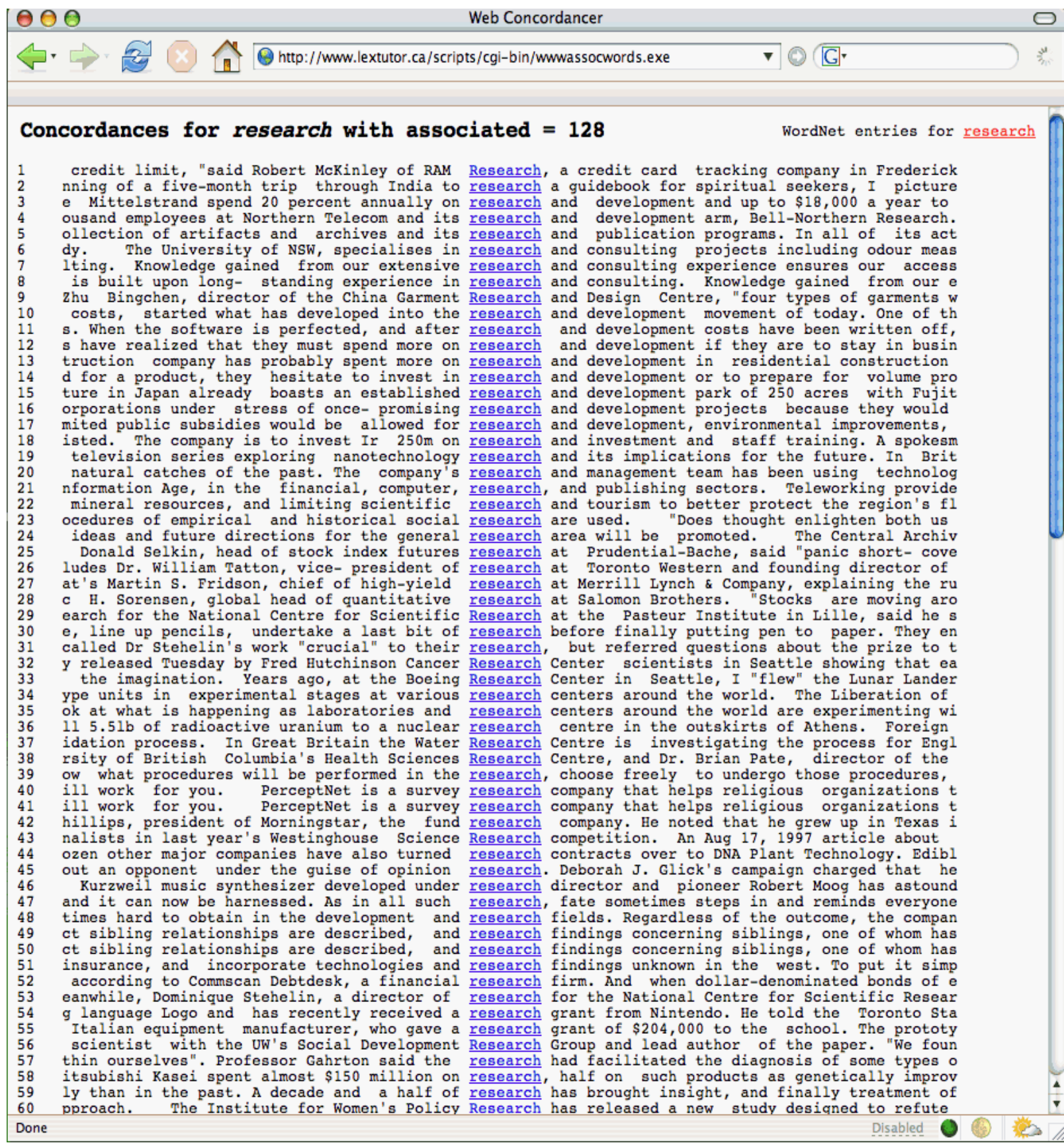




\section{Appendix E}

\section{Background and technology understanding questionnaire}

Name:

Gender: M ( ) - F ( )

Age: $\quad$ Under $18 \_18-24 \_25-30$
$31-35$
$36-39$
over 40

1. How long have you studied English - including the time you studied English in your home country?

2. What's your native language? Do you speak any other languages? If yes, which ones?

3. How do you usually study vocabulary?

4. What do you usually do when you come across a new English word in class or outside class?

5. Do you like using computers and the Internet in general? Why (not)? What do you usually use computers and the Internet for?

6. Which computer and/or Internet programs/tools (for example: Word, iTunes, CDROMs, online dictionaries, etc) are you familiar with?

7. Are you familiar with using a computer or the Internet to study vocabulary? If so, how have you used the computer and the Internet to study vocabulary? 


\section{Appendix F}

\section{Moodle Sample Exercise - Odd one out}

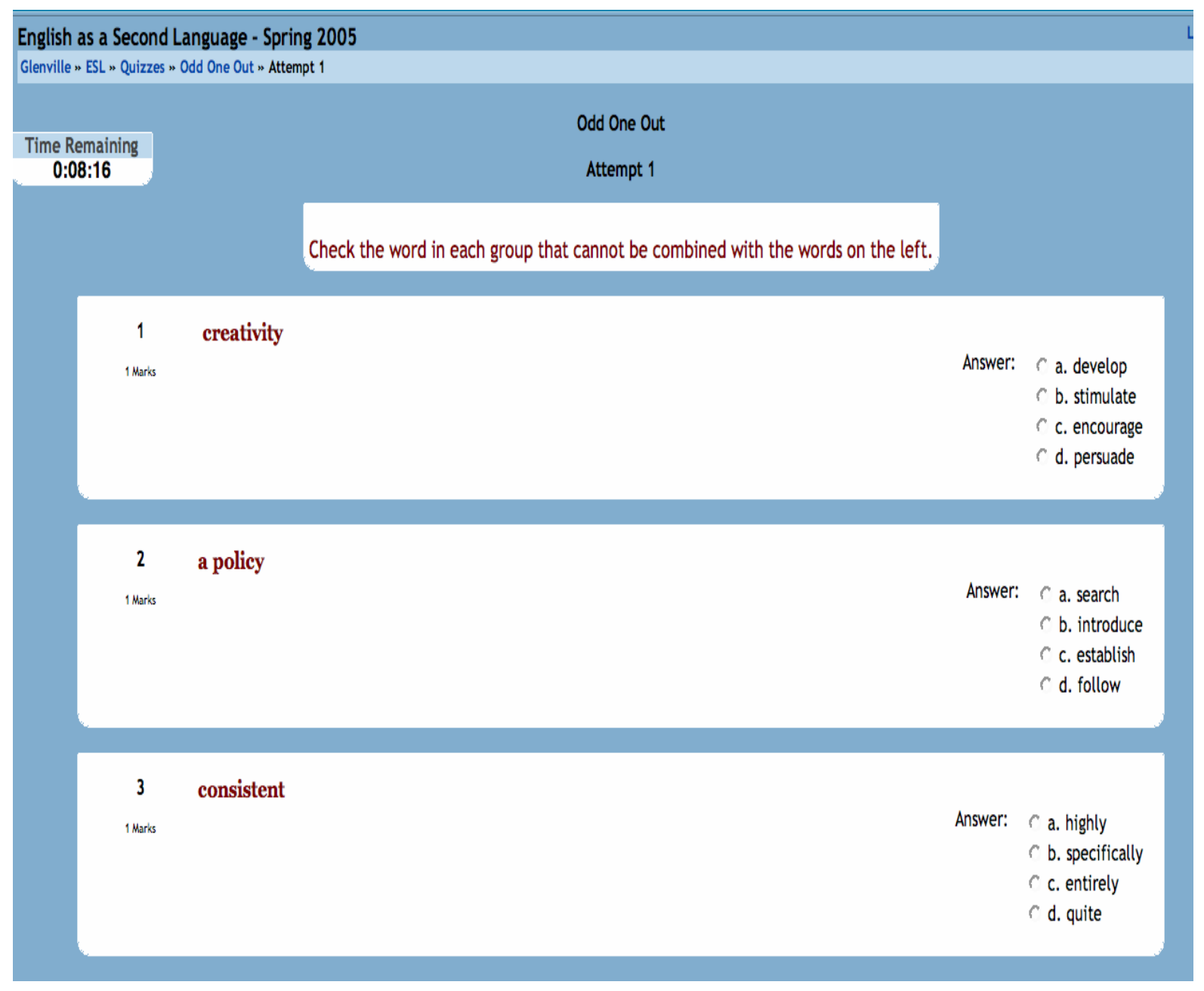




\section{Appendix G}

\section{Journal Entry}

Name:

Date:

Week \#

Journal entry \#

After working on the lab session for this week, answer the questions below. Please type your answers and email them to the researcher.

1. What was it like to do the online activities today? Describe.

2. While doing the exercises, did you look up any words in a dictionary? If so, which words and in which dictionary? What did you read about the word? Did you take any notes about this word? [what did you write down about the word] If so, what did you write?

3. Did you notice any word combinations you were familiar with? Which one (s)?

4. Did you notice any word combinations you were not familiar with? Which one (s)?

5. How do you feel about your scores on the exercises today?

6. What did you enjoy about doing the activities presented?

7. Please add any other comments or suggestions you may have. 


\section{Appendix $\mathbf{H}$}

\section{Mid-Course Reflection/Feedback}

Name:

Date:

In the space below, reflect on and write answer the following questions:

1. Which vocabulary activities/assignments do you think worked well in the class? Explain.

2. Which exercises worked well in Moodle? Explain.

3. Which activities/assignments do you think did not work well in the class? Explain.

4. Which exercises did not work well in Moodle? Explain.

5. What have you learned about vocabulary?

6. What do you think you have learned in this course? [consider in-class and Moodle activities] 


\section{Appendix I}

\section{Writing Sample - Assignments instructions}

Write a response to one of the following topics. Include at least six to eight vocabulary words in your paragraph. (Instructions to writing sample \# 1 \& \#2).

\section{Writing Sample \#1 -}

"Describe an experience when you worked with others on a project. Describe the benefits and the negative aspects of working cooperatively. In what ways did you learn more about the topic and about your classmates?” (Huntley, 2006, p. 10)

\section{Writing Sample \#2 -}

"Who was your favorite teacher in elementary school or high school? What do you remember about this teacher? What special personal qualities did this person possess? What made this teacher different from other teachers? What special teaching strategies did this teacher use to motivate students? Can you identify the teacher's philosophy of education?” (Huntley, 2006, p. 63)

\section{Writing Sample \#3 -}

"Write a paragraph about a personal experience in the workplace. This experience could range from an after-school job in a fast-food restaurant to a well-paid professional position. Describe the difference tasks you had to perform in your job, the positive and negative aspects of the position, and the approximate period of time that you were employed there? Use and underline at least $\mathbf{1 0}$ words (with collocations if appropriate) from the Academic Word list, including words used in the previous part of the test” (from the final exam). 


\section{Appendix $\mathbf{J}$}

\section{Interview - Sample Questions}

1. What is your purpose for studying English? / How are you going to use English?

2. What's your opinion of this semester in the academic vocabulary class? / How would you describe this semester in the vocabulary class?

3. How do you feel about studying vocabulary collocations?

4. How did you feel about having someone observing the classes? / Tell me more about...

5. What do you think about having activities in class and online? / How did you feel about having activities in class and on websites?

6. Describe your experience working with the different websites.

7. What did you think about doing the exercises on the Moodle website? / Did you see any advantages and disadvantages in doing the Moodle exercises?

8. How do you feel about your writing at the beginning of the semester? How do you feel about your writing now?

9. What would you like to see in a course that combines classroom and online activities? 


\section{Appendix K}

\section{Vocabulary Journal, Chap 9}

\section{Vocabulary Journal, Ch 9}

Work together in your group to find the answers to the following questions from your vocabulary journals. No dictionaries, please!

1. Label the following words as Noun (N), Verb (V), Adjective (A), Adverb (A). Some words can be more than one part of speech.

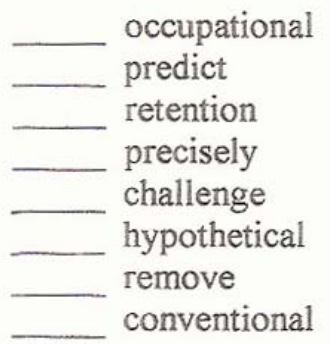

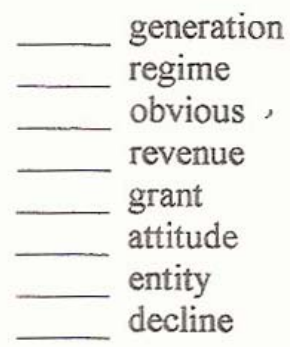

2. Add an appropriate noun (and articles, prepositions etc. if needed) to each verb.

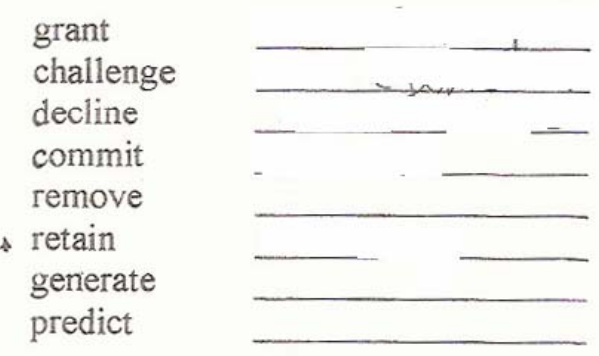

3. Write down a collocational phrase that contains the following words (you can change the word form if necessary).

commitment
behalf
currency
revenue
regime
generation
occupational
conventional
compound
attitude




\section{Appendix L}

\section{Final Exam - Collocation Section.}

\section{E. Collocations}

1. In the space provided, write the adjective that can precede all four words in each group to form common collocations

$$
\text { global physical instant ethical adult }
$$

1.

2.

3.

4.

5 . values, behavior, conduct, standards education, attraction, therapy, exercise language, theme, population, education warming, travel, business, population access, coffee, success, response

II. In the space provided, write the verb that can precede all three words in each group to form common collocations

$$
\text { coordinate impose register promote resolve }
$$

1.

2.

3.

4.

5. sales, production, products problems, arguments, difficulties regulations, taxes, laws events, organizations, programs births, mail, marriages

III. Complete each phrase with a suitable adjective from the list below:

$$
\begin{array}{lllll}
\text { special } & \text { basic } & \text { theoretical } & \text { satisfactory } & \text { disappointing } \\
\text { challenging } & \text { rewarding } & \text { considerable } & \text { successful administrative }
\end{array}
$$

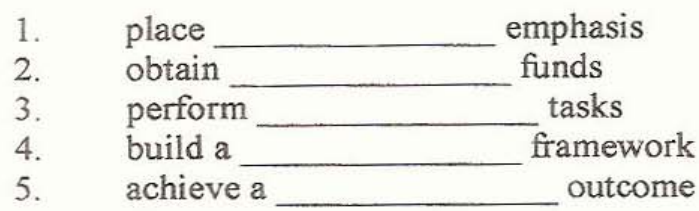

IV. Give 2 examples of the following collocations (half point each):

1. foreign currency

2. weather predictions

3. valid documents

4. occupational diseases

5. the generation gap

6. precooked food

7. chemical compounds

8. unethical behavior

9. technological innovations

10. media events

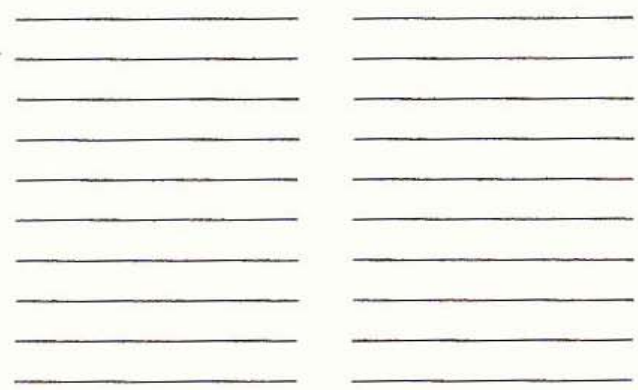




\title{
Appendix M
}

\section{Moodle Sample Exercise - Moodle Short Answer exercise.}

\author{
Start again \\ Started on: Saturday, January $202007,11: 43 \mathrm{PM}$ \\ Completed on: Saturday, January 20 2007, 11:43 PM \\ Time taken: $1 \mathrm{sec}$ \\ Raw score: $0 / 5(0 \%)$
}

Grade: 0 out of a maximum of 10

Read the article below from the Voice of America and identify the collocations for the words: finance, policy, percent, financial, and significant.

When writing your answers, be sure to write the complete collocations. If there's more than one, separate them with a comma as in the example below.

E.g.: debt relief, debt reductions

World Bank, IMF Endorse \$40 Billion Debt Relief for Poorest Countries

By Barry Wood

Washington 200

Meetings in Washington of global financial institutions ended Sunday with agreement on implementing the ambitious debt relief program reached at last July's eight-nation (G8) summit in Scotland.

Gordon Brown, Britain's Chancellor of the Exchequer, is pleased that the deal he sponsored and worked on for many years is now becoming a reality.

"Agreement is now reached on all the elements. The managing director [of the IMF] has notified the [policy making] committee that he will now call the executive board together to complete its approval of the arrangements to deliver debt relief by the end of 2005 ," Mr. Brown said.

Trevor Manuel, South Africa's finance minister, Sunday announced that the World Bank had joined the International Monetary Fund in endorsing the debt reduction agreement.

"I think we can all say thank you very much to the World Bank and the IMF. The development committee [which I chaired] is satisfied as is reflected in the communiqué that those [debt reductions] agreements are met," Mr. Manuel said.

New World Bank president Paul Wolfowitz, agreed that the debt reduction accord is a significant achievement.

"The high point of the meetings is the historic endorsement provided by both the development committee [the bank's policy making group] and the IMFC [the IMF's policy making group] of the G8 proposals to cancel 100 percent of the debts of some of the world's poorest countries," he said.

For the first time, official debts to the IMF and the World Bank are being canceled with the financial shortfall being made up by fresh contributions from rich countries. The debt deal was initialed last July at Gleneagles, Scotland at the summit of the leaders of the Group of Eight industrialized countries.

The G8 includes the United States, Japan, Canada, Britain, France, Germany, Italy and Russia.

The article can be found at http://www.voanews.com/english/archive/2005-09/

1 (86) What example(s) of collocation can you find for the word financial? [There are 2.]

Marks: 1

$$
\text { Answer: }
$$

Incorrect

2 (87) What example(s) of collocation can you find for the word policy?

Marks: 1

Answer:

policy making

Incorrect
Marks for this submission: 0/1

3 (88) What example(s) of collocation can you find for the word percent?

Marks: 1

Answer:

Incorrect

4 ( 85$) \quad$ What example(s) of collocation can you find for the word finance?

Marks: 1

Answer:

finance minister

Incorrect
Marks for this submission: 0/1

5 (89) What example(s) of collocation can you find for the word significant?

Marks: 1

Answer:

Incorrect
Marks for this submission: 0/1 


\section{Appendix N}

\section{Moodle Sample Exercise - Hot Potatoes rational cloze exercise}

\section{Use a word from the list below to complete the dialogue. Make changes to verbs whenever necessary.}

List of words: affect, aspects, conduct, consume, consumption, features, and restricted.

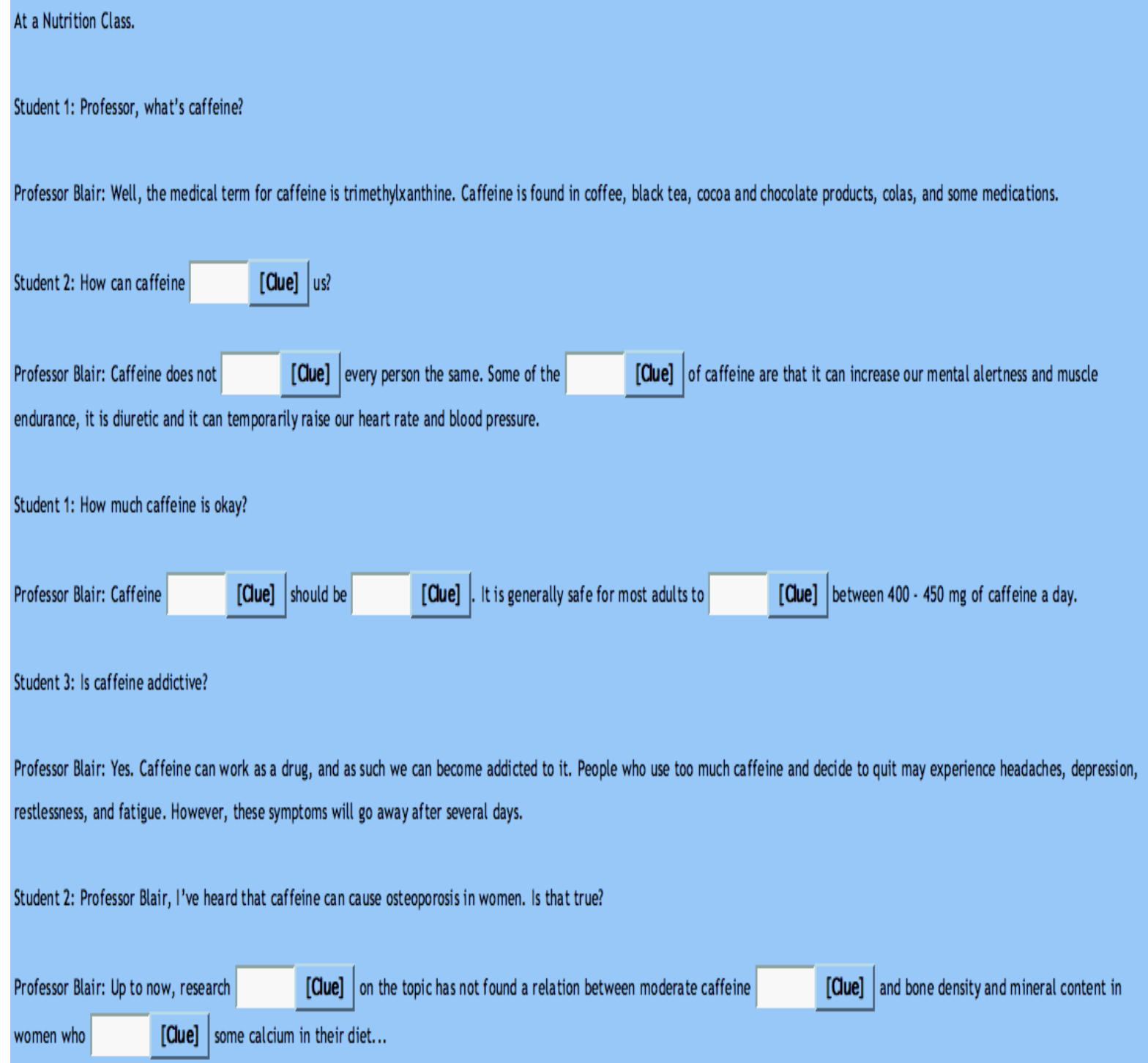




\section{Appendix 0}

\section{Abbas' Writing Samples}

\section{Sample \#1.}

In fact the cooperative learning is good because it has many benefits for me. I have my own knowledge, but I will add another knowledge or edit some mistakes, and it good chance to establish a new relationship with others. Like if we have research it is will be better than on person working on it. That is mean working as a team we will get more data and our analysis will be very clear - but in specific area need to work alone depends on the major. (87 words - 11 AWL items)

\section{Sample \#2.}

Mustafa was my favorite teacher at that time. The core of student in my between 40 and 45 students of one sex (male) I mean boys. This teacher has reacted to the demographic theories challenging constant for other challengers. Some time the funds is insufficient from government he bought some things to our school from his income because he want to have outcome for students. (65 words - 10 AWL items)

\section{Sample \#3}

In fact my job in my country at the coast guard I had a strong determination to get this kind of difficult job, that is resolve a lot of illegal situations of trying to enter my country with drugs or other bad goals. Usually, some people as a minority in their countries trying to live in my country. The employee got a promotion from Saudi government to innovate a good ways to decrease problems. These people who trying to get in my country by illegal ways don't have enough justification. Thousands of them exclude of their countries because they had internal crimes. (103 words - 10 AWL items) 


\section{Appendix P \\ Tariq's Writing Samples}

\section{Sample \#1.}

When I worked with others on a project, I had experience because this project gave me a lot of benefit. So, this benefit told me how could I analysis some information and the method for them. Also, this concept gave me process to involve many formula in my life. In fact, if I want to identify some variables for study any science. These information help me to establish all of them by a good way. (75 words -11 AWL items)

\section{Sample \#2.}

My favorite teacher named Ahmad. He was immigrant from Palestine. His major was Arabic language and he was inveterate teacher. Also, his job in the school was manager addition to teach some classes. He was great with students and with the public people. When he left the school leave a big location. He had there decade. He was emphasis but all the student got a good grade. I can’t forget him because he had did his task by a good way. (82 words -8 AWL items)

\section{Sample \#3.}

I try to integrative my experience in my job with my experience in my life. I had a lot of outcome for it. Some of them correspondence with other. For example, interaction with student here and there. Now, I try to get a good grade because I came here for task and I should do great because my job will give me promotion when I come back. Also, I have scheme to study $\mathrm{PhD}$ in future. I should implement my study by a good great. I will register some classes next semester in [a university]. Finally, I will undergo this life to do my undertake with my job. (107 words -12 AWL items) 


\section{Appendix Q}

\section{Atsushi’s Writing Samples}

\section{Sample \#1}

The benefit of cooperative working is that the we can share variables that the other members established. When we work with others, we have to talk with them about the project. At that time many approaches for a project are exchanged each members.

The negative aspect of working cooperatively is that the decision is slower than that of individual working. We have to use the working method according to the situation not to occur bad problems. (76 words, 11 AWL items, and 13 tokens)

\section{Sample \#2}

My favorite teacher is Mr. Kaburagi who is a teacher of judo club in my university days. He taught me not only judo techniques but also importance of effort. He commented that it was important to achieve successful outcome on judo games, but it was more important to continue effort. His philosophy is that process to perform challenging task is important. The circumstance of our judo club team was not good. Each member of our team did not have sufficient grades to surpass the other team. So it was difficult to win in the game. Our mind to the game was easy to go down. But we motivated by his philosophy because no need to care about outcome of the game. I think this is important if we finished judo, began work, situation altered. (134 words, 13 AWL items)

\section{Sample \#3}

Right now I am working for Japanese Company. My company is a global company. We import and export commodities all over the world. The category of our job is not only domestic product. For instance, I am actually responsible for importing X-ray machines 
from the U.S. company and selling ones for Japanese Airline companies and Custom. I need to promote sales and coordinate delivery schedule of that machines. My customers request me to implement the task as scheduled. And also the sales target is imposed on me by my boss. So I need to refine my job all the time to achieve a successful outcome. (107 words, 17 AWL items, and 19 tokens) 


\section{Appendix R \\ Naomi’s Writing Samples}

\section{Sample \#1 N/A}

\section{Sample \#2}

My favorite teacher is a woman who taught music for me in the elementary school. When I met the first time, her initial impression is good, because she looked very kind. I met her when I belonged to brass club. She was a teacher for the club. Her interaction was great, and she is also expert to illustrate, students were getting a good player for each part. I learned a lot of things from her such as to play the drum and so on. Then, when we had in trouble, she always give some comments for us. Students had a reliance for her. In addition, she has a special talent for music, so we were reacted by her. Then we could play a big hall, and we could have successful outcome. I could learn a lot from her not only music, but also reliance. Therefore I liked her.

(148 words, 7 AWL items)

\section{Sample \#3}

I have a part-time job as a tutor, when I was a college student. I worked twice a week for 2 years. I think teaching is very difficult, but I had to teach as a professional. I sometimes went into partnership with my coworkers to teach our children. There were some diversity students, so I could learn a lot. They had own objectives, so they did their best. My boss who is the main teacher emphasized the importance of studying hard. Students were required to resolve questions by yourself. If they had question they could ask us, but initially they have to try themselves. They studied some subjects. For instance, they studied math, English, and Japanese. Then I could learn myself, because if I don’t understand, I can’t teach 
them, so I always needed to study. Although it was hard for me to teach them, the circumstance was nice, so I had sufficient reason to continue this job. The job was simple such as checking their answer, but I enjoyed it. I like to do with children, so I could communicate with them. Now I miss them.

(190 words, 13 AWL items) 


\section{Appendix S}

\section{Yunjin's Writing Samples}

\section{Sample \#1}

I don't like cooperative working. Just it is my individual thinking. It is not bad but it occur a lot of problems. Cooperative working is so bothersome. We should empty time for meeting, but it is hard to adjust to same time and we should do controversy. So sometimes it can be fought when our issue is different to each other. We maybe spend a lot of time for making one issue. This is demerit of cooperative working. It has also benefit. We can establish good relationship.

(88 words, 8 AWL items and 11 tokens)

\section{Sample \#2}

My really favorite teacher was my high school teacher. He was remained core in my heart. My high school's circumstance was special compare with other schools. There are teachers in my school of various ethnic diversity. Some teachers were immigrants. They made students carry out challenging task.

I like my English teacher who is Korean. My English teacher always emphasized that to be a good person is more important than get good grade or get compensation. I believe he is constantly a good teacher. (84 words, 11 AWL items)

\section{Sample \#3}

I want to be a global business woman. My mom always emphasized that I should perform rewarding tasks and try to achieve a successful outcome of my life. She also emphasized that don't reliance on my husband who will be in my future. So now I am doing challenge to be that kind of woman. Actually now I am working a part time in a Japanese restaurant, but it's 
not professional job. It's just kind of physical working. So I could be known why should I study. The reason is that physical working is so harder than professional job. (102 words, 10 AWL items, and 14 tokens) 


\section{Appendix T \\ Ziyi’s Writing Samples}

\section{Sample \#1}

I've worked with others several times. I think the cooperative learning is an approach for study. People work together always have good concept, and we could find out data quickly. But sometimes also occurred problems. For example, somebody don't want to work hard in the team or people can't identified several method. Those may put off finishing the project. Even though I still think cooperative learning is a good way to study.

(75 words, 9 AWL items and 10 tokens)

\section{Sample \#2}

One of my favorite teachers was a principal of my class when I was in dancing school. Even in China teachers do not have good compensation, he was trying hard to give us a good environment and circumstance. We sometimes completed some challenging tasks of dancing by his constraint, however we still like him, and he always gave us a fair grade. We see him as our core of the class. In his class we were always in interaction. He seems knew all the diversities between all ethnic dances. (89 words, 12 AWL items)

\section{Sample \#3}

I had had two jobs, one was modeling, another was teaching. For those two jobs, the most dominant thing are compensation from the company and techniques of myself. To be a model, I had to face many challenges. For instance, different commercial required different type of performs. In contrast, to be a teacher, I just had to teach my students how to dance, and for different students, I used different aspects to teach them. Sometimes, when my students can't understand me, I had to demonstrate the movements of that particular part of 
dance. I tried to illustrate every thing for them to make them understand. Unlike when I was a model, it was the directors of commercials taught me how to perform. They told me about major idea of commercial. Also, both of two jobs were very tiring. I couldn't get enough time to sleep, but however, I had really enjoyed those two jobs. I think I have a good potential to be a teacher or model. If I have chance, I would like to do it again. (180 words, 13 AWL items and 16 tokens) 